Portland State University

PDXScholar

$1-1-2010$

\title{
Child Welfare Workforce Turnover: Frontline Workers' Experiences with Organizational Culture and Climate, and Implications for Organizational Practice
}

Melanie Dawn Sage

Portland State University

Follow this and additional works at: https://pdxscholar.library.pdx.edu/open_access_etds Let us know how access to this document benefits you.

\section{Recommended Citation}

Sage, Melanie Dawn, "Child Welfare Workforce Turnover: Frontline Workers' Experiences with Organizational Culture and Climate, and Implications for Organizational Practice" (2010). Dissertations and Theses. Paper 365.

https://doi.org/10.15760/etd.365

This Dissertation is brought to you for free and open access. It has been accepted for inclusion in Dissertations and Theses by an authorized administrator of PDXScholar. Please contact us if we can make this document more accessible: pdxscholar@pdx.edu. 
Child welfare workforce turnover: Frontline workers' experiences with organizational culture and climate, and implications for organizational practice

\author{
by
}

Melanie Dawn Sage

A dissertation submitted in partial fulfillment of the requirements for the degree of

Doctor Of Philosophy

in

Social Work and Social Research

Dissertation Committee:

Joan Shireman, Chair

Katharine Cahn

Richard Hunter

Stephanie Wahab

Sherril Gelmon

Portland State University

(C) 2010 


\begin{abstract}
Public child welfare agencies experience front line worker turnover rates as high as $25 \%$ a year. Worker turnover has significant financial costs to agencies, and has been linked to negative outcomes for children in care. Prior research has linked organizational factors, such as organizational climate, culture, and supervisor satisfaction, to turnover intent in child welfare populations.

This research uses an empowerment framework to turn to workers directly to answer the question, "What are the organizational factors that lead frontline child welfare workers to stay or leave the agency, and what, then, are the implications for agency administrators?"
\end{abstract}

This study relies upon secondary data of a workforce study conducted by the Child Welfare Partnership at Portland State University's School of Social Work. The data was collected via a pilot internet survey of approximately 400 State-employed Oregon child welfare case workers across all geographic regions in the state, and focuses on workers who plan to leave for preventable reasons. This study explored links between organizational factors and turnover in a sample of Oregon public child welfare workers.

This research finds that climate, culture, supervision, and knowledge of the job prior to hire are all significantly correlated with intent to leave. Climate is most significantly correlated to Intent to Leave, and explains $25 \%$ of the variance in intent to leave in a regression model. 
These research findings suggest that agency administrators who are interested in improving worker retention can monitor and address local culture and climate as one tool for increasing workforce stability. Retention may be improved by maintaining an organizational culture and climate that is empowering to workers and that encourages workers to be a part of the change process. Additional implications for the child welfare workforce, social work research, and social work education are discussed. 


\section{DEDICATION}

I dedicate this dissertation to my loved ones, especially

my mother, who was an amazing child welfare social worker and led me to this path with her lived examples of kindness, integrity, intellectual curiosity, creativity, hard work and love;

my husband, Todd, a child welfare social worker who continues to gives tirelessly to the profession, inspires me with his desire to improve practice, and keeps me grounded in the work there is to be done in the field, all the while supporting me in my pursuits;

my son, Kristofer, who is blessed and cursed by having two social workers as parents, and promises that he will choose another profession but has all the skills of a natural-born social worker, who asks me the toughest questions, and who is the source of my greatest joy;

my beautiful nieces, Rain and Samantha, who make me want to make the world a better place,

and the family and friends who have stood close even though I missed many opportunities for friendly visits while attempting to balance doctoral studies, family life, and other professional obligations...

I am blessed - thank you for being a part of my journey.

To live content with small means; to seek elegance rather than luxury, and refinement rather than fashion; to be worthy, not respectable, and wealthy, not, rich; to listen to stars and birds, babes and sages, with open heart; to study hard; to think quietly, act frankly, talk gently, await occasions, hurry never; in a word, to let the spiritual, unbidden and unconscious, grow up through the common--this is my symphony. William Henry Channing 


\section{ACKNOWLEDGEMENTS}

I would like to express the deepest gratitude to my dissertation chair, Joan Shireman, who, through her life work, embodies the characteristics I find most admirable: scholarship, the desire to improve the child welfare field through research and service, and kindness and mentorship.

I offer sincere appreciation and thanks to my committee members and mentors at the Center for Improvement of Child and Family Services, Katharine Cahn and Richard Hunter, who have supported me, challenged me, offered me opportunities and connections, provided patience and wisdom, guided me in big and small ways throughout my doctoral program, and encouraged me with their dedication to the child welfare field.

In addition, I am grateful to have benefited from the mentorship of Stephanie Wahab, who served on my dissertation committee and is a model for the kind of professor I hope to become, and who reminds me with her supportive presence that there are stories and voices behind each "data point." She has welcomed me in to the ranks of scholar with kindness and trust and provided encouragement when I needed it most.

I offer my thanks to Sherril Gelmon for serving on my committee, for her careful editing, and for providing valuable guidance in helping me organize my work and produce a quality dissertation. 
Many thanks to Jenny Powers, my fellow doctoral student who worked many long weekends alongside me and kept me motivated for action even as many others in our cohort drifted away.

Finally, I offer my gratitude to the State of Oregon Child Welfare administrators who provided access to their workers and supported this investigation of culture and climate issues in child welfare system. My appreciation, thanks, and admiration go to all the child welfare workers who answered the survey that I used in my data analysis in enduring hope that their feedback might improve the system, despite their many other obligations. 
TABLE OF CONTENTS

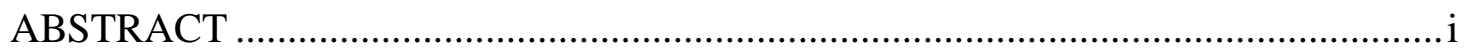

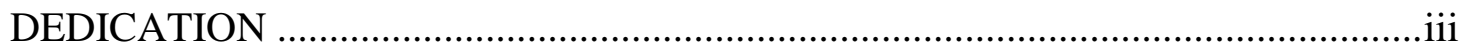

ACKNOWLEDGEMENTS ………….................................................................

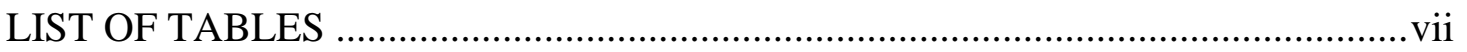

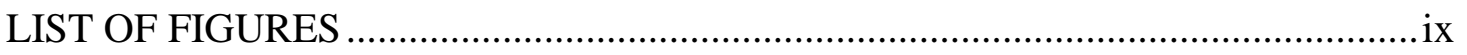

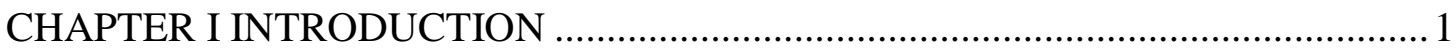

CHAPTER II THEORETICAL PERSPECTIVES ………………………………....

CHAPTER III TURNOVER IN THE CHILD WELFARE WORKFORCE ................21

CHAPTER IV RESEARCH QUESTIONS AND HYPOTHESES ................................. 65

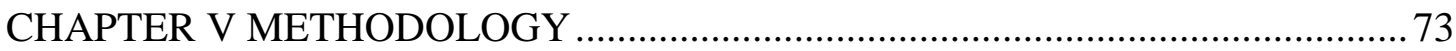

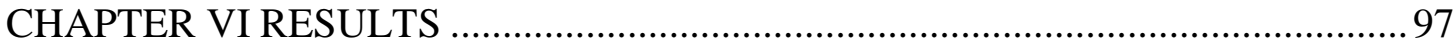

CHAPTER VII FINDINGS, IMPLICATIONS, LIMITATIONS, DISSEMINATION,

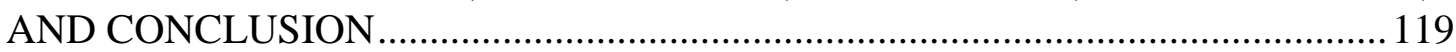

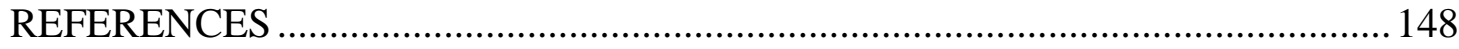

APPENDIX A: SCALES AND CORRESPONDING SURVEY QUESTIONS.....168

APPENDIX B: DATA COLLECTION INSTRUMENT ...........................................171

APPENDIX C: VARIABLES MEASURED BY THE CHILD WELFARE

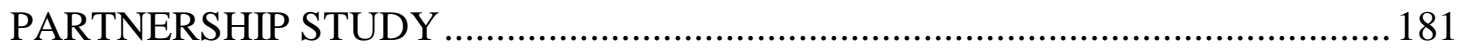

APPENDIX D: INSTITUTIONAL REVIEW BOARD STATEMENT.......................183 


\section{LIST OF TABLES}

Table 1 National Rates of Child Welfare Worker Turnover ..................................... 24

Table 2 Operational Definitions of Organizational Variables Related to Turnover .... 30

Table 3 Subscale Definitions of Organizational Variables Related to Turnover ..........31

Table 4 Measures Utilized and Corresponding Survey Numbers for Major Variables 81

Table 5 Meeasures Utilized and Corresponding Survey Numbers for Subscales ........ 82

Table 6 Response Rates by Service Delivery Area ................................................. 86

Table 7 Worker Demographics of all Workforce Survey Participants....................... 86

Table 8 Demographics of Participants who Intend to Leave for Preventable Reasons 87

Table 9 Workers' Reported Length of Time until Intent to Leave in Full Sample ...... 88

Table 10 Child Welfare Workforce Survey Scale Reliability ................................ 95

Table 11 Research Variables and Statistical Methodologies ....................................96

Table 12 Correlation Matrix for Variables for Hypothesis I .....................................98

Table 13 Hypothesis I Regression Model of Climate Predicting Intent to Leave...... 100

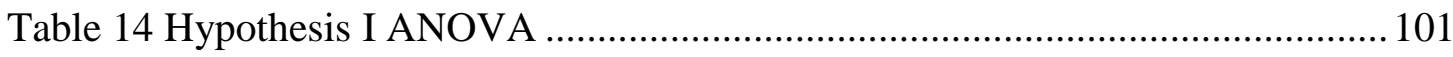

Table 15 Hypothesis I Correlation Coefficients for Climate and Intent to Leave...... 102

Table 16 Correlations for Hypothesis II Culture and Intent to Leave ....................... 103

Table 17 Hypothesis II Regression Model of Culture Predicting Intent to Leave ..... 105

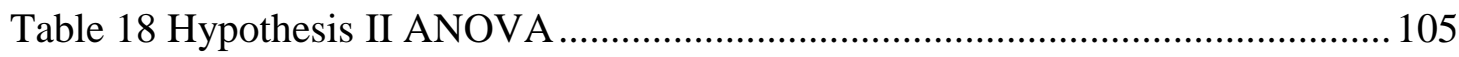

Table 19 Model Coefficients for Hypothesis II................................................... 106

Table 20 Supervisor Support Scale Item Correlations with Intent to Leave............. 116

Table 21Supervisor Competence Items Correlations with Intent to Leave................ 116 
Table 22 Supervisor Satisfaction Correlations with Intent to Leave .................................... 116 


\section{LIST OF FIGURES}

Figure 1 Theory of Factors that Cause Preventable Turnover ...................................66

Figure 2 Map of Service Delivery Areas Participating in Workforce Survey ............ 83

Figure 3 Scatterplot of Supervision Satisfaction and Intent to Leave ...................... 108

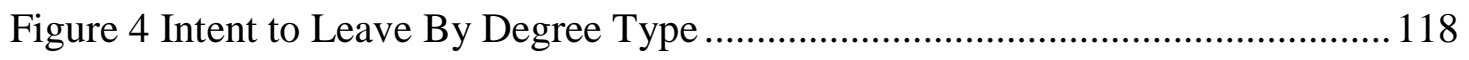




\section{CHAPTER I}

\section{INTRODUCTION}

Those who have chosen employment as caseworkers in state or county administered child welfare agencies perform vital services. They assess the safety of children when a member of community thinks that the child might be abused or neglected, offer stabilizing services to families in crisis, take children in to protective custody and foster care, work to reunify children with their families, and find alternative long-term placements when it is not safe for children to be at home. These workers are vital to the health of our communities. However, their ability to perform these critical tasks is affected by rates of caseworker turnover that average $25 \%$ per year nationally (e.g., Jordan Institute for Families, 2000; American Public Human Services Association [APHSA], 2005; Child Welfare League of America, 2001a).

High worker turnover in child welfare results in longer out-of-home care for children, creates a loss of worker expertise, and leads to eventual service degradation (Annie E. Casey Foundation, 2003; Flowers, McDonald, \& Sumski, 2005). Worker turnover decreases opportunities for workers to establish productive relationships with clients, and has many other organizational costs, both fiscal and service-related (Graef and Hill, 2000; Dorch, 2007; Dorch, McCarthy, and Denofrio, 2008). Worker turnover has been linked to slower time to permanency for children, repeated incidents of abuse, and causes obvious problems for children, parents, and foster parents who have to form relationships with a series of caseworkers. Turnover has also been linked to 
system inefficiency and overload for workers who stay (e.g., Flowers et al., 2005; Strolin-Goltzman, Kollar, \& Trinkle, 2010).

This research analyzes which organizational variables are linked to workers' intent to leave, with a focus on organizational culture, organizational climate, supervisor satisfaction, job readiness, job role, and the outcome variable intent to leave. Links between culture, or organizational variables associated with the way things are done in an organization, and climate, or the impact of the work environment on workers' well-being, (Glisson \& James, 2002) are explored. This study also explores the impact of supervisor satisfaction, the impact of realistic job expectations, and the impact of job role on workers' intent to leave. These variables are analyzed using data from direct survey of those who experience the organization and its impacts from the front-line: the child welfare case workers.

This Oregon-based sample can help administrators understand state-specific workforce demographics of child welfare case workers, and is expected to identify strategies that will enable agencies to move away from continuously training new workers, and instead think about ways to improve the culture of their organizations to retain current workers.

\section{Oregon Context}

Oregon's rate of turnover for child welfare caseworkers is unknown; in the state's child welfare agency statistics, turnover for caseworkers is combined with the rate of turnover for child welfare support staff and administrators, and reported at the 
DHS agency-level. However, Oregon is attempting some shifts that are hoped to impact turnover and child welfare practice.

Oregon has recently initiated a culture shift toward clinical supervision instead of task supervision as an orientation for supporting case workers. The supervisor job description was adjusted to reflect this change, and all supervisors in the state have recently been trained to use clinical supervision. It is anticipated that this shift will improve retention and case work. Across the United States, many public child welfare agencies are taking similar measures to improve supervision, and thereby worker satisfaction, retention, and outcomes for children. However, it has been unknown whether workers in Oregon are currently satisfied with their supervision.

Oregon has also recently initiated a three million dollar evaluation of the State's social service system efficiency, which is meant to identify system slowdowns and make recommendations that will save the agency money. Administrators assume that the findings will lead to financial savings, which will allow the agency to lower caseload sizes. Caseload size is often linked to worker turnover in child welfare workforce research (Cornerstones for Kids, 2006). Other organizational variables linked to worker turnover include role ambiguity, role conflict, peer support, supervisor support, career advancement opportunities, autonomy, and realistic job preview (Glisson \& James, 2002; Glisson \& Green, 2004; Bride, Jones \& McMaster, 2007; Chernesky \& Israel, 2009; Annie E. Casey Foundation, 2003). Oregon is not systematically intervening to address most of these issues. In fact, salary has been 
frozen, career ladders have decreased, and the opportunities to claim overtime for work that occurs beyond the regular schedule have been diminished. Some efforts have been made to improve the quality of clinical supervision and decrease the span of supervision in child welfare.

A recent budget crisis, nationally and in Oregon, may affect the current climate and culture of Oregon's workforce. Child welfare caseworkers are being asked to forego annual step-increase raises this year, and were not given cost of living increases in the last two years. Although case workers in Oregon have not experienced layoffs, there have been intermittent hiring freezes of caseworkers and of the support staff who help them do their work. These factors might increase departures; however, during difficult economic times, workers may be less likely to consider a job change.

Oregon Demographics. According to the 2008 estimates of the U.S. Census Bureau, Oregon has nearly 4 million residents, of whom $23 \%$ are under 18 years old. Demographically, Oregon is fairly homogenous; $80 \%$ of the population in Oregon is Caucasian, 11\% Hispanic, 3.6\% Asian, 2\% black, and 1.4\% Native American (2009). According to Oregon Department of Human Services (DHS), 28,000 reports of abuse and neglect were investigated and 11,000 children were found to be victims of abuse and neglect in 2009 (DHS, 2010). As is the case in most states, children of color in foster care are over-represented (Hill, 2006); 62\% of children who spent time in foster care in 2009 were Caucasian. Drug and/or alcohol use was a family stressor for half of 
the cases, and domestic violence was present in about a third of founded cases. Familial neglect or abuse played a role in 13 child fatalities in 2009.

A report by McKinsey \& Co. indicates that child welfare workers in Oregon spend an average of 75 minutes per day with families; most of the other time is spent on paperwork and court (2008). They advise that 120 to 600 more child welfare workers should be hired, as workers typically currently carry caseloads that average 20 children; the McKinsey \& Co. report indicates that child welfare is staffed at $81 \%$ of its necessary level (2008).

Child Welfare Workforce Survey. This research offers a secondary analysis of a recently collected workforce survey. Portland State University's School of Social Work Child Welfare Partnership conducts child welfare research and training in Oregon. A child welfare workforce research team, led by Principal Investigator Richard Hunter, PhD, and assisted by Doctoral Students Melanie Sage, MSW (this author), Amanda Fixsen, MA, and Michael Ponder, MA, have developed and piloted a workforce study that focuses on worker well-being in the context of the organization, explores worker demographics, and asks questions about worker satisfaction with supervision, peer support, culture and climate, and other variables that literature supports as being related to retention. The data from the web-based survey has not yet been analyzed outside of this dissertation.

This dissertation investigated the findings from this survey as they relate to organizational factors that influence worker turnover in Oregon, and the interventions 
suggested by these factors. The analysis reveals previously unknown links between intent to leave and organizational factors, and suggests specific variables within the organization as appropriate targets for intervention to help reduce problem turnover.

Specifically, this research suggests statistically significant links between intent to leave and organizational climate, culture, supervision, and job readiness. The constructs of climate and culture that were found to have the most significant impacts on a worker's intent to leave include opportunities for advancement and role clarity, and the degree to which the agency rewards expertise and professional development. Although it was expected that there would be differences in intent to leave between job roles for workers, none were found. There were also no statistically significant findings in differences in intent to leave based upon degree type.

Because this survey relies on workers directly to answer questions about the interventions that they believe are most relevant to their satisfaction, this analysis has potential to speak to change strategies that come directly from those that a workplace stabilization intervention seeks to support. The open-ended qualitative responses are used to illustrate the quantitative survey data. This exploration makes a contribution to the child welfare workforce literature in that worker voice is emphasized and direct links between workplace variables and intent to leave are explored. The measures piloted can be refined and the impact of proposed interventions can then be tested in subsequent research. 


\section{CHAPTER II \\ THEORETICAL PERSPECTIVES}

Theoretical approaches discussed below help guide the research questions presented in this dissertation. Systems theories offer a broad framework from which to understand the interconnectedness of people and environment, and are nested within an ecological framework. An ecological framework supports a multiple-intervention perspective in addressing the problem of social work turnover. Davies (1977) explains that a systems theory approach accounts for multiple explanations of a problem, at both micro and macro levels, and supports models that target the group and community for intervention.

Empowerment theory, also considerate of an ecological framework, supports the practice of going to workers directly to answer questions about the workplace culture in order to highlight their voices within the system, encourage reflection, and subsequently attempts to raise the consciousness of all people within the organization. Workers across the system, from employee to manager, can be empowered to participate in organizational change. Workers are benefited by being asked to reflect on their own and collective well-being.

\section{Ecological Framework}

Whereas some previous studies have focused on the personal factors that lead a worker to leave an agency and sees the worker as the source of the problem (e.g., Bennett, Plint, \& Clifford, 2005; Drake \& Yadama, 1996), an ecological framework 
begins with the understanding that the entire environment impacts a worker's decision to stay or leave. An ecological framework suggests that the problem of social work turnover has its roots in the environment, and that the environment includes all the layers of systems (such as the worker's personal and family relationships, workplace, and community characteristics) that impact the worker. Through the lens of ecological theory, a person's behavior, in this case the worker's intent to stay or leave, is always dependent on the context of the system. The office setting is the primary environment for child welfare workers, serving as their "home base," the place where work-related cultural norms are generated. An ecological perspective suggests that the work environment has an important role in the worker's devotion to the agency.

General Systems Theory and Dynamic Systems Theory

The social work field has utilized concepts based upon a systems theory framework to help understand how people are impacted by their environments. Systems theory refers to a number of theoretical perspectives across a range of disciplines to describe interconnectedness between a system, and the way the parts of a system influence each other, and often refer back to the 1930's work of Ludwig von Bertalanffy (Gray \& Rizzo, 1973), who suggested a new frame from which to think scientifically about the effects of associations in problem solving. Systems theory had a significant role on social work, beginning in the 1970's, but much of the systems theory in social work has focused on the family or small group as a system, or the 
interaction between clients and their environment, often described as an ecosystems approach (Payne, 2002).

General Systems Theory suggests that group systems strive toward four main tasks (Bales, 1950; Garvin, 1987; Parsons, Bales \& Shils, 1953; Toseland \& Rivas, 2005): integration (to work together), pattern maintenance (adhere to processes and procedures), goal attainment (task achievement), and adaptation (ability to adjust to change). These tasks are achieved through the processes of group activities, interactions and communication, sentiments and emotional feelings manifested, and norms about behavior within a group, which all affect system well-being (Homans, 1958, in Kirst-Ashman, 2008). These tasks are thought to affect the quality in which members of a group system interact with their external environment. A healthy system is open to inputs from the environment to allow for the exchange of energy needed to revitalize the system; a closed system has to regenerate its own energy and often experiences negative entropy (Kast \& Rosenzweig, 1972). When conceptualized as a system, the child welfare work environment is thought to be influenced internally by individual members of the system, and by subsystems within the system; collectively the system's interactions, sentiments, norms, and activities will influence how the agency interacts with other systems in the community.

The field of organizational theory has given greater attention to system issues and the effect on organizational productivity, also drawing upon Bertaflanffy's general system's theory. Systems theory added greater complexity in understanding how 
organizations can change dynamically in order to adapt to their environment based upon small shifts or decisions made within any part of the organization (Shafritz \& Ott, 1996). In the case of child welfare turnover, one would expect, for instance, that group members within the system are impacted when a worker leaves, and that the functioning of the larger system is impacted by the workforce turnover. It is also expected that workers within a system share certain experiences of the work environment. In this study, some of those shared experiences are used to describe the concepts of organizational culture and climate, and measure shared perceptions of other variables that impact workforce stability.

Katz and Kahn introduced the concept of organizations as open systems that are embedded within their environments, and therefore must adapt to environmental factors, while in turn also realizing how they affect their environments (1966). This understanding helps organizations introduce purposeful changes that promote agency effectiveness. Katz and Kahn propose that maintenance of the desired goals (outputs) of the system relies upon the input (energy) and the transformation and renewal of that input as a system activity. Systems rely upon energy and stimulation from the outside world and other institutions, and they reorganize this energy into a new service in order to meet agency goals; energy continually leaves the system, and thus new energy must refresh the system in order to avoid entropy (Katz \& Kahn, 1966).

In order to maintain the goal of child safety in a child welfare setting, the organization must offer the appropriate renewal of the right types of resources and 
rewards, and must maintain an appropriate balance of these resources and rewards in order to maintain the system functioning. As child welfare workers leave, new workers with equitable skill sets must replace them in order to avoid entropy. However, in the case of turnover, experienced workers are often replaced with new workers who require training, and that causes an imbalance of system functioning and requires readjustment of caseloads and resources across a work group. This frequent negative entropy causes system disruption that is thought to have a negative effect on children (e.g., Flowers, McDonald, \& Sumski, 2005; Strolin-Goltzman, Kollar, \& Trinkle, 2010).

Thompson adds that organizational systems are evolutionary, and that a dysfunctional system will adapt to overcome the dysfunction (1967). From this perspective, a child welfare agency that provides inadequate resources and rewards to support worker longevity might naturally reinforce high workforce turnover, as workers who are no longer satisfied will depart and the new workers who are not yet affected by the negative organizational impacts will take their places. This system maintenance pattern helps the system work toward equilibrium. This supports Bertalanffy's theory of system equifinality; that is, systems can work toward balance from a variety of paths Kast \& Rosenzweig, 1972). Another potential path to help maintain system balance is to reconsider the organizational rewards that might better support worker satisfaction. Thompson further suggests that organizational systems experiencing crises related to unpredictable environmental conditions may ration 
services, which keeps an agency from operating at maximum effectiveness, and may (in the case of social services work) redirect attention to cases with the most pressing needs, to the detriment of other cases, and eventually cause an organization to operate as a closed, rather than open, system (1967). This further reduces system efficiency.

Dynamic systems theory expands upon the concept of system balance by introducing systems as complex and creative, adapting to extreme changes, and suggest that not all system goals are for equilibrium; they must also respond to new needs. Many systems exist and they are intertwined, so from a social work approach we must focus on a point in the system (the "focal system") but not rule out influences of other systems (Robbins, Chatterjee, \& Canda, 2006).

Systems are set up to be open to certain kinds of inputs, and "react only to those information signals to which they are attuned" (Katz \& Kahn, 1966). The child welfare organization research continues to explore which organizational factors have the greatest impact on the goal of child safety. An organizational systems approach reinforces that all the parts of a system, including the resources and rewards offered to workers within the system, will have an impact on the eventual productivity of the organization.

By adopting a systems perspective, the focus of interventions falls the larger system instead of the micro system (Mills, 1959); instead of job exit being the problem of the individual, it becomes a public issue of the child welfare organization. A systems theory perspective encourages the role of the practitioner in system change; 
"Practitioners should be included in the search for new knowledge because they control access to an essential ingredient — organizational data — and they are the ones who ultimately put the theory to the test" (Kast \& Rosenzweig, 1972).

An organizational systems approach would theoretically support the removal of power blocks, as defined in empowerment theory, as a way to help systems function to full potential, because all systems are interdependent and interventions that allow systems to operate at full potential can have a positive effect on other systems. Empowerment theory does a better job at suggesting an actionable intervention.

\section{Empowerment Theory}

Empowerment of an individual or a group occurs within an ecological framework (Perkins \& Zimmerman, 1995). Empowerment is considered both a theoretical framework and values orientation (Zimmerman, 1992.) Empowerment theory has value in that it encourages awareness and guides practice, whereas most human behavior theories focus on explanation and prediction (Robbins et al., 2006). Empowerment theory rests on the philosophical assumptions that all knowledge has historical and social context and is subject to power differentials, and that we must give preference to the views of marginalized people versus the social systems that seek to maintain power (Robbins et al., 2006), and develop a situated view of the environment of oppression. Empowerment is the "process of increasing personal, interpersonal, or political power so that individuals can take action to improve their life situations" (Gutiérrez, 2001). Although empowerment-guided practice is often 
framed at the individual level, empowerment theory is also conceptualized by researchers at the organizational and community levels and focuses not on individual blame, but instead on designing or changing the system in ways that empower constituents (Peterson, Lowe, Aquilino, \& Schneider, 2005; Lee, 2001). Disempowerment, or oppression, manifests both internally and externally when a social system withholds opportunities or resources (Lee, 2001). Research indicates that child welfare workforce stability benefits from resources such as supervisor support, peer support, autonomy, and career ladders (Pecora, Whittacker, Maluccio, \& Barth, 2000; Jacquet. Clark, Morazes, \& Withers, 2007; Glisson \& James, 2002). This dissertation research seeks to understand workers perceptions of access to those resources and how workers' perceived access to resources impacts workforce stability.

Psychological empowerment theory suggests that empowerment is composed of interpersonal, interactional, and behavioral components (Zimmerman, Israel, Schulz, \& Checkoway, 1992). In other words, empowerment is conceptualized not only by a person's impression of their efficacy and ability to influence systems important to them (interpersonal empowerment), but also by transactions between themselves and their environment (interactional empowerment) and critical consciousness of the environment (Freire, 1973), and knowledge of the resources to change it (Zimmerman et al., 1992). A person takes specific actions that demonstrate empowerment (behavioral empowerment) through participation in community or organizational activities that change. Empowerment theory helps to explain how 
people gain a sense of empowerment within a situation, and which interventions lead to feelings of empowerment.

Empowerment theory can be applied to groups in order to increase social justice (advocate for positive change), raise consciousness (enhance awareness), support mutual aid (whereby participants work to empower each other), share power (through communication styles that emphasize shared leadership), and multicultural association (appreciate differences within the group) (Breton, 2004; Gutiérrez \& Lewis, 1999; Lee, 2001). Keffer (1984) explains that empowerment develops within an organizational setting when a person develops the skills to participate in the decision making process, experience a sense of importance, and has a perception of self-efficacy. Zimmerman (1992) suggests that personal control, competence, awareness of the political and environmental setting, and participation in the community or organization all comprise the conceptual theory of personal empowerment.

Social work empowerment theory operates to help explain and address oppressive structures, and encourage strategies that consider a group's history of oppression, an ecological view of the situation, the interconnectedness of social injustice, and racism and gender structures that contribute to oppression (Robbins et al., 2006). Feelings of powerlessness can affect a group's ability to create change when members of the group (caseworkers in this case) see themselves as incapable of creating change, due to lack of training and information, lack of education about 
political processes, or their own sense of power (Cox, 1988). In order for empowerment strategies to be effective, "power blocks" must be identified (Solomon, 1987). Power blocks are conditions that interrupt the ability of individuals to develop effective personal and social skills, and occur at multiple levels.

Although social work empowerment theory most commonly describes interactions between a social worker and oppressed client group, the empowerment theory model and intervention methodology addresses many of the issues faced by caseworkers who experience a sense of powerlessness and lack of access to a supportive organizational climate and culture. The child welfare agency professes to help children in families, but when organizational conditions for workers lead to worker turnover, families the agency serves are negatively impacted.

Just as social workers use an empowerment framework to strengthen the selfefficacy, awareness, and strategies to achieve personal and collective goals of clients served, child welfare administrators and others (such as unions, child welfare workers, social work or child welfare advocacy organizations, or other community change agents) can adopt an empowerment framework that supports the self-efficacy, political awareness, and resources of workers in meeting the collective goals of workers that would support greater workforce stability. Simultaneously, child welfare caseworkers can raise their critical consciousness of their environment to create solidarity and organizational culture and climate change (Friere, 1973). This is achieved first through generation and dissemination of knowledge (like these research outcomes), and then 
education around technical strategies for creating change and access to participation in change efforts. By adopting this theoretical approach, empowerment begins by surveying the workers about their condition, which encourages them to reflect on their own well-being. This research will offer the workers and administration a tool that contributes to their critical consciousness of the worker condition, and offers some options for intervention that addresses identified needs.

Administrators have numerous motivations for adopting a framework that better supports the caseworker, including improved culture and climate, workforce stability and the financial savings that come with it, and improved client outcomes. Child welfare caseworkers are expected to use empowerment frameworks with their clients. Parkin \& Green (1997) note that child welfare caseworkers who are disempowered in their work are unlikely to be effective in protecting children from harm; it is likely that they also adopt oppressive and dehumanizing casework practice as a result of being disempowered.

Child welfare workers are uniquely situated to participate in the knowledge generation of what comprises a positive work setting and what tools are most valuable in their ability to do their work. Additionally, given the ability to influence change within their environment and be given the tools to critically evaluate their work setting, they are able to shape practice. This research offers workers an opportunity to participate in the generation of knowledge and proposes to offer workers the feedback necessary to evaluate their workplace. These steps toward interpersonal and 
interactional empowerment support the worker in considering the resources needed to develop a sense of behavioral empowerment.

One way to offer consciousness-raising to workers is by encouraging their participation in local knowledge generation about their workplace, with tools such as the Child Welfare Partnership Workforce Survey. It is hoped that asking questions about climate and culture issues increases conversations about the work setting, and that offering the findings to the workers will support collective consciousness. It is hoped that findings of this survey will also help validate the personal experiences through sharing the findings about the collective experiences of caseworkers.

\section{Limitations of Explanatory Theories}

Ecological framework and general systems theories are often criticized for not giving enough guidance toward interventions in social work (Barker, 1995), and they offer unclear boundaries about what composes a system (Greene, 1994), it gives little direction about how to build an intervention within a system. Greene suggests that systems theory offers a way to think about a problem more than it offers a method to intervene in a problem. In the case of the child welfare organization, systems theory indeed offers a helpful way of thinking about the problem, but does not help clarify where systems begin and end or dictate an intervention model. Systems theory can also cause "subsystems thinking" (Kast \& Rosenzweig, 1972) where the focus is limited to a certain level of the subsystem (the child welfare organization practice 
setting, for example) and gives insufficient focus to the broader supra-systems of this organization.

In traditional systems theory, emphasis is placed on system stability or equilibrium, which is not necessarily a good fit for a profession focused on social change (Hutchison, 2007). Additionally, the concept of general systems theory often focuses on measuring the effectiveness of a subsystem, instead of the benefit to society in which the subsystem is situated (Kast \& Rosenzweig, 1972).

Updates to systems theory, such as chaos theory and complexity theory, help explain sudden and radical change in systems, but remain vague or inconsistent in their application, which make them difficult to test or develop empirical support (Hutchison, 2007). Kast \& Rosenzweig explain that understanding the complex nature of systems has limited utility in that we are not sophisticated enough to fully understand the statistical complexity of predicting outcomes based on system interactions (1972).

Traditional systems theory also emphasized the shared norms necessary to hold a functional system together, but this neglects issues related to oppression of minority groups who lack power within a system (McMichael, 2006). However, dynamic systems theory supports the system's ability to adapt and stay fresh, encourages open boundaries that allow for new perspectives, and supports empowerment theories. Exploring these theories in partnership helps guide the social worker toward systems-level interventions. 
Empowerment has been over-used to describe ways in which the oppressed can claim more responsibility for their own well-being, and sometimes ignores the social structures and policy issues that contribute to disempowerment (Rose, 1994). Empowerment theory emphasizes how individuals can take action to increase their personal power (Lee, 2001; Gutiérrez, 1990). If one approaches empowerment theory with a narrow point of view, this perspective appears to have a very micro focus and assumes there will be opportunities in an environment for a person to participate in decision-making and develop a sense of control and the access to the tools necessary to create change. This may be particularly difficult in some types of systems, including the bureaucratic child welfare system. However, this theory has strength in supporting healthy environments that respect worker empowerment, and its philosophy encourages researchers to perform action-oriented work that helps workers evaluate their situation. Empowerment theory has also been criticized as overly conflictoriented with an oppressor/oppressed lens (Speer, 1999), but this assumes that both the oppressor and oppressed cannot be empowered and experience increased consciousness, or that these roles do not blur. Finally, empowerment theories lack significant research as a tool to explain human behavior due to the strong practice orientation (Robbins et al., 2006); however, an understanding of the way oppression works and affects human behavior is central to the values of social work and the interventions that social workers propose when addressing issues of social justice. 


\section{CHAPTER III}

\section{TURNOVER IN THE CHILD WELFARE WORKFORCE}

The organization and workplace have been studied in a number of bodies of literature, most notably in business and administration. Likewise, factors that influence employee satisfaction and well-being in the workplace are studied in many different pools of literature. This review draws upon knowledge from these tertiary fields, and focuses on literature development specific to the child welfare workforce. It begins by defining concepts in the child welfare workforce literature related to turnover and the reasons that this topic has emerged as one of the most important in addressing the child welfare workforce instability, and also focuses narrowly on concepts of the organization related to climate and culture in non-profit child welfare settings, and the organizational variables thought to be associated with child welfare worker stability specifically.

\section{Defining Turnover and Retention}

Caseworker turnover occurs when any child welfare worker leaves the agency. Administrators who work in the field note that not all types of turnover are detrimental. In fact, some ascribe to the belief that given the high rate of burnout among child welfare workers, an accompanying high rate of turnover is acceptable, if not beneficial; workers who begin to experience burnout and depersonalize clients leave the agency, or perhaps those who leave were not a good fit for the job. In the literature, this is often referred to as beneficial or desirable turnover (Lawson et al., 
2006; Ellett, Ellis, Westbrook \& Dews, 2007). Desirable turnover also includes those who are fired or do not pass training. Promotions or lateral moves to new positions are generally not labeled as turnover, although they also impact the stability of client relationships critical to case outcomes.

Unpreventable turnover includes retirement, death, marriage or parenting, returning to school, or a spousal job move (Child Welfare League of America, 2001b). These types of turnover will always exist and the reasons are beyond the control of the child welfare agency. The combination of beneficial and unpreventable turnover results in a portion of turnover that is less likely affected by interventions that seek to improve the organizational climate and culture; however, some burnout is related to organizational factors, and some intent to leave to return to school or other personal reasons could be linked to satisfaction with the workplace. This makes the categories of desirable, preventable, and unpreventable turnover difficult to differentiate.

Preventable turnover happens when good workers leave the agency out of dissatisfaction. This type of turnover is the target for workplace interventions because when a good worker leaves, the agency loses the expertise the worker holds, and ultimately coworkers and clients are impacted by the loss (e.g., Cornerstones for Kids, 2006; Ellet et al., 2007; Lawson et al., 2007; Glisson, 2007).

While much of the child welfare literature has focused on turnover, some research focuses instead on retention (Ellet et al., 2007). Researchers study retention to learn what causes workers to stay or be committed to the agency. The factors that 
cause a worker to stay are thought to be different than those that cause a worker to leave. The factors that cause a worker to leave are sometimes labeled "push factors" (they push a worker to leave a dysfunctional agency) and "pull factors" (those that pull a worker away from an agency). Those that cause workers to stay are then labeled "keep factors" (those that keep the worker at the agency) (Mitchell \& Lee, 2001).

Although there are differences in beneficial, preventable, and non-preventable turnover, and one can assume differences in how to impact each, agencies generally do not measure turnover based upon these subtypes. In some instances, agencies attempt to find out reasons people leave during job exit interviews (Zlotnik, DePanfilis, Daining, \& Lane, 2005), and categories are estimations at best. The American Public Human Services Association (APHSA) estimates that preventable turnover makes up about half of all turnover (APHSA, 2005).

While turnover can be measured directly via follow up with workers who leave, these measurements are often cumbersome, as people are sometimes difficult to locate once they leave the agency. A worker's "intent to leave" is thought to be the best proxy and a precursor for actual turnover (Mor Barak, Levin, Nissly, \& Lane, 2001; Steel \& Ovalle, 1984; Martin, 1979). The intent to leave data are generally collected via survey, where workers who are currently employed are asked how long they intend to stay at an agency, and can explain which factors are most likely to lead to their departure. 


\section{Rates of Turnover}

Reported turnover rates vary widely by state, and often within a state (Lawson et al., 2006). In 2003, APHSA reported on collected administrative data from 42 states. Eighteen of those states offered turnover data. Ten of those states classified their turnover as either preventable or non-preventable. These are the data that APHSA uses to estimate that nationally the rate of preventable turnover among caseworkers accounts for half of all turnover. This figure comes primarily from exit interviews with workers. According to APHSA, in cases of preventable turnover the worker has been in her position for an average of five years. Examples of published turnover rates across the United States are in Table 1.

Table 1

National Rates of Child Welfare Worker Turnover

\begin{tabular}{lllll} 
Turnover Rate & Location & Sample & Year & Source \\
\hline $44 \%$ & Georgia & $\begin{array}{l}\text { Population } \\
\text { (n not reported) }\end{array}$ & 2000 & $\begin{array}{l}\text { State of GA report } \\
\text { to Commissioner }\end{array}$ \\
\hline $9.5 \%$ & $\begin{array}{l}\text { California minus } \\
\text { Los Angeles } \\
\text { County }\end{array}$ & $\begin{array}{l}\text { Population } \\
\text { (n not reported) }\end{array}$ & 2004 & Clark, 2005 \\
\hline $26 \%$ & $\begin{array}{l}\text { 12 California } \\
\text { counties }\end{array}$ & $\begin{array}{l}\text { Population } \\
\text { (n=3000) }\end{array}$ & 2002 & Cornerstones, 2006 \\
\hline $25 \%$ & North Carolina & $\begin{array}{l}\text { 356 workers from 32 of } \\
100 \text { random counties } \\
\text { (response rate 50\%) }\end{array}$ & 2005 & $\begin{array}{l}\text { Jordan Institute for } \\
\text { Families, 2008 }\end{array}$ \\
\hline $27 \%$ & $\begin{array}{l}\text { N=1,165 (all workers } \\
\text { hired between 2000-2001 } \\
\text { in 44 counties) }\end{array}$ & 2002 & $\begin{array}{l}\text { Weaver, D., } \\
\text { Chang, J., \& Gil de } \\
\text { Gibaja, M. (2006) }\end{array}$ \\
\hline $\begin{array}{l}\text { California } \\
\text { agencies; }\end{array}$ & $\begin{array}{l}\text { 333 state and } \\
\text { local CWLA } \\
\text { member agencies, } \\
\text { including state, } \\
\text { county, and } \\
\text { nonprofit }\end{array}$ & & 20001 unique salaries. & CWLA, 2001a \\
$20 \%$ in public & & & \\
agencies & & & & \\
\hline
\end{tabular}


The definition of turnover is not consistent between studies, and rates of turnover are affected by whether a study counts internal turnover or lateral moves, how a "caseworker" is defined, and whether turnover information for caseworkers is separate from turnover of other child welfare staff (such as office support). In many agencies data are not collected at all. Some reports indicate a difference in turnover by job role; for instance, protective service workers (child abuse investigators) have higher turnover rates than ongoing caseworkers, and adoption workers have the lowest rate of turnover (e.g., Jordan Institute for Families, 2000, APHSA, 2005). APHSA reports a national turnover rate of $22 \%$ for protective services workers and $18 \%$ for ongoing caseworkers. APHSA reports that the turnover rate for caseworkers alone was $39 \%$ higher than that of all child welfare agency staff together (including support staff). For perspective, the Bureau of Labor Statistics reports only a 5\% turnover average for local, state, and federal government workers in 2007 when retirement is excluded (Bureau of Labor Statistics, 2008).

\section{Costs of Turnover in Child Welfare Settings}

Costs of turnover include direct fiscal costs, such as those of training and replacement, indirect costs, such as the time it takes to train a new worker, emotional costs, such as those suffered by children who experience frequent worker loss, and unknown long-range costs to society.

All types of turnover have significant fiscal impact on taxpayers, as well as a number of costs for organizations (Mor Barak et al., 2001). The fiscal costs of 
turnover include administrative time and costs to recruit, perform background checks, and verify references, interview, hire, and train new workers (Cornerstones for Kids, 2006). Graef and Hill (2000) report the estimated direct cost of replacing one CPS worker was \$10,000 in 1995. Daly, Dudley, Finnegan, Jones, and Christiansen (2000) report the cost at $\$ 17,000$ in California. A more recent study of a rural East Coast county indicates that replacement costs are about $\$ 24,000$ per person for training alone, without calculating indirect costs (Dorch, 2007). Another public agency in a Northeastern State provides tuition reimbursement to some employees, at the approximate cost of $\$ 16,000$ for an MSW; not counting this benefit, researchers found that the average cost in 2003 of replacing a child welfare worker was $\$ 27,000$ when including separation, replacement, local, and state training costs (Dorch, McCarthy, and Denofrio, 2008). The average cost of replacing an employee who received tuition subsidy for a MSW degree was $\$ 50,000$. The statewide cost of replacing workers in this study state for the year 2003 was approximately 19 million dollars in total.

The Human Resources Services staffing group in California suggests that money spent on turnover in child welfare could be redirected to turnover prevention at a savings to the agency. They offer this scenario as an example; an agency has 100 workers at an average salary of $\$ 35,000$ a year, and an average turnover rate of $26 \%$. If turnover costs are calculated at $70 \%$ of salary, each incident of turnover costs about $\$ 25,000$ and yearly turnover costs for the agency are about $\$ 650,000$. If turnover costs were cut in half to $\$ 325,000$, the result is the ability to hire 11 more workers, 
significantly reducing caseload sizes (Cornerstones for Kids, 2006). While there is not a well-documented count of how many child welfare workers serve families throughout the United States, there are 8,200 child welfare workers in California alone (Clark, Smith, \& Mathias, 2009); the potential effect of redirecting costs is substantial. Workers also generate financial costs as they leave the agency that are difficult to calculate, via administrative paperwork, payouts of time or leave balances, and unemployment compensation, which are not included in these figures (Annie E. Casey Foundation, 2003).

There are also opportunity costs related to the time and energy expended by turnover. A study of North Carolina child welfare workers found that, on average, it takes about six months to move from position recruitment to a new caseworker carrying a full caseload (Gunderson \& Osborne, 2001). Time is lost when a worker returns to the office from new worker training and has to consult with a peer or supervisor about regional protocol. New workers may be less productive or more likely to make mistakes (Annie E. Casey Foundation, 2003). There is an emotional cost to workers who have to cover caseloads that were deserted by workers who have left the agency, and cumulative effects on worker productivity. Office morale is affected by turnover. Burnout, which is thought to be a predecessor to turnover, had contagious effects on other workers (Bennett, Plint, \& Clifford, 2005). There are difficult-to-measure costs of lost institutional expertise when workers leave. This includes the time supervisors spend transferring knowledge to workers who leave the 
agency, the pre-service and ongoing training, and job skill that leaves with an employee (Westbrook, Ellis \& Ellett, 2006).

Child welfare agencies identify turnover as a contributing factor in failing to meet their federal benchmarks related to outcomes for children. A U.S. Government Accounting Office evaluation of Child and Family Service Reviews (CFSR's) for 27 states found that workforce issues were linked to the reviewed state not meeting at least one outcome measure in all states, with some states indicating that turnover interferes with as many as 17 outcome goals (2003).

In a 2006 report, the U.S. Government Accounting Office (USGAO) suggests that one of the three most pressing challenges of improving the quality of services to those in foster care is the stabilization of the child welfare workforce. This statement is supported by research that finds that children are in care longer if they have experienced worker turnover, likely due to the effects of new workers not being able to make timely decisions (USGAO, 2003). The extra time a child spends in care is one of many difficult-to-measure indirect costs of worker turnover. Research suggests that permanency (return home, adoption, or another permanent plan) is achieved more slowly when a child experiences worker turnover; one study found that children with multiple workers are almost $60 \%$ less likely to be placed in a permanent living situation within federal timeline requirements when they have multiple workers (Flowers, McDonald, \& Sumski, 2005). When time to adoption is slowed, a state's 
ability to receive federal adoption subsidy monies is also jeopardized (APHSA, 2005) and children are denied the permanency vital to their development.

Qualitative research and case study work suggests that adolescents have a hard time developing new relationships with rotating social workers, which increases issues related to mistrust, separation, attachment, and loss already prevalent in the lives of these youth (Folman, 2000). A qualitative study of 25 adolescents in New York reports themes in interviews with youth that include a loss of stability and loss of trusting relationships related to caseworker turnover, and a statistical regression in this sample supported that children had more placement changes when they had more workers (Strolin-Goltzman, Kollar, \& Trinkle, 2010). Little research exists on the enduring emotional effect of a child having to retell their story to a new worker at each turn, or the indirect impacts on the cases of other workers when they are forced to cover a vacant caseload, but one can speculate that the far-reaching impacts go beyond what is currently documented.

\section{Retention-related Variables in Public Child Welfare}

Yoo, Brooks, \& Patti (2007) identify three themes in child welfare workplace retention studies: worker response to workplace (i.e. job satisfaction and burnout), workplace conditions that influence worker responses (i.e. social support and leadership), and worker characteristics that influence worker responses (i.e. worker demographics and attributes.) Variables that measure individual worker's characteristics have received the most attention in the literature, although this trend is 
changing as more researchers focus on organizational variables in child welfare settings. This review focuses primarily on workplace conditions and workers responses to the workplace.

Several organizational variables are cited in child welfare literature as having an impact on the stability of the child welfare workforce in particular. This literature review focuses on the items listed below in Table 2 that were identified by the Portland State University Child Welfare Workforce team as the organizational factors most frequently linked to turnover in the child welfare literature.

Table 2

Operational Definitions of Organizational Variables Related to Turnover

Variable Brief operational definition

1. Culture Deeply embedded norms, expectations, and the way things are done in an organization; incorporates many variables from scales of peer support, autonomy, and career ladders; this variable is thought to change slowly (Glisson \& James, 2002; Glisson \& Green, 2005, Glisson, Dukes \& Green, 2006.)

2. Climate The individual employees' perception of the psychological impact of the work environment on their own well-being; incorporates employee's reactions to the variables of burnout (emotional exhaustion, depersonalization), role conflict, role overload, role clarity; plus issues that relate to sup satisfaction, personal accomplishment, advancement, job satisfaction (Glisson \& James,2002; Glisson \& Green, 2005; Glisson, Dukes \& Green, 2006).

3. Supervision Clinical supervision refers to support that helps a worker review and develop clinical skills; Task supervision refers to how a supervisor monitors and supports task completion. Clinical supervision is thought to be more important than task supervision in supporting worker longevity (Gibbs, 2001; Jacquet, S., Clark, S., Morazes, J., \& Withers, R. 2007)

4. Job role Child welfare caseworker's specific job duties within the agency; some positions have been shown to have a higher rate of turnover than others, such as investigative roles (Jordan Institute, 2008; APHSA, 2004).

5. Realistic job A worker's orientation to the duties of the job prior to accepting the perceptions/Job Readiness position; realistic perceptions are associated with decreased turnover (Breaugh, 1983; Jordan Institute, 2008; Wanous, 1973, Masternak, 2004).

6. Intent to Leave A worker's personal estimate of how long they plan to continue working with the child welfare agency. This is self-reported information (Bluedorn, 1981). 
Additional variables help to understand the data. These variables are subcategories

within the culture and climate scales, and are presented below. These were used in the

development of scales to measure culture and climate in this research.

Table 3

Subscale Definitions of Organizational Variables Related to Turnover Construct Definition

a) Advancement Caseworker's access to options for upward mobility. Fewer options for Opportunities mobility are sometimes associated with higher $\mathrm{n}$ (Institute for the Advancement of Social Work Research, 2008; Pecora, P., Whittacker, J., Maluccio, A., \& Barth, R., 2000).

b) Autonomy Caseworker's ability to use professional judgment to guide decisions in the field, a privilege that can be given or withheld by supervisors (Casey Foundation, 2003; Michigan State, 2008).

c) Role Conflict Unclear job roles/expectations, or roles and expectations that are incompatible with each other, and are thought to have a negative impact on workforce stability (Jones, 1993; Glisson, 2006.)

d) Role Overload Being asked to do too much work or perform work without the necessary resources; overload interferes with life beyond the work day; work load that feels never ending or unreasonable (Glisson, 2006; Ivancevich \& Matteson, 1980; Reilly, 1982; Thiagarajan, Chakrabarty \& Taylor, 2006).

e) Peer Support Perception that peers work well together and are supportive of each other, associated with workers staying (Byrne, 1994; Bride, Jones, \& McMaster, 2007; Glisson, 2007).

f) Role clarity vs Existence of clarity in behavioral requirements and knowledge that guide role ambiguity one's role and knowledge of where to find answers; clear feedback on performance (Rizzo, House, \& Lirtzman, 1970; Posner \& Butterfield, 1978; Jaskyte, 2005)

g) Burnout Measures feelings of increased depersonalization, reduced personal accomplishment, and emotional exhaustion. Maslach Burnout Inventory is the most frequently cited measure associated with increased child welfare worker turnover (Maslach, Schaufeli, \& Leiter, 2001).

Other variables that sometimes appear in the literature include worker safety, worker salary, caseload size, time to full caseload, and organizational fairness.

\section{Culture and Climate}

Organizational culture is comprised of the deeply embedded norms, expectations, and the way things are done in an organization (Glisson \& James, 2002). 
Culture and climate exist within an organization at a level that is often unspoken, and these variables describe explicit and implicit rules about how an organization works and how people work together within the organization. According to Kreitner and Kinicki (2000), the culture of an organization serves to give members an organizational identity, facilitates collective commitment, promotes social system stability, and shapes behavior by helping members make sense of their surroundings. In a child welfare setting, commitment to the organization has been shown as a primary predictor of intent to remain employed (e.g., Chernesky \& Israel, 2009; Landsman, 2007; Jones \& Cho, 2006.)

Organizational climate is the individual employees' perception of the psychological impact of the work environment on their own well-being (Glisson \& James, 2002). Climate describes employee's personal experience with variables such as supervision, satisfaction with salary and career ladders, job demands such as overtime and work/life balance, ambiguity and role conflict, aspects of burnout and satisfaction, peer support, whereas culture describes the group expectations regarding variables like these, in attempt to capture how workers experience their work environment in totality. As the empirical research continues to grow, the role of organizational culture and climate emerges as an increasingly-important component of child welfare worker satisfaction and retention. Some evidence-based interventions for improving organizational culture and climate in child welfare agencies demonstrate promise for impacting worker retention and provide support for the theory that 
retention is influenced by the work environment (e.g., Glisson, Dukes, \& Green, 2006; Lawson, McCarthy, Briar-Lawson, Miraglia, Strolin, \& Caringi, 2006).

Elements of a positive work climate, including empowerment and input in decision making, good communication, and encouragement for creativity, have been linked to job satisfaction (Johnson \& McIntye, 1998). Positive climate is thought to be a buffer for burnout, which occurs at a high rate in child welfare organizations, and also may be linked to positive outcomes for consumers (Bednar, 2003).

The definition of climate and culture is evolving in the literature. Often, organizational culture is not separated from climate, and is described broadly as a set of implicit assumptions that determines how a group responds to an environment (Ostroff, Kinicki, \& Tamkins, 2003). Organizational culture is passed on through socialization to new employees, has an influence on work behavior, and reflects the work environment, the larger social culture, and the behavior and values of administrators; this culture affects employee attitudes and ultimately organizational outcomes (Ostroff, Kinicki, \& Tamkins, 2003). However, when climate appears as a separate construct, it generally refers to the psychological impact of the work environment on each individual, with the expectation that individuals will be impacted differently by the work environment based on their personal characteristics, different exposures to tasks, differences in roles, or other situational encounters (James \& Sells, 1981). 
Kreitner and Kinicki (2000) divide organizational culture into three layers: observable artifacts, promoted values, and basic assumptions. Artifacts are defined as physical or visual items, such as lists of values, manner of dress, and stories repeated about an organization's history, as well as behavior exhibited by members of the group. Artifacts are thought to be easier to change than less visible aspects of culture. Values are both explicitly stated, such as in a values or mission statement, and are also behavioral; explicit and implicit values may be in conflict within an organization. Basic assumptions are widely held beliefs about how things work and are difficult to change because they are so engrained in an organizational culture.

Disciplines such as management science and career development have gone further in exploring the concepts of culture and climate. These are growing areas of awareness and concern in the child welfare field, as attempts are made to understand the impacts of these issues on turnover and the families served by the child welfare system. Culture and climate in the context of child welfare work presents some unique issues, in that it appears that they have the potential to impact the safety of children in the community (Bendar, 2003). Although organizational influences on turnover have been cited in research, interventions are not systematically applied at this level (Bendar, 2003; Luongo, 2007; Yoo, Brooks, \& Patti, 2007).

Charles Glisson, who conducts research in areas of culture and climate in public child welfare and child mental health organizations, defines culture as the norms, expectations, and the way things are done in an organization. He isolates 
climate as a different variable, defined as the individual employee's perception of the psychological impact of the work environment on their own well-being. These perceptions shape an organization's culture when the experiences are shared with and by other workers within an organization. For example, in a constructive agency culture, workers are supportive of each other and norms encourage helpfulness between employees. Attributes of a positive work culture include low conflict, role clarity, and personalization (Glisson \& Hemmelgarn, 1998). Climate explains personal reactions to the workplace that are shared within the environment, which then impacts culture. For instance, in an agency with a constructive culture, the climate is likely to be one in which employees have energy and feel empowered. Climate is thought to be easier to change, although changing the agency's culture has a longer-lasting impact (Glisson, 2007).

Glisson (2007) maintains that the social context (the organization) directly affects service quality and service outcomes, and the social context is heavily influenced by the climate and culture. Glisson has developed a climate and culture study, based upon earlier organizational work by James \& Sells (1981). His survey measures 14 domains of the work environment, including conflict, cooperation, role clarity, job satisfaction, personalization, fairness, personal accomplishment, job satisfaction, growth and advancement opportunities, and organizational commitment (2007). In a 1998 study based on this instrument, he and co-author Hemmelgarn identified organizational climate as the most significant predictor of outcomes for 
children among a variety of personal and organizational factors, as measured by the psychological functioning of 600 children. In this experimental study, large and small counties in Tennessee were matched to control-group counties, and data gathered from providers, clients, and teachers. The "Psychological Climate Questionnaire" was administered to 206 caseworkers. This measured areas such as fairness, role clarity, role overload, role conflict, cooperation, growth and advancement, job satisfaction, emotional exhaustion, personal accomplishment, and depersonalization. Linear structural equation analysis was used to model the results. The study found that improvements in children's psychological functioning were significantly greater for children served by offices with more positive work climates. This supports the notion that the social context of agencies like public child welfare can be changed with organizational level interventions, thereby enhancing services to families.

For newer workers, organizational culture may be very important. A largescale survey $(n=1,400)$ of Georgia child welfare workers found that for workers who had been with the agency for three years or less, the three factors that most differentiated those who planned to stay from those who planned to leave were measures of work morale, organizational culture, and human caring (Ellis, Ellett, \& Deweaver, 2007). This study also found that workers who reported very high or very low scores about job culture did so in response to the questions about work morale and job satisfaction. Organizational factors such as poor career ladder, inadequate salary, 
high caseloads, too much paperwork, and the employee evaluation process were all statistically related to workers' intent to leave.

Bednar (2003), in a review of pertinent literature, identifies a satisfying work climate in child welfare as one that hires workers who express a strong sense of professional mission, where workers are well matched to their position and are adequately prepared for the work, and rewards workers through lateral moves and internal promotion. Additionally, roles should be clearly defined, including not demanding conflictual roles such as the expectation of high quality services for large caseloads and extensive report writing. Goal setting and rewards should encourage achievement and personal accomplishment. Staff should have input in decision making and collaborative work, creativity, and innovation should be rewarded. Supervisors should develop trust and open communication with workers.

Westbrook, Ellet, \& Deweaver have recently published findings from development and validation of a culture measure in child welfare agencies (2009). They studied a 2003 three-dimension measure of professionalism in child welfare that included measures of quality supervision, collegial sharing and support, professional commitment, and autonomy. Each item on the survey was explored separately and only those items that explained at least one percent of variance were kept in the survey. They found that supervisory support explained $14 \%$ of variance in their culture measure; administration support explained $9 \%$ of variance, professionalism explained $8 \%$, collegiality explained 5\%, and organizational ethos explained 3\%. Several of their 
measures were found to need additional work toward reliability, including the Advancement measure and organizational ethos measure, which did not perform well in Cohen's test of Reliability. These constructs appear to need clearer definition in the literature.

Research on Culture and Climate as Impacted by Personal Demographics

Mor Barak, Levin, Nissly, \& Lane (2006), attempt to model the path from personal demographics to work climate variables to worker well being, and to eventual intent to leave, which is used as a proxy for actual turnover. They measured perceptions of fairness, inclusion/exclusion, social support, organizational stress, organizational commitment, worker well-being, job satisfaction, intent to leave, and personal demographics with a sample of 418 workers from an urban child welfare setting. Direct and indirect paths between these variables were tested in stages using Hierarchical Linear Modeling. These researchers suggest that people attach meaning to their demographic variables and workers are also treated differently based on their demographics, which in turn relates to whether they perceive the organization as fair. When workers feel excluded, they are less likely to report a fair work climate, which affects variables such as job satisfaction and commitment. The data fit the expected model at each step, with demographics affecting experience of climate, and climate affecting satisfaction. There were mediated, but not direct paths, between many demographics and intent to leave. They report that workers of color are more likely to 
experience the organization as unfair, and suggest that as part of organizational culture and climate shifts, issues of diversity must also be addressed.

A study by Ellett, Ellett, \& Rugutt, consisting of 198 items, attempts to conceptualize how some workforce variables work together (2003). Measures used include extensive personal demographics, intent to remain employed at the agency, work morale, a human caring scale, organizational culture, self-efficacy beliefs and expectations, and a list of factors contributing to intent to leave and intent to stay. Data consisted of 1,423 surveys from a Georgia child welfare population sample, which equated to a $63 \%$ response rate. This study found that the most significant predictor of intent to stay at the agency was professional commitment on the human caring measure. However, this study relied on regression and not modeling, and it is unknown how other variables affected one's professional commitment. Ellett suggests that five of her measures (professional commitment, lack of job stress, job satisfaction, professional support, and external relations) account for $54 \%$ of the variance in intent to remain employed at the agency.

Finally, in a meta-analysis of research studies published between 1980-2000, Mor Barak, Nissly and Levin (2001) use constant comparison and structural equation modeling to explore reasons for turnover and retention, and they found that personal demographics, perceptions of work, and organizational demographics all statistically explain some turnover. However, they discovered that variables most associated with each other are organizational commitment, professional commitment, burnout, and job 
satisfaction. This study supports attention to job satisfaction and interventions that increase a worker's organizational commitment and work perceptions to impact problematic burnout and increase satisfaction.

Most research recognizes that personal values and demographics, along with organizational variables, contribute to worker transition (Mor Barak et al., 2001; Ellett et al., 2003). However, organizations have better control of organizational variables than personal demographics such as extent of human caring or age of applicants, and have greater opportunities to intervene in problematic turnover by addressing these variables.

Supervision. Supervision is thought to play an important role in worker retention. In a 2006 National Council on Crime and Delinquency (NCCD) study of former child welfare workers, $45 \%$ said that inadequate supervision was a contributing factor to leaving the agency. Worker-to-supervisor ratio has also been found to be different in high-functioning versus low-functioning agencies; those with smaller span of supervision are significantly higher functioning, and agency functioning is connected to turnover (NCCD, 2006). The role of the supervisor as consultant and to offer guidance (clinical supervision) seems to be more important to workers than the roles of instruction and monitoring (task supervision) (Rycraft, 1994). Scannapieco, \& Connell-Carrick (2007) compared workers who stayed at the agency and those who left, and found those who stayed spent more time with their supervisors than those who left. 
A study of 767 California child welfare workers in multiple counties conducted by Chenot, Benton, \& Hansung (2009) found that supervisor support and peer support were both negatively correlated with intent to leave in early career social workers (less than three years) but peer support was no longer significant when exploring the sample across their tenure. This research found that other findings related to satisfaction with the organization dissolved with years of service, and indicates early retention (within the first three years) may be the most important as related to supervision and other organizational issues.

Intervention efforts in recent years have focused on the important role of quality clinical supervision for child welfare workers (e.g., Landsman, 2007; Gibbs, 2001; Bride, Jones, MacMaster \& Shatilaa, 2003). Several ongoing research projects are studying supervision interventions in efforts to improve worker retention. For instance, Michigan State University (MSU) School of Social Work is currently involved in dissemination of a grant-funded supervision curriculum for child welfare workers that identifies the tasks of a clinical supervisor (2007). Fordham University (FU) School of Social Work was awarded a 5-year grant from the Children's Bureau to develop recruitment and retention strategies for workers in Connecticut. After surveying about 1000 employees, they identified nine areas in need of attention: supervision, salary, benefits, promotion, the nature of the work, contingent rewards, communication, co-worker support, and operating conditions (U.S. Department of Health and Human Services [USDHHS], 2007). Notably, of all these organizational- 
level needs that were identified by the workforce, they chose to focus on supervision and offered training to individual supervisors. To date, these projects have not reported on retention-related outcomes for their intervention.

Although quality of supervision is a function of the organization, it often relies on changing or improving the supervisor through advanced training and focuses on the important role supervisors have in affecting a worker's experience of the agency. Sometimes organizational/structural interventions are also designed, such as reducing the span of supervision or redefining the role of a clinical supervisor. However, the literature suggests that as an organizational-level target, the goal of supervisor training should not just improve the supervisor's skill set, but also improve what it feels like to work at the agency because of the values supervisors are able to embrace and share with their workers, and should increase the amount of time supervisors are able to spend with their workers.

Job Role. Job duties are thought to have a unique impact on turnover. For instance, in North Carolina protective service workers (child abuse investigators) have higher turnover rates than ongoing caseworkers, and adoption workers have the lowest rate of turnover (Jordan Institute for Families, 2008). APHSA (2004) reports a national turnover rate of $22 \%$ for protective services workers and $17 \%$ for ongoing caseworkers based on reports from 17 states. APHSA calculates the average preventable turnover rate as twice as high for protective services workers versus ongoing case managers based on data from 9 reporting states, but their report does not 
present information on correlation or causation. The connections between job role and intent to leave are relatively unknown, although research supports that job demands, such as negative public perception, less peer support, and increased role conflict all lead to higher intent to leave, and it is expected that these conditions appear more frequently in some job roles. James \& Sells (1981) discuss the effect of psychological climate on the individual worker, due, in part, to their job roles and duties, which supports the theory that workers in some job positions may be more likely to experience job climate more negatively. A better understanding of this variable will allow retention efforts to be tailored and targeted if a difference exists.

Realistic Job Expectations. A worker's expectation of the job prior to hire is thought to influence their intent to stay in the job. Offering workers a realistic preview of the job empowers them to make an informed choice about the work. The Realistic Job Expectation Scale by The Jordan Institute is a scale that considers the match between the worker's expectations of the job and the reality of the job. Data available from the Jordan Institute for Families (accessed 2009) suggest an inverse relationship between workers' perception of expectations about the child welfare job and intent to leave. The short scale created by the institute asks three questions about whether workers feel they got enough information to make an informed decision about their employment, and those who said they did not were more likely to express intent to leave. This survey was tested with only 386 workers in North Carolina, and is not a validated measure, but offers an interesting avenue for further work. Use of this tool 
can help an agency decide whether creating a Realistic Job Preview might be a useful tool for their agency, and comparing these data with other variables can help support or refute links between job expectations and intent to leave.

The Realistic Job Preview tool is emerging in child welfare as a way to strengthen the workforce (Masternak, 2004). Realistic Job Previews, which are customarily detailed explanations of the job, including written descriptions, videos, pictures, or job shadowing, highlight both the positive and negative outcomes of the job. Realistic Job Previews are thought to be successful because of psychological principles: participants feel a sense of met expectations, it provides an opportunity to cope with the reality of the job, it provides an "air of honesty" between the recruiter and applicant, and it allows for self selection, or the opportunity for potential candidates to withdraw if the job is not a good fit (Breaugh, 1983).

Realistic Job Previews are linked to reduced turnover, increased job satisfaction, and clearer employee expectations (Buckley, Veres, Fedor, Wiese, \& Carraher, 1998, Masternak, 2004). Realistic Job Preview tools have been used in other disciplines for a number of years; in fact, a 1973 study of telephone company applicants found that new hires who first received a Realistic Job Preview tool had more realistic perceptions of the job, fewer thoughts of quitting, and longer survival on the job versus those who had only a traditional interview (Wanous, 1973).

A recent study by Chernesky and Israel (2009) investigated survey results from a cross-section of Connecticut child welfare workers, and found that regardless of the 
reason workers took the job, they were more likely to think about leaving if the agency did not provide what they expected. Workers expressed greater intent to stay if they were committed to the agency; findings suggest that the reasons workers take a job may be as important as the reasons workers leave.

Title IV-E of the Social Security Act provides federal funding to states for child welfare services; in 2004, this portion of federal funding was 5.8 billion dollars (Scarcella et al. 2006). This state-matched funding pays for child welfare activities such as foster care and adoption assistance, worker training, and program administrative and data collection costs (U.S. Department of Health and Human Services, 2005). Child welfare IV-E funding, is used to specially train social work students, at BSW and MSW levels, for entering the child welfare workforce. Workers are offered tuition reimbursement and stipends in exchange for agreeing to work in the child welfare field, typically an amount of time equal to their time in a social work program. This supports one of the theories behind Realistic Job Previews; workers who better understand the work they are committing to will be more satisfied with their job. A recent study of 24 matched cases (of BSW and non-BSW child welfare workers) found that graduates of BSW programs were indeed more likely to be retained after two years of service, and were also more likely to engage in best practices than non-social work degreed employees (Barbee et al., 2009). However, they began leaving the field in a higher rate after four years of employment, at which time $20 \%$ of these workers left the agency. The qualitative study found that poor 
supervision, lack of coworker support, and organizational stress all impacted their departure, even though they were well-prepared for the positions (Barbee et al., 2009). This may also support a theory that Realistic Job Preview is most important in the first years after hire, after which time the other organizational variables play a bigger role in retaining workers.

Advancement Opportunities. Career ladders are defined as "structured mobility in the job series." Although there are no child welfare studies that statistically addresses the direct connection between career ladders and turnover, it is often assumed that lack of career ladders affects turnover, and it is often mentioned as a factor that affects job satisfaction during qualitative studies and job exit interviews with child welfare workers (e.g., Institute for the Advancement of Social Work Research, 2008; Pecora, Whittacker, Maluccio, \& Barth, 2000; Ellis, Ellett, \& Deweaver, 2007).

Child Welfare League of America's 2001 salary study notes that there is not a pay differential for level of education in most agencies (Child Welfare League of America, 2001a). This was also found to be a theme that workers expressed as influencing their decision to leave in focus groups conducted in Wisconsin's high child welfare worker turnover areas (Flowers, McDonald, \& Sumski, 2005). This affects career ladders in that there is no financial benefit, in many cases, to receive additional training or an advanced degree, and also no financial incentive for taking on more complex casework or obtaining new skills. According to APHSA's 2000 study 
of child welfare agencies, 25 of 42 state-run agencies reported that they do have a social work career ladder.

The Children's Bureau funded a number of Child Welfare Recruitment and Retention Studies from 2003-2008. In one of the research sites, a sample of 72 child welfare workers participated in a longitudinal study in 2004 and 2006. Regression analysis from this study indicate that Promotional Opportunities explain variance in emotional exhaustion and job satisfaction, which are both correlated to intent to stay (Potter, Comstock, Brittain, \& Hanna., 2009). In the North Carolina project, 157 child welfare workers completed a web survey that asked 101 questions about work attitudes related to 16 scales and intent to leave. This study found that depersonalization, supervisor support, organizational commitment, shared authority, advancement, degree type and age were all significant predictors of intent to leave (Dickinson \& Painter, 2009.)

In the state of Oregon, there is no differentiation between caseworkers based upon educational degree or amount of experience. A Bachelors degree in any discipline is the current minimum standard for caseworker employment, although some workers with less education have been "grandfathered" in because they were hired when different standards were in place. Workers who have a Masters in Social Work and 2 years experience are theoretically assigned the same cases as someone with a Bachelors Degree in Philosophy and no experience. In practice, workers with more experience and skills are often assigned more difficult cases and are expected to 
mentor new workers; these expectations do not come with the benefit of either an advanced title or salary increase.

Autonomy. Autonomy appears in the retention literature as an organizational construct; very rule-bound and bureaucratic systems often give less respect to workers' professional knowledge, and may create a frustrating one-size-fits-all approach to client care (Annie E Casey Foundation, 2003). Autonomy is linked to supervision in the literature, as a benefit that can either be given or withheld (Michigan State, 2008). Some studies demonstrate a statistically significant link between autonomy and job satisfaction, which are in turn thought to influence retention-- however, these studies do not report directly on the link between autonomy and retention (Barber, 1986; McMurtry \& Rose, 2005).

Role Clarity/Ambiguity. Role clarity refers to the existence of clarity in behavioral requirements and knowledge that guide one's role and knowledge of where to find answers, and organizational practices that support clear feedback on performance (Rizzo, House, \& Lirtzman, 1970). It is hypothesized that when role clarity exists, workers are able to function successfully, even in high pressure positions, because they know what to do and how to find answers (Bliese \& Castro, 2000). Research from other fields supports links between role clarity and organizational effectiveness; for instance, a study $(\mathrm{n}=489)$ by Posner and Butterfield found a strong correlation between underwriters' experience with role clarity and job satisfaction, as well as how they ranked the effectiveness of their organization (1978). 
Role ambiguity and role conflict are both found to be impacted by new worker socialization practices (Jaskyte, 2005). Some measure of ambiguity and clarity is often included in organizational climate and culture studies, although its individual contribution to variance is often small (e.g., Glisson et al., 2006; Westbrook et al., 2009).

Role Conflict. Role conflict occurs when workers are expected to perform to incompatible functions (Jones, 1993). Often, workers are directed by conflicting policies or receive unclear direction in supervision. Child welfare workers are almost always in the position of working both toward family reunification and concurrent alternative plans for permanency, goals that are at odds. Workers are also in the position of trying to be supportive of parents and be partners to families, while at the same time mandating parents complete certain tasks as a contingency of a child's return home and presenting "allegations" that demonstrate a parent's inability to provide safe care of their children. Jones' 1993 qualitative study of 40 child welfare administrators report that there is also a bind for workers who feel like they have to defend and support the role of the child welfare system in public, but realize its deficiencies in private. In a study of social services workers in a variety of Ohio social service agencies $(n=255)$, role conflict was highly correlated with measures of job stress (.42) and role ambiguity (.47) for this population (Pasupuleti, Allen, Lambert, \& Cluse-Tolar, 2009). Glisson's organizational intervention includes a goal of reducing 
role conflict, which his research has shown is a significant contributor to measures of culture (2006).

Role Overload. Role overload has been defined as "conflict that occurs when the sheer volume of behavior demanded in the position set exceeds available time and energy" (Reilly, 1982). Role overload is often found in agencies with scarce resources and threats of cutbacks (Lauderdale, 1982). Role overload can lead to mental and physical fatigue, as well as work/life conflict (Sweeney \& Summers, 2002), and eventually burnout and turnover (Maslach \& Jackson, 1985). Role overload has been shown to have a strong effect on emotional exhaustion, and as a predictor of burnout (Yip \& Rowlinson, 2009; Pasupuleti et al., 2009). It has been shown to be highly correlated to job stress and work-family conflict (Pasupuleti et al., 2009), and negatively correlated to job satisfaction (Pearson, 2008). 
Peer Support. Peer support is reported to have a moderating or buffering effect on turnover. For instance, Bride et al. (2007) found that peer support decreases the relationship between Secondary Traumatic Stress and intent to leave in a sample of 187 child welfare workers in Tennessee. Peer support has also been linked to reduced burnout in studies in fields similar to social work, such as nursing and teaching (e.g., Byrne, 1994; Ducharme, Knudsen, \& Roman, 2008). Peer support scales (along with supervisor support) appear in climate and culture surveys, and Glisson (2007) has linked this variable to turnover in his climate and culture research.

Findings related to peer support are often mixed, and the value of peer support is a less significant impact than that of administrator and supervisor support. A recent study by Nissly, Mor Barak, \& Levin found that peer support and supervisor support were both negatively correlated to intent to leave, but were not buffers for organizational stress (2010). This study found that organizational stress was much more important than work/life balance in explaining intent to leave. Findings from this study suggest that other types of support, such as friend and family support are not significant in impacting intent to leave and have only a small impact on work/life balance.

Burnout

Burnout is linked to both personal attributes and organizational attributes. Some research (e.g., Anderson, 2000; Bennett, Plint, \& Clifford, 2005) suggests that a person with certain personality characteristics is more likely to experience burnout. 
However, burnout also measures one's response to factors in the workplace (Maslach Jackson, \& Leiter, 1996). Thus, a person's rating on a burnout scale is impacted by their personal characteristics and by their work environment.

Measures of worker "burnout" or "engagement" are often used as proxies to describe worker well-being, and some of the child welfare workforce research has focused on the relationship between burnout and turnover or burnout and service delivery. Burnout rates of child welfare workers are often measured at around $30 \%$, and are correlated with turnover rates in child welfare settings (Drake \& Yadama, 1996). Thus, the construct of burnout is often used as an outcome measure in intervention studies aimed at improving workplace wellbeing. The expectation is that if findings suggest that if burnout has been reduced, turnover will also be reduced (Mor Barak, Nissly, \& Levin, 2001).

The term "burnout" is sometimes used casually to describe workers who feel overwhelmed. As a formal definition, it is used to describe the prolonged effects of work stress, measured by three subscales: (1) depersonalization of clients, (2) reduced feelings of personal accomplishment, (3) and emotional exhaustion. Burnout was first categorized this way by Maslach and Jackson in the late 1970's (Maslach, 1976). Emotional exhaustion is considered the hallmark of early burnout, and high rates of emotional exhaustion are common in child welfare workers. Maslach is best known for the creation of the Maslach Burnout Inventory for Human Service Workers, (MBIHS) (Maslach et al., 1996), the most consistently used measure of worker well-being 
in child welfare workplace literature (Mor Barak et al., 2001). Certain subscales of the MBI have been correlated with client outcomes; for instance, Glisson \& Hemmelgarn (1998) found depersonalization and job satisfaction were significant predictors of service quality, and that "higher levels of job satisfaction, fairness, role clarity, cooperation, and personalization" together led to better mental health outcomes for children.

The MBI-HS produces three distinct scores for depersonalization, emotional exhaustion, and personal accomplishment. Depersonalization describes whether a worker objectifies a client. Emotional exhaustion refers to the extent workers feel overextended and exhausted by their work. Personal accomplishment defines the degree to which people feel competent and useful in their work (Maslach, 1976). These three subscales are meant to be scored individually, but can also be calculated to create a total burnout score. Workers who are "burned out" are expected to score high on depersonalization and emotional exhaustion, and low on the reversed-scaled personal accomplishment measure. Some research suggests those who score well in the personal accomplishment area, regardless of emotional exhaustion and depersonalization scores, are less likely to leave their jobs (Koeske and Koeske, 1993).

Drake and Yadama (1996) conducted a study of job exit among child welfare workers in an attempt to study how burnout progresses in this population. They believed that emotional exhaustion would precede depersonalization for workers, and personal accomplishment would be inversely related to both. In a 1993 study, they 
sent a survey to a random sample of 230 workers in Missouri, and received back 177 complete MBI-HS surveys. They then tracked job exit from the participating workers over the next 15 months. They found a direct effect from emotional exhaustion to job exit, but not a significant direct effect from depersonalization or personal accomplishment to job exit. The proposed model of job exit (increased emotional exhaustion and depersonalization and lack of personal accomplishment) explained only $8 \%$ of the variance, only slightly higher than the effect of emotional exhaustion on its own. However, higher personal accomplishment did have a significant effect on reducing emotional exhaustion and depersonalization (Drake \& Yadama, 1996).

Hence, these authors suggest that emotional exhaustion is the most important factor in explaining child welfare worker turnover.

The Maslach Burnout Inventory is useful in that it offers national samples of workers and provides norms with which agencies can measure themselves. This instrument has utility for pre/post testing, as it demonstrates whether an intervention impacts a worker's degree of burnout, which may be a predecessor of turnover. The measure still operates at the level of the individual, although it begins to raise speculation about the impact of organizational culture on burnout, as it focuses on the impact of job-related stress on the individual.

More recently, some researchers encourage a strengths paradigm to reframe the problem of burnout; thus, burnout is now sometimes described as "a loss of job engagement" (Maslach \& Leiter, 2008). Job engagement is characterized as worker 
energy, involvement, and efficacy (Maslach, Schaufell, \& Leiter, 2001). Job engagement is measured by the subscales (1) vigor, (2) dedication, and (3) absorption. It should be noted that these are not exact opposites of burnout, and the engagement and burnout scales are not necessarily negatively correlated. Therefore, one could potentially score high on both the burnout and engagement scales. Maslach \& Leiter suggest that interventions can be more useful if they focus on increasing engagement rather than reducing burnout (2008). No known published studies to date have used the Maslach engagement scale to predict child welfare worker retention.

\section{Turnover versus Retention}

Although this literature review focuses mostly on predictors of turnover, Lawson (2005) points out that knowing about turnover does not tell a complete story. The reasons that workers leave are not necessarily the opposite of the reasons a worker stays. For instance, workers might leave an agency out of dislike of a supervisor, but this does not mean that the supervision is the clear issue; other workers might stay because they like the same supervisor, and polling only those workers who leave might point to supervision as the problem. Therefore, it is important to find out why workers leave (turnover) and why workers stay (retention), and interventions must not only focus on preventing good workers from leaving, but also support workers who stay so that they do not become the group who is likely to leave. There are also some important distinctions to consider about low-turnover agencies (Lawson et al., 2006). Sometimes an agency's turnover overall is low, but there is high turnover experienced 
in one kind of role, office, unit, or among the most veteran workers, which can have debilitating effects on child safety. Also, Lawson's team experienced an anomaly in their turnover study in that a county with low turnover seemed to be keeping workers who were a poor fit for the agency and losing those who were good fits, so low turnover did not reflect the most positive outcomes in this case.

Climate and Culture Interventions: Three Examples

There are few interventions that have taken an organizational intervention approach to addressing issues of culture and climate in the child welfare and mental health fields. There are two authors who publish extensively about their intervention efforts in this area, Hal Lawson, PhD (Anderson-Butcher, Lawson, \& Barkdull, 2002; Caringi et al., 2008; Lawson \& Claiborne, 2005; Lawson et al., 2006), and Charles Glisson, PhD (Glisson, 2007; Glisson. Dukes, \& Green, 2006; Glisson \& Green, 2006; Glison \& Hemmelgarn, 1998; Glisson \& James, 2002; Glisson \& Schoenwald, 2005). Additionally, the US Children's Bureau has funded a number of small intervention projects for workforce retention, and the results of some of those projects are in the dissemination and findings phase (Zlotnik, Strand, \& Anderson, 2009).

Lawson. Lawson has developed an organizational intervention that involves the use of "Design Teams" (Caringi et al., 2008). Child welfare workers, supervisors, and managers make up these teams and meet together to discuss the results of survey data after it is collected and analyzed by researchers through a University-Agency Partnership. They have received funding from Children's Bureau, the Department of 
Health and Human Services, and the New York Department of Child and Family Services. Lawson identifies this approach as "Simultaneously top-down (through management consultations) and bottom-up (through design teams), outside-in (through social work faculty facilitation), and inside-out (as knowledge generated in agencies is exported by social work faculty intermediaries to other agencies)" (Lawson et al., 2006).

Lawson uses a 244-item workforce survey (96 items for supervisors) that targets the extent to which particular problems are troubling for the local agency. Workers rate on a scale whether a presented statement is "no problem" to "severe problem." All statements begin with the phrase "workers leave because..." An example statement is "Workers leave because ineffective workers are rewarded and promoted" (Lawson \& Claiborne, 2005, Appendix C). Lawson reports on the positive effects that come with administering the survey even before an intervention, in that it gives a voice to workers and attention to the problems of the workplace.

The Design Team intervention has been piloted in four states, and outcome evaluation to date consists of follow-up surveys and personal interviews (Caringi et al., 2008). The actual implementation of the Design Team concept has varied by site in response to other environmental indicators such as existing system-change efforts. Forty-eight team members across the four sites completed questionnaires administered by an outside evaluator, and twenty participants completed in-person or telephone qualitative interviews. The interviews, in particular, illuminated worker's experiences 
that the Design Teams improved intra-agency communication and increased worker empathy and communication for families via hearing from families who participated on the Design Teams. One of the most impressive findings was that $95 \%$ of families who participated felt that the use of the Teams enhanced attitudes and beliefs about family-centered practice. Workers also expressed that their participation contributed to their sense of personal growth (Anderson-Butcher, Lawson, \& Barkdull, 2002). The Design Teams are considered a Participatory Action Research Model, and were designed based on Lawson's years of research in child welfare workforce issues. These groups are still considered pilots, and there is not yet published outcome data on turnover from the multi-state project. As with many child welfare studies, this research relies upon a non-experimental design. However, these outcomes offer starting points for researchers considering worker-empowering organizational interventions.

Lawson and colleagues (2006) have reported on the results of survey research conducted in New York counties measuring organizational impact on intent to leave. Twelve high turnover counties (HTC) with more than $25 \%$ annual turnover were matched to 12 low turnover counties (LTC) with less than $17 \%$ turnover. In all, 688 workers $(71 \%)$ completed the survey, which asks questions about the effect of the organization and the supervisor on turnover. One item measured intention to leave, i.e., workers answered yes or no to whether they had looked for a job during the last year. Through the use of independent t-tests, they found that workers in the low turnover counties tended to have been in their jobs longer, and worked in offices with 
more diversity. The results demonstrate no difference in satisfaction with supervision between the HTC and LTC counties. A logistic regression model tested the hypothesis that organizational and supervisory satisfaction moderates a worker's intention to leave differently in high and low turnover counties. Subscales of clarity of practice, life work fit, job satisfaction, job supports and commitment, paperwork, salary and benefits, supervisor support and supervisor competency were used in a regression model to explain turnover differences in low turnover and high turnover counties. Regression results indicated that the model was statistically significant in distinguishing between the group of respondents who intended to leave and those who did not. The model correctly predicted intent to leave in $72 \%$ of cases, whereas whether a worker comes from a low or high turnover county alone predicts intent to leave in $62 \%$ of cases. Work-life fit was found to predict intent to leave equally in high and low turnover counties, and thus might be an area for attention across low and high turnover system types. High turnover county employees were less satisfied with salary and were paid less, but salary did not predict intent to leave in either type of county.

Additional findings have been published regarding the Design Team's effects on turnover in high turnover counties. The intervention and non-intervention group were compared at two points: the first in 2002 and the second in 2005 . In the control group, the control group sample had a $78 \%$ identified intention to leave at the first mark, and an $81 \%$ intention at the second mark, representing a non-significant change. 
However, the intervention group that utilized Design Teams had a significant change in intent to leave, moving from $76 \%$ of employees indicating intention to leave to $54 \%$ indicating intent to leave (Caringi et al., 2008).

Laswon's findings support the organization as a target for intervention, especially in considering outcomes of high turnover offices to low turnover offices. Low turnover counties seem to experience more peer support and better agreement about how competent practice is defined. Lack of satisfaction with supervision, as well as poor life/work fit, are equally related to intent to leave in both types of counties.

Lawson also points to the snowball effect of the problem in high-turnover agencies. Processes take longer and are more difficult when there are many people within an agency who do not know procedures based upon their newness to the agency, which creates more frustration in the workplace about how things get done and less time for workers to see clients, which ultimately contributes to turnover. A similar problem of poor communication with external systems (juvenile justice, community providers) leads workers down the same road. Qualitative interviews in counties led to rich information about problems related to the lack of training in the local offices, and transferability of training given differences between the ideal practice guidelines offered in pre-service training and the types of practice supported and rewarded in practice settings. Lawson also reports about the problem of common organizational values in the workplace; some workers measure their success based upon the completion of paperwork rather than client outcomes. This is not to say that 
workers do not care about outcomes for clients. In fact, Lawson found that many leave because of a sense of deprofessionalization; they are not able to offer best services to clients given the bureaucracy of their organizations, and are not consulted about changes that affect their work. He reports that workers in the Design Teams feel that the intervention is one step toward demonstrating that the agency is supportive to workers, which affects both culture and climate.

Glisson. Glisson has emphasized the importance of culture and climate in the workplace by focusing on outcomes that support the ways in which positive organizational culture and climates benefit clients. For instance, Glisson and Green (2006) found that children in the child welfare and juvenile justice system were 11 times more likely to receive mental health care in an agency with the most constructive culture versus the least constructive culture, when controlling for the child's need for mental health care and other family demographics using Hierarchical Linear Modeling (HLM). Additionally, a 2007 study of mental health therapists found that those who worked at organizations with positive cultures and climates, as identified by their scores on the Organizational Social Context (OSC) survey, had turnover rates of $10 \%$, which was half the rate of turnover of organizations who scored poorly on the OSC survey (Glisson, 2007).

Glisson has designed and tested an intervention for improving workplace climate and culture in mental health and child welfare settings. His intervention design is called Availability, Responsiveness, and Continuity (ARC) (Glisson et al., 2006). 
Glisson used a pretest and one-year posttest randomized experimental design, in which 26 child welfare/juvenile justice agencies were assigned to an intervention or control. The ARC intervention was administered by Master's and Doctoral students in Social Work and Counseling Psychology after they attended six months of training for 20 hours per week. Each of these "researcher-change agents" worked with about three teams of cross-level agency employees for two hours per week in 5-6 week blocks over the course of a year. The researchers returned to the research center between blocks for additional training. Additionally, there were all day workshops for participants from the agencies, as well as quarterly meetings with participants and stakeholders from the community. The intervention is value based and described as participatory, and works toward addressing policy issues that cause workers frustration. The intervention also helps workers to develop a shared agency mission and shared way of evaluating success. Using HLM, Glisson found that the intervention improved organizational climate by reducing role conflict, role overload, emotional exhaustion, and depersonalization (subscales of Glisson's climate and culture scales) and reduced worker turnover. Specifically, the intervention group experienced $39 \%$ actual turnover, and the control group experienced $65 \%$ turnover during the one-year study (Glisson, Dukes, \& Green, 2006.) The authors report an even larger effect when controlling for demographic factors; they suggest that actual difference in turnover is two-thirds. They report that the intervention did affect the climate, but not the agency culture, which seems to take much longer to change. 
Glisson and his colleagues admit to the flaws of the intervention design, which rely upon a long-term and heavy commitment from an agency where workers are known for having little time to dedicate to work that is not required to manage the caseload. There are many components of the Glisson model, and it is hard to know which piece of the intervention had the most impact on improving the climate of the organization. Information about the construction and testing of the scale and subscales is not yet available, and the instrument has not been validated by other researchers.

The Recruitment and Retention Projects. In 2003, the US Children's Bureau issued grants to support eight five-year investigations that were designed to support child welfare workforce recruitment and retention. These projects ended in 2008. Some of the findings are reported specifically in preceding sections of this dissertation. These projects focused on supervision, worker commitment, the effects of hiring degreed social workers, as well as personal factors and organizational factors that impact turnover. Zlotnik et al. (2009) summarize the cross-cutting themes of these studies in an editorial report:

No single intervention will impact (recruitment and retention). A multipronged approach addressing recruitment, selection, training, professional development, and support is necessary... Key factors contributing not only to high rates of turnover, but also low morale and detachment from the agency for staff that stay, are organizational factors, such as lack of organizational leadership, supervisory shortcomings, failures to recognize and reward staff, lack of opportunities for promotion, and unmanageable workloads. If organizational factors contribute to turnover, then organizational change is required. 
This summary of prior research indicates a complex set of contributors that affect workforce stability. An emerging literature is developing in relationship to organizational-level interventions in child welfare settings. Measures of organizational factors that are thought to impact child welfare turnover are still in development and not consistently applied (e.g., Glisson, 2007; Lawson et al., 2006; Chenot, Benton, \& Hansung, 2009). A picture is developing of frequently-cited contributors to workforce turnover, but much is left unknown about what leads workers to stay or leave and how agency administrators can utilize these findings. 


\section{CHAPTER IV \\ RESEARCH QUESTIONS AND HYPOTHESES}

Aims of this Study

This research seeks to contribute to knowledge regarding an important question: "What are the organizational factors that lead frontline child welfare workers to stay or leave the agency, and what, then, are the implications for agency administrators?" The goal of this study is to explore the way culture and climate impact workers' intent to leave in Oregon. Additionally, the variables that best explain the concepts of culture and climate will be explored. The utility of the data collection tool used in this study will be explored. The responses of workers to the survey used are expected to help administrators target systems for intervention in Oregon, and help equip workers with information necessary to understand the shared experiences of their fellow workers within the organization and where they can advocate for change efforts. This research will also help strengthen the understanding of connections between organizational factors and intent to leave in the child welfare literature. Ultimately, as this issue is better understood in the field, targeted interventions will support workforce stability and lead to better outcomes for children and families.

Research Questions and Hypotheses

Drawing from the literature, the primary variables of interest are culture, climate, supervisor satisfaction, and job role, and the impact of these factors on preventable turnover. The climate scale incorporates items from scales that measure 
perceived opportunities for advancement, burnout, role clarity, role conflict, role overload, depersonalization, emotional exhaustion, personal accomplishment, and worker perception of supervisor competence and supervisor satisfaction. The culture scale incorporates items from peer support and caring culture scales. The culture scale additionally includes three items that are written for their respective scales and are not a part of any of the above-referenced scales. A graphic explanation of the organizing theory is offered in Figure 1.

Figure 1

Theory of Factors that Cause Preventable Turnover

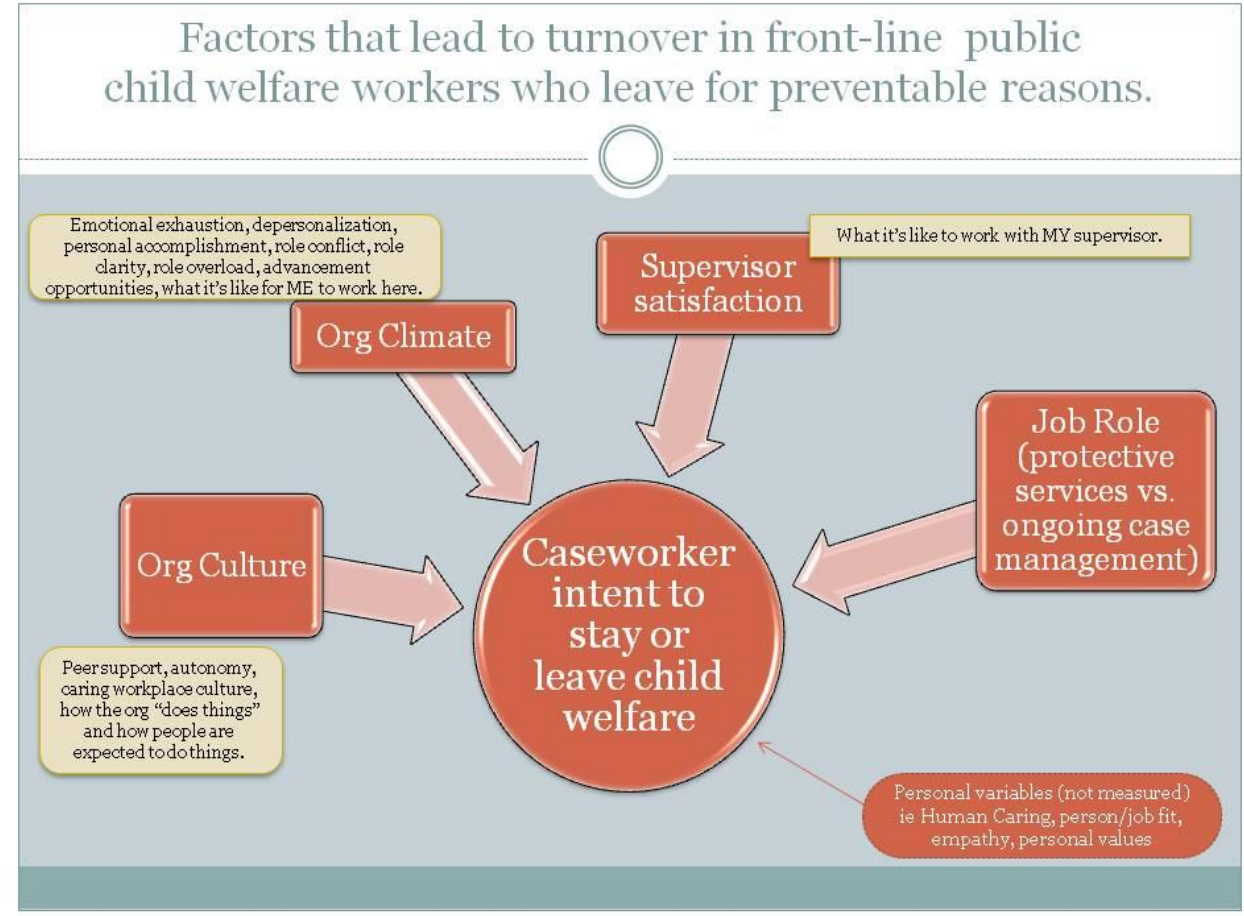

The primary questions addressed in the current study focus on the major constructs highlighted in Table 2 on page 30. The following questions related to these constructs were addressed in this study: 
1) Does organizational culture affect caseworkers' intention to leave in Oregon public child welfare systems? What organizational culture issues most impact caseworkers' intention to leave?

2) Does organizational climate affect public child welfare caseworkers' intention to leave in Oregon public child welfare systems? What organizational climate issues most impact caseworkers' intention to leave?

3) Does the worker's perception of supervision impact caseworkers' intention to leave in Oregon public child welfare systems? What supervision qualities are most related to intention to stay?

4) Do workers express greater intent to stay if they have greater knowledge of what child welfare work entails before they are hired? Is this effect different for early-career caseworkers?

5) Do workers express different intentions to stay dependent on whether they conduct investigations of allegations of abuse and neglect versus ongoing case management work?

The research questions were guided by the literature review, which suggests links between worker retention and the variables of culture, climate, supervisor satisfaction, job role, and understanding of the job. The variables culture, climate, and supervisor satisfaction have been the focus of many research studies in child welfare, and the research questions in this study build upon existing research and offer additional information for comparison to previous studies. The variables of job 
readiness and job role are emerging issues linked to retention in child welfare, and answering these questions will support greater knowledge in the field. Table 4 identifies existing and emerging research that supports attention to the identified variables, and also identifies the scales and methodology used in this research to answer the questions presented.

Systems theory and empowerment theory guide these questions in helping us understand how workers are impacted by their environment. In this study, the system boundary is drawn around the organization, in that the research questions focus on the impact of the organization on the worker. However, the organization is part of a much broader network of systems, and the local Department of Human Services office is influenced by the other local offices, the community, the higher-level administration, and even the political environment of social services across the United States and the world. It is expected that the worker's immediate environment will explain some of the variation in worker intent to stay, but that culture and climate are also impacted by external systems. This dissertation will not explore the external influences and demands upon the organization. Additionally, intent to leave is also influenced by personal variables that have been studied in the literature but are unaccounted for in this analysis.

It should be noted that in many of the previous studies on culture and climate (e.g., Lawson et al., 2006; Glisson, 2007), comparative measures are made among multiple offices, which allows sites to be labeled as either having a supportive or non- 
supportive culture and climate. Relationships are studied among the shared experiences of workers to determine the culture of an agency. Hemmelgarn, Glisson, \& James argue that one cannot adequately measure culture without exploring organizational-level scores to understand the shared themes that make up culture (2006). However, in this study questions that ask workers about the personal impact of the agency on them were identified as "climate" measures, and questions that asked about how things are done within the organization were labeled "culture" items. No measures attempted to determine whether experiences of workers were shared by workers within or between the sites.

\section{Hypotheses}

The hypotheses that guided the current study flow directly from the research questions above.

Hypothesis 1: Higher levels of worker satisfaction with organizational culture will be predictive and negatively correlated with workers' intent to leave the agency. Hypothesis 2: Higher levels of worker satisfaction with organizational climate will predict and be negatively correlated with a worker's intent to leave the agency. Hypothesis 3: Worker satisfaction with supervision will be inversely correlated with intent to leave the agency. Hypothesis 4: Job readiness will be inversely correlated with intent to leave the agency. 
Hypothesis 5: A job in protective services will be more predictive of intent to leave than a position in an ongoing/case management role.

\section{Conceptual and Operational Definitions}

\section{Independent Variables}

The following working definitions for climate and culture have been developed from the literature:

Climate. Climate is an employee's own perception about what it is like to work at an agency, and the psychological impact of that work on the employee's well-being. This includes an employee's perception of supervisor support and competence, role conflict, role overload, role clarity, depersonalization of clients, emotional exhaustion related to the job, personal accomplishment, and opportunities to advance. This is operationalized by scales that measure the worker's response to questions about how it feels for an employee to work at the agency. The items on this measure should hold together for each employee, but this is not necessarily a shared perception; each employee may have different senses of what the climate is like, even within the same unit (Glisson \& James, 2002; Glisson \& Green, 2006, Glisson, Dukes, \& Green, 2006.)

Culture. Culture refers to employees' shared beliefs and norms that drive the way things are done within an agency, including what is rewarded, how people should interact, and what is important. This includes how things are done within the organization, such as how well peers collaborate, and experiences of fairness, 
adaptability, NS integrity. Those who work together share experiences of an agency's culture, and this measure explores organizational expectations about goals, achievement, and interactions (Glisson \& James, 2002; Glisson \& Green, 2006;

Glisson, Dukes, \& Green, 2006). Although previous work has looked at culture at an organizational level to measure shared perceptions, this study focuses on the impact of culture on intent to leave at the individual level because so many work sites are included, and assumedly they have different workplace cultures.

Supervision. Clinical supervision refers to support that helps a worker develop and review clinical skills; task supervision refers to how a supervisor monitors and supports task completion. Clinical supervision is thought to be more important than task supervision in supporting worker longevity (Jacquet, Clark, Morazes, \& Withers, 2007). This is operationalized through exploration of perceived support, as well as supervisor skill toward meeting casework goals (Gibbs, 2001; Jacquet et al., 2007).

Job Role. A child welfare caseworker is generally assigned specific job duties within the agency, and the majority of workers generally fill positions of either investigating abuse and neglect, or providing ongoing maintenance, reunification, or adoptive services to children and families; some positions have been shown to have a higher rate of turnover than others, such as investigative roles (Jordan Institute, 2008; APHSA, 2004).

Realistic Job Perceptions/Job Readiness. "Realistic job perceptions" refers to a worker's realistic perceptions and orientation to the duties of the job prior to accepting 
the position; unrealistic perceptions are often associated with higher turnover (Breaugh, 1983; Jordan Institute, 2008; Wanous, 1973).

\section{Dependent Variables}

Intent to Leave. Intent to leave refers to a worker's personal evaluation of how long they plan to continue working with the child welfare agency. Intent to leave is thought to be a good proxy for actual job exit (Bluedorn, 1981; Mor Barak et al., 2006).

Preventable vs. Non-preventable Turnover. Preventable turnover can be distinguished from turnover that the agency cannot prevent. A worker who will eventually leave the agency for reasons such as a career change, move to another social services job, or move to a non-social work job are all considered preventable reasons for turnover, and are more likely to be positively impacted by interventions than non-preventable turnover (CWLA, 2001b). Non-preventable turnover includes retirement, death, return to school, or relocation, and are thought to be less likely impacted by interventions. This study is concerned with preventable departures (CWLA, 2001b). 


\section{CHAPTER V}

\section{METHODOLOGY}

The research for this study investigated the relationship between organizational factors and intent to leave among Oregon public child welfare caseworkers. Workers' experiences of work-related variables were examined to see if they had the hypothesized effect on worker retention.

\section{Design}

A secondary analysis of a cross-sectional internet-based survey research design was used to answer the questions concerning the relationships between organizational issues and intent to leave. Convenience sampling was used in the original survey; although the measure was sent out to entire SDA's, participation was voluntary. Please see the section labeled Sample for further explanation of sampling methods.

\section{Data Source}

The Child Welfare Workforce Study is the name of the survey used for this research. This is a tool developed by the Portland State University's Child Welfare Partnership. The focus of the original data collection was to learn more about the Oregon Child Welfare Workforce Demographics, including intent to leave. The Partnership study also seeks to validate findings related to burnout based on the Partnership's 2006 study findings on burnout in Multnomah County child welfare workers. Additionally, it was designed to evaluate worker satisfaction as part of an evaluation study on graduates versus non-graduates of the Title IV-E Child Welfare 
Stipend Program for MSW students. Finally, it study was developed to begin exploring a pilot measure of culture and climate specific to the child welfare workforce. However, this is a recently-completed study and the analysis is currently taking place. Thus, there are no findings to report from these data thus far.

The Child Welfare Workforce survey, presented in Appendix B, contains 111 open and closed-ended items. Of the questions, 63 are 5 point Likert scales that range from responses of "Strongly Agree" which are scored as zero, to "Strongly Disagree," which is scored as four. Additionally, 22 questions from Maslach's burnout measure are on a 6 point Likert Scale and ask respondents to rank how often they feel a particular way, choosing from "A few times a year or less, monthly, a few times a month, every week, a few times a week, every day" and is scored zero-five. Content validity of the Child Welfare Workforce survey scales was conducted via a thorough literature review of research about workforce organizational issues, and particularly of issues related to culture and climate.

The original study was approved by the Portland State University Human Subjects Research Review Committee prior to data collection under the direction of Richard Hunter, PhD, Primary Investigator. The risk to participants was minimal. Social workers are not usually seen as an at-risk population. The secondary data analysis conducted in this dissertation research qualified for a waiver review, as all identifying information has been removed and data cannot be linked back to individuals, no contact with subjects is/was involved, data has been previously 
collected by another investigator, and data already exists. The waiver request was approved on February 22, 2010.

Although this study is the first recent statewide survey to attempt to collect climate and culture information in a way that draws upon a child-welfare specific literature review, the survey is not a validated measurement tool and is considered exploratory research. This survey contains scales specific to the research questions addressed in this dissertation, and is the first statewide survey to ask organizational satisfaction questions specifically to front-line caseworkers in Oregon.

The actual survey tool (Appendix B) contains several subscales (Appendix C), developed either by the Child Welfare Partnership (CWP) team, or items that have been used in previous research studies, as described below.

The Maslach Burnout Inventory-Human Services (MBI-HS) Third Edition is a 22-item scale that contains three subscales: Emotional Exhaustion (ee), Depersonalization (dp), and Personal Accomplishment. There are 5 questions in the depersonalization scale. There are 9 questions in the emotional exhaustion scale, and 8 questions in the personal accomplishment scale. Respondents are asked to report how often they experience each feeling. A Likert scale allows respondents to rank each response on a six-point scale from "a few times a year or less" to "every day."

Emotional exhaustion measures feelings of being over-extended and exhausted by work; Depersonalization measures impersonal response toward clients or work; Personal Accomplishment measures feelings of competence and success with clients. 
The scale has been tested around the world and translated in to several different languages. Maslach, Jackson, and Leither have found that the development of depersonalization is linked to exhaustion, and that these subscales are generally correlated (1996). The scale has been normed with social workers and child welfare workers (Anderson, 2000; Drake \& Yadama, 1996; Maslach et al., 1996). Maslach and Jackson report in the MBI-HS handbook that their own research has found burnout associated with deterioration of quality of care, turnover, absenteeism, and low morale (1996). Burnout is a continuous variable, with scores ranging from low to high. Scores are considered high if they are in the upper one third of a normative distribution.

Maslach and Jackson report internal consistency, as estimated by Cronbach's coefficient alpha $(n=1,316)$, in their survey handbook (1996). The reliability coefficients for the subscales were .90 for Emotional Exhaustion, .79 for Depersonalization and .71 for Personal Accomplishment. They report that other studies have also tested reliability using test-retest procedures, and have been found to be reliable over time gaps as wide as 1 year at .001 . Convergent validity has been tested by having an outside person rate a worker's behaviors, comparing test results to outcomes thought to be related to burnout, and measured in comparison with jobs that are thought to be high burnout professions. In studies of discriminant validity, the MBI-HS was found to be correlated with a measure of general job satisfaction, and they were found to have moderate correlations, as expected. The items have also been correlated to Beck's Depression Inventory, but each of the scales (emotional 
exhaustion, personal accomplishment, and depersonalization) are better correlated to each other than to depression (Maslach \& Jackson, 2001).

Jordan Institute's Realistic Job Portrayal. The Jordan Institute's RJP scale is a 3-item scale and each question is ranked from "strongly agree" to "strongly disagree" on a 6-point Likert scale. The items were used with a sample of North Carolina child welfare workers $(\mathrm{N}=386)$. The Jordan Institute reports the mean score for this scale as 3.9. No other information is reported (Jordan Institute, 2008).

Jordan Institute's Supervisor Satisfaction Scale. The SSS is a 12-item scale that contains the subscales of "practice support" (the degree to which a supervisor helps a worker with concrete tasks) comprised of 10 questions, and "team support" (the degree to which the supervisor supports workers to work together) compromised of 2 questions. The Institute reports a mean of 4.7 on the practice support subscale and 4.6 on the team support scale in a study of 386 North Carolina child welfare workers. The Child Welfare Workforce Survey adds additional questions about supervisor satisfaction based on a literature review (Jordan Institute, 2008).

Intent to Leave Index. For this measure, Bluedorn's Staying or Leaving Index (SLI) is combined with Sara Schwartz' Job Search Behaviors Questionnaire to create one continuous variable (Bluedorn, 1981; Schwartz, 2007). The SLI asks respondents offers four choices about how long a worker expects to stay at the agency. The authors report an internal consistency ratio of .87 to $.95(n=741)$. The Partnership's Workforce Survey adjusted the ratios slightly to offer six time span choices in order to better 
capture how long a worker plans to stay with the agency. Each of the six time frames is given a score (0-5), with the highest range (10+ years) scored at 0. Sara Schwartz' Job Search Behaviors Questionnaire is a 4-item tool previously tested with a sample of Oregon workers. It asks whether workers are engaging in job seeking behavior, including looking, applying, or interviewing for other work within the last 12 months. Each of these items is given a score between 0-3, with "not looking for another job" scored as zero. The combined items offer a total score between zero and eight. Zero indicates the lowest intent to leave, and eight indicates the highest intent to leave.

Culture, Climate, and Subscales. Additional questions were developed by the Oregon Child Welfare Workforce research team. Scales were developed based upon reviews of other culture and climate scales and the definition of culture and climate. The following groupings of questions were developed based on this literature review: Peer support (5 items), Autonomy (4 items), Opportunities for Advancement (5 items), Role clarity (10 items), Role conflict (3 items), and Role overload (3 items). Jordan Institute's supervisor satisfaction and competence scale was expanded by four questions after a literature search, and is composed of 16 total questions in this survey. These scales do not have previous empirical testing.

Culture. A culture scale was created by the Oregon Child Welfare Workforce research team from all the items on the peer support and autonomy scales. Additionally, 14 more questions were created based on items from the literature, reworded specifically for the child welfare population, about how the child welfare 
organization "does things" and how people are expected to do their jobs. The culture scale began as a 24 item measure. Five questions are grouped in to the Peer Support scale, and 10 questions are grouped within the "culture of caring" scale. There are 3 questions that stand alone. For regression analysis, the mean of each scale is entered, along with the 3 stand-alone questions, for a total of 5 independent variables. The three independent questions are "There is only one way to do the job--- the boss's way,'(11e), “This agency emphasizes professional growth and development," (13e) and "This agency rewards expertise" (13g). These questions are hypothesized to measure autonomy, professionalism, and rewards for strong performance.

Climate. A climate scale was created from the scales of emotional exhaustion, depersonalization, role conflict, role overload, role clarity, supervisor satisfaction scale, personal accomplishment scale, advancement scale, and job satisfaction scale, plus two additional questions that ask the worker what it is like for workers to work at the agency. These items were drawn from climate questionnaires in the literature, and rewritten specifically to be applicable to child welfare workers. There are 52 items included in the climate scale. For measurement, the mean of each scale is entered, along with the 2 stand-alone questions, for a total of 11 independent variables. The two independent questions are "I like doing the things I do at work" and "I like my coworkers." These questions were chosen by the Oregon Child Welfare Workforce research team, based on review of the literature, as important predictors of how it feels to work at an agency, but they are not part of a scaled construct. 
Although the focus of this study is on relationships among variables and not on instrument development, it is prudent to consider whether the pilot survey instrument holds together well and contains items that are individually correlated with the dependent variables studied in this dissertation. A factor analysis was conducted on each of the scales, and reliability reported; see Table 10. Further instrument development will be informed in part by outcomes of this survey, and will be left to future research. Appendix A includes the actual survey questions used for analysis to answer the hypotheses presented.

Table 4 includes the measures that were utilized in this study and the specific item number that corresponds with the Workforce Study, and identifies items included in the culture and climate scales. Some variables are expected to be used in subanalysis to help explain findings. They include those listed on Table 5.

\section{Human Subjects}

A Human Subjects review was not required for this dissertation study, as it meets the conditions outlined by the review board: It is a secondary data analysis, and (1) All identifying information has been removed and data cannot be linked back to individuals; (2) No contact with subjects is/was involved; (3) Data has been previously collected by another investigator, (4) Data already exists. However, a waiver was required in order to proceed with analysis for this research, and was obtained prior to analysis, approved on February 24, 2010 (See Appendix C). 
Table 4

Measures Utilized and Corresponding Survey Numbers for Major Variables Measure Source \# of Corresponding Question \#s

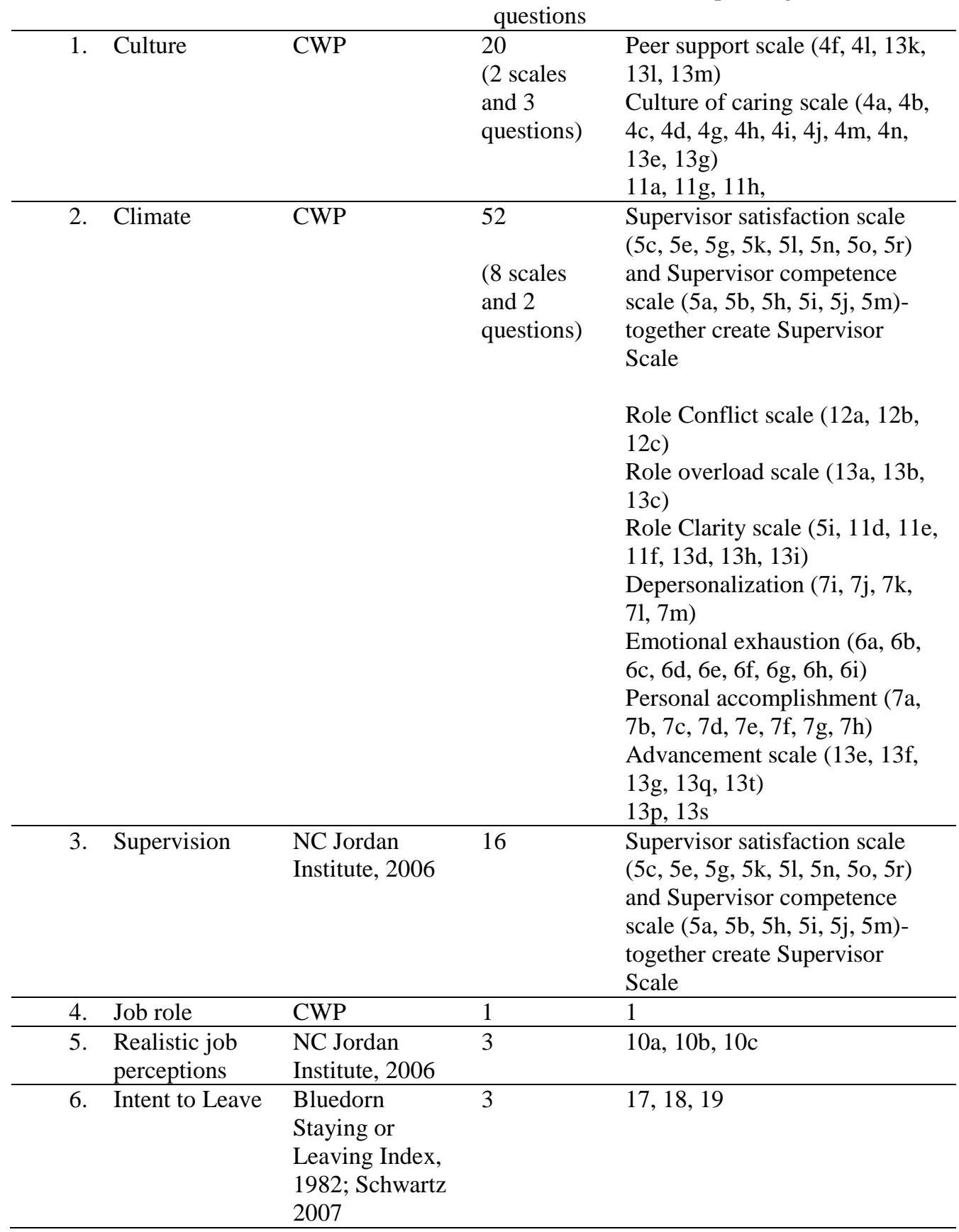


Table 5

Measures Utilized and Corresponding Survey Numbers for Subscales

\begin{tabular}{lllll} 
& Scale & Source & $\begin{array}{l}\text { \# of } \\
\text { questions }\end{array}$ & Corresponding question numbers \\
\hline a) & Advancement & CWP & 5 & $13 \mathrm{e}, 13 \mathrm{f}, 13 \mathrm{~g}, 13 \mathrm{q}, 13 \mathrm{t}$ \\
\hline b) & Autonomy & CWP & 4 & $11 \mathrm{~b}, 11 \mathrm{c}, 11 \mathrm{~g}, 11 \mathrm{~h}$ \\
\hline c) & Role Conflict & CWP & 3 & $12 \mathrm{a}, 12 \mathrm{~b}, 12 \mathrm{c}$ \\
\hline d) & Role Clarity & CWP & 4 & $5 \mathrm{i}, 11 \mathrm{f}, 13 \mathrm{~h}, 13 \mathrm{i}$ \\
\hline e) & Role Overload & CWP & 3 & $13 \mathrm{a}, 13 \mathrm{~b}, 13 \mathrm{c}$ \\
\hline f) & Peer Support & CWP & 5 & $4 \mathrm{f}, 41,13 \mathrm{k}, 131,13 \mathrm{~m}$ \\
\hline g) & Burnout & Maslach & $22-$ & (dp) 7i, 7j, 7k, 71, 7m, (ee) 6a, 6b, 6c, \\
& & & 3 scales & $\begin{array}{l}6 \mathrm{~d}, 6 \mathrm{e}, 6 \mathrm{f}, 6 \mathrm{~g}, 6 \mathrm{~h}, 6 \mathrm{i},(\mathrm{pa}) 7 \mathrm{a}, 7 \mathrm{~b}, 7 \mathrm{c}, \\
7 \mathrm{~d}, 7 \mathrm{e}, 7 \mathrm{f}, 7 \mathrm{~g}, 7 \mathrm{~h}\end{array}$ \\
\hline
\end{tabular}

\section{Data Collection}

The original surveys were delivered via the internet email link from the service delivery area managers, with a message from the Portland State University School of Social Work Child Welfare Partnership inviting response for the purpose of learning more about the Child Welfare Workforce. The email included an informed consent statement and invitation to opt-in, with two weeks to complete the survey. A reminder email was sent 3 days before the survey's end, and a 3-day extension was sent on the survey deadline date. The survey was sent out to all employees, but asked that the survey only be completed by those designated as Social Service Specialists, which is the designation of front-line workers. All respondents were anonymous, but Internet Protocol addresses were reviewed and indicated that no surveys were filled out from the same computer. Data was collected from June 2008 through June 2009, and saved on investigators' computer hard drives on password protected computers. 


\section{Sample}

The data was gathered from a nonprobability sample of front-line public child welfare workers across the state of Oregon. Oregon is divided in to 16 service delivery areas (SDA's) and an invitation for participation was sent to each of the 16 managers of the entire child welfare workforce population in Oregon. Of those, the managers from 10 of the service delivery areas agreed to send the invitation out to the workers in their respective geographic regions. The final sampling frame of workers invited to participate by their managers was $n=1002$. The participating SDA's are highlighted in Figure 2.

Figure 2

Map of Service Delivery Areas Participating in Workforce Survey (Shaded)

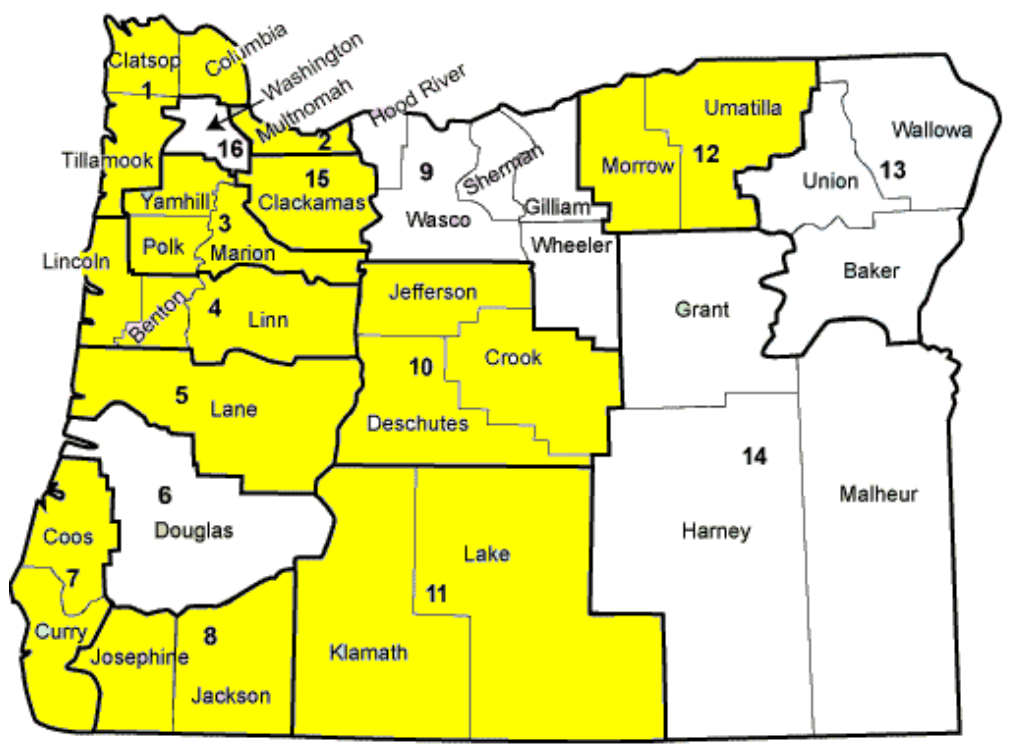

One of the goals of the Oregon Child Welfare Workforce research team is to explore links between geography and culture and climate and intent to leave. There is 
some evidence that culture and climate, job opportunities, and other independent variables differ in rural versus urban areas. This dissertation does not address regional differences in outcomes, and only explores whether independent scores for each worker vary together with those workers' intentions to leave the agency. Therefore, while the sampling frame for the original study is all Oregon child welfare caseworkers, the sampling frame of interest for this study is workers who plan to leave for preventable reasons. Since this is self-reported information, the number of workers who intend to leave for preventable reasons within the sampling frame is unknown. However, amongst respondents, 141 of 401 survey respondents identified themselves as those who would eventually leave for preventable reasons, and is the response group of interest for this analysis.

Non-preventable turnover includes retirement, death, marriage or parenting, returning to school, or a spousal job move (CWLA, 2001b). Respondents who said they would eventually leave the agency for these reasons were eliminated from the sample when exploring the main research questions. The remaining sample of 141 workers are those who say they will eventually leave to change careers, to move to another social service job, or due to job stress.

\section{Inclusion Criteria and Response Rate}

Workers were asked to complete the survey only if they were designated as a Social Service Practitioner. Part-time, full-time, and temporary workers fill that role, and all of those types of respondents were included in the data collection. Workers 
were asked to identify their job role, and an option included "other." Five respondents took the survey and indicated in the "other" box that they were supervisors or support staff. Their data was eliminated from the findings. There were two cases in which more than $50 \%$ of the response data was missing from the survey, and these cases were also eliminated from analysis. Supervisors, support workers, and administrators were not included in this survey because caseworkers are thought to have a unique set of job duties and turnover that is different from other types of respondents. The survey was designed with consideration to their unique job roles and duties The actual final number of surveys collected, once non-eligible participants (such as those who identified themselves as supervisors) were removed, was 401 , for a response rate of $40 \%$. The regional response rates varied among service delivery areas. The lowest participation rate was $23 \%$, and the highest rate was $69 \%$ of workers in a single region. Workers participated across the entire state of Oregon. However, the service delivery areas (SDA's) with the greatest populations (and thus, the greatest number of workers) are in just a few SDA's $(2,3,5,8,15$, and 16; refer to map on page 91). All but one (SDA 16) of these more densely populated SDA's participated in the survey. The non-participating large county did not want to participate due to significant organizational changes that their administration perceived might affect their findings.

The respondents in SDA's 2, 3, and 15 comprise $77 \%$ of the responses, but this is consistent with the proportion of workers who serve these areas. Workers who report intent to leave for preventable reasons $(n=141)$ were included in this analysis. 
Non-preventable turnover includes those who plan to leave for reasons of retirement, child rearing, return to school, relocation, and medical/disability, and these workers are excluded from the data set. The response rate of each participating SDA is presented in Table 6. Most demographics of Oregon caseworkers are unknown. The demographic data of participants is shown in Table 7.

Table 6

\begin{tabular}{llll}
$\begin{array}{l}\text { Response Rates by Service Delivery Area } \\
\text { Service Delivery Area }\end{array}$ & $\begin{array}{c}\text { Total } \\
\text { estimated } \\
\text { number of } \\
\text { caseworkers }\end{array}$ & $\begin{array}{c}\text { Useable } \\
\text { Surveys } \\
\text { Received }\end{array}$ & $\begin{array}{c}\text { Response } \\
\text { Rate }\end{array}$ \\
\hline 1: Clatsop, Tillamook, Columbia Counties & not available & 3 & Unk \\
\hline 2: Multnomah County & 298 & 95 & $32 \%$ \\
\hline 3: Yamhill, Polk, Marion Counties & 174 & 76 & $44 \%$ \\
\hline 4: Linn, Benton, Lincoln Counties & 75 & 17 & $23 \%$ \\
\hline 5: Lane County & 125 & 61 & $49 \%$ \\
\hline 7: Coos, Curry County & 27 & 17 & $63 \%$ \\
\hline 8: Jackson, Josephine Counties & 103 & 45 & $44 \%$ \\
\hline 10: Jefferson, Cook, Deschutes Counties & 33 & 19 & $58 \%$ \\
\hline 11: Lake, Klamath Counties & 39 & 27 & $69 \%$ \\
\hline 12: Morrow, Umitilla Counties & 28 & 8 & $29 \%$ \\
\hline 15: Clackamas County & 65 & 33 & $51 \%$ \\
\hline
\end{tabular}

Table 7

Worker Demographics for All Workforce Survey Participants

\begin{tabular}{|c|c|}
\hline Demographic & Sample $(n=401)$ \\
\hline Race/ethnicity & $\begin{array}{l}\text { Native American: } 3 \% \text {; Asian: } 1 \% \text {; African American: 1\%; Hispanic: } 5 \% \text {; } \\
\text { Caucasian: } 87 \%\end{array}$ \\
\hline Job role & $\begin{array}{l}\text { Protective Services: } 26 \% \text {; Ongoing: } 41 \% \text {; Foster Care: } 13 \% \text {; Adoption: } \\
\text { 13.5\%; Specialized Services: } 19.5 \% \\
\text { (note: some workers perform more than one role) }\end{array}$ \\
\hline Highest Degree & AA: $2 \%$; BA: $45 \%$; BSW: $28 \%$; MA: $10 \%$; MSW: $13 \%$ \\
\hline Tenure at agency & $\begin{array}{l}\text { Mean: } 71.6 \text { months (almost } 6 \text { years) } \\
\text { Median: } 48 \text { months ( } 4 \text { years) }\end{array}$ \\
\hline Gender & Female: $84 \%$; Male: $16 \%$ \\
\hline Age & Mean: born 1969 (41 years old); Median: born 1972 (38 years old) \\
\hline Annual Income & Mean: $\$ 41,562 ;$ Median: $\$ 41,000$ \\
\hline Monthly overtime & Mean: 6.75 hours; Median: 5 hours \\
\hline
\end{tabular}


The analysis for this survey focuses on those workers who plan to leave for reasons that are identified as "preventable" in the literature, such as to change to another job. The demographics for this selection of the population are displayed in Table 8 . Note that workers leaving for preventable reasons are slightly younger and have slightly lower tenure, which corresponds with their slightly lower annual incomes.

Table 8 Worker Demographics of Survey Participants who Intend to Leave for Preventable Reasons

\begin{tabular}{ll} 
Demographic & Sample (n=141) \\
\hline Race/ethnicity & Native American: 5\%; Asian: 1\%; African American: 1\%; Hispanic: \\
& $6 \%$; Caucasian: 84\% \\
\hline Job role & Protective Services: 28\%; Ongoing: 44\%; Foster Care: 14\%; Adoption: \\
& 3\%; Specialized Services: 19\% \\
& (note: some workers perform more than one role) \\
\hline Highest Degree & AA: 1\%; BA: 35\%; BSW: 31\%; MA: 12\%; MSW: 19\% \\
\hline Tenure at agency & Mean: 55 months (almost 4.5 years) \\
& Median: 45 months (almost 4 years) \\
\hline Gender & Female: 77\%; Male: 16\% \\
\hline Age & Mean: born 1971 (39 years old); Median: born 1974 (36 years old) \\
\hline Annual Income & Mean: \$40,928; Median: \$40,000 \\
\hline Monthly overtime (in hours) & Mean: 6.88; Median: 5 \\
\hline
\end{tabular}

Worker turnover is reported to be as high as $25-50 \%$ annually in some studies. In the group of workers who plan to leave for preventable reasons, $46 \%$ plan to do so in the next two years. In the preventable turnover group of 141 respondents, $71 \%$ expect to leave within five years. In the entire sample of 401 respondents, $11 \%$ plan to leave within one year, but $30 \%$ plan to leave within two years. See Table 9 for more demographic information about the sample. 


\section{Power}

The study relies on convenience sampling. Although randomized samples are often preferred for statistical analysis, a convenience sample offered the largest possible recruitment, which is also linked to better statistical power. There were no similar studies to draw upon to calculate power analyses for some of the chosen hypotheses. However, similar work conducted by Glisson and James (2002) found that organizational culture and work attitudes explained a variance of .155. In order to estimate the sample size needed to achieve an acceptable level of power for this survey, the Glisson and James figure is used in the power analysis formula outlined by Cohen (2003). A moderate effect size (.15) can be found when the statistical power is set at .80 and up to 10 independent variables are used as long as the sample size is at least 118. This sample meets criteria needed to assume moderate effect sizes from significant findings with an $n=145$.

Table 9

\section{Workers' Reported Length of Time until Intent to leave in Full Sample ( $n=401)$}

\begin{tabular}{clrrr}
\hline & & Frequency & Percent & $\begin{array}{r}\text { Cumulativ } \\
\text { e Percent }\end{array}$ \\
\hline \multirow{4}{*}{ Valid } & Less than 6 months & 13 & 3.2 & 3.3 \\
\cline { 2 - 5 } & 6-12 months & 30 & 7.5 & 10.9 \\
\cline { 2 - 5 } & 1-2 years & 74 & 18.5 & 29.8 \\
\cline { 2 - 5 } & 3-5 years & 73 & 18.2 & 48.3 \\
\cline { 2 - 5 } & 6-10 years & 60 & 15.0 & 63.6 \\
\cline { 2 - 5 } & 10+ years & 143 & 35.7 & 100.0 \\
\cline { 2 - 5 } & Total & 393 & 98.0 & \\
\hline Missing & System & 8 & 2.0 & \\
\hline Total & & 401 & 100.0 & \\
\hline
\end{tabular}


Missing Data

All data was entered in to SPSS Version 18.0 and an analysis was undertaken to investigate the level and nature of missing data. The missing data was explored visually and by running a Missing Values Analysis. There was a pattern around missing data in relationship to the questions on the Depersonalization and Emotional Exhaustion scale. The missing data for these questions reached as high as 27 skipped responses per question in the sample of 401 participants (6.7\%). It is likely that these questions were skipped by respondents who felt strongly about the questions, and this missing data may affect the results of the outcomes. However, this is still under the $10 \%$ missing values rate considered acceptable for this sample size (Little \& Rubin, 2002.) In other scales, the highest number of missing data points is 5 . The items on all the scales were eliminated pairwise when they were missing, which means that if there was one missing item, nothing in the scale was used.

\section{Reliability}

Internal consistency is measured by intercorrelation between items on each scale, with strong correlations demonstrating that the items are measuring the same thing. Reliability of all the scales was tested using Cronbach's alpha to measure internal consistency. If a scale is internally consistent, then the coefficient alpha estimates should equal or exceed .70 (Cronbach, 1951). An alpha score of lower than .70 indicates poor scale reliability. An alpha from .70-.80 indicates respectable 
reliability, and an alpha of.80-.90 indicates very good reliability (Devellis, 2003). See Table 10 for reliability alpha scores.

Advancement. The items in this scale are all positively correlated. Reliability was assessed by calculating coefficient alpha. The reliability estimate is .821 . An itemby-item analysis was performed to determine if the coefficient alpha could have been improved by removing items. All of the items comprise a fine scale.

Autonomy. Reliability was assessed by calculating coefficient alpha. The reliability estimate is .63. This is an unacceptable scale alpha. Upon theoretical review and correlation analysis, it appears that these questions do not adequately explain the construct of autonomy. These questions will not be used as a scaled measure. The item $11 \mathrm{~b}$ is not correlated to the main outcome variable at all. This scale will be dropped from the measure.

Burnout-Depersonalization. The items in this scale are all positively correlated. Reliability was assessed by calculating coefficient alpha. The reliability estimate is .756. An item-by-item analysis was performed to determine if the coefficient alpha could have been improved by removing items. The alpha increases to .796 when the item "I feel clients blame me for some of their problems" is removed. Thus, the item is removed from all analysis.

Burnout- Emotional Exhaustion. The items in this scale are all positively correlated. Reliability was assessed by calculating coefficient alpha. The reliability estimate is .919. An item-by-item analysis was performed to determine if the 
coefficient alpha could have been improved by removing items. All of the items comprise a fine scale.

Burnout-Personal Accomplishment. The items in this scale are all positively correlated. Reliability was assessed by calculating coefficient alpha. The reliability estimate is .825 . An item-by-item analysis was performed to determine if the coefficient alpha could have been improved by removing items. All of the items comprise a fine scale.

Culture of Caring. The items on this scale are all positively correlated with each other. Reliability was assessed by calculating a coefficient alpha. The reliability estimate is .866. An item-by-item analysis was performed to determine if the coefficient alpha could have been improved by removing items. All of the items comprise a fine scale.

Job Readiness. The items on this scale are all positively correlated with each other. Reliability was assessed by calculating coefficient alpha. The reliability estimate is .838. An item-by-item analysis was performed to determine if the coefficient alpha could have been improved by removing items. The reliability of this scale would be slightly improved by removing one question of this three-item scale, moving the Alpha from .838 to .879 . However, keeping all questions in this scale is theoretically justified, and the Alpha is acceptable without removing the question. All of the items comprise a fine scale. 
Job Satisfaction. The items on this scale are all positively correlated with each other. Reliability was assessed by calculating coefficient alpha. The reliability estimate is .753. An item-by-item analysis was performed to determine if the coefficient alpha could have been improved by removing items. All of the items comprise a fine scale. Removing an item would potentially increase the Alpha from .753 to .763 , but leaving all items in is theoretically justified and results in an acceptable Alpha score. This scale will not be used in the climate scale because of item overlap within this scale.

Peer Support. The items on this scale are all positively correlated with each other. Reliability was assessed by calculating coefficient alpha. The reliability estimate is .852 . An item-by-item analysis was performed to determine if the coefficient alpha could have been improved by removing items. All of the items comprise a fine scale.

Role Clarity. The items on this scale are all positively correlated with each other. Reliability was assessed by calculating coefficient alpha. The reliability estimate is .729. An item-by-item analysis was performed to determine if the coefficient alpha could have been improved by removing items. The analysis showed that by removing the question "I know what procedures to follow in most situations." Upon theoretical review of the items, it was determined that the item could be removed from the scale, which increases the reliability Alpha to .742. 
Role Conflict. The items on this scale are all positively correlated with each other. Reliability was assessed by calculating coefficient alpha. The reliability estimate is .770 . An item-by-item analysis was performed to determine if the coefficient alpha could have been improved by removing items. All of the items comprise a fine scale.

Role Overload. The items on this scale are all positively correlated with each other. Reliability was assessed by calculating coefficient alpha. The reliability estimate is .773. An item-by-item analysis was performed to determine if the coefficient alpha could have been improved by removing items. All of the items comprise a fine scale.

Supervisor Competence. The items on this scale are all positively correlated with each other. Reliability was assessed by calculating coefficient alpha. The reliability estimate is .921 . An item-by-item analysis was performed to determine if the coefficient alpha could have been improved by removing items. All of the items comprise a fine scale.

Supervisor Satisfaction. The items on this scale are all positively correlated with each other. Reliability was assessed by calculating coefficient alpha. The reliability estimate is $\mathbf{9 3 2}$. An item-by-item analysis was performed to determine if the coefficient alpha could have been improved by removing items. All of the items comprise a fine scale. 
Supervisor Total Satisfaction. Due to a high degree of covariance between the two above scales, a single scale was created using the means of both of the supervisor competence scale and supervisor satisfaction scale. Reliability was assessed by calculating coefficient alpha. The reliability estimate is .960 . An item-by-item analysis was performed to determine if the coefficient alpha could have been improved by removing items. All of the items comprise a fine scale. None of the individual items are correlated above .80 , which might indicate they were measuring the same thing.

Culture of caring. The items on this scale are all positively correlated with each other. Reliability was assessed by calculating coefficient alpha. The reliability estimate is .891 . An item-by-item analysis was performed to determine if the coefficient alpha could have been improved by removing items. All of the items comprise a fine scale.

The autonomy scale was removed due to lack of scale reliability, and a “culture of caring" scale was created, consisting of 10 questions. Factor analysis was considered, but not used, because the tests of reliability demonstrated that items in the scale were correlated between .30 and .70 and all scaled demonstrated high reliability with no more than minor adjustments to the scales. This investigation did not attempt to determine whether the scales could be simplified, although this may be a task for future research. The methodology used to answer each of the research questions is summarized in Table 11. 
Table 10

Child Welfare Workforce Survey Scale Reliability

\begin{tabular}{|c|c|c|c|}
\hline Scale & $\begin{array}{l}\text { Cronbach's Alpha } \\
\text { score }\end{array}$ & $\begin{array}{l}\text { Meets reliability } \\
\text { standards? }\end{array}$ & $\begin{array}{l}\text { Higher alpha if } \\
\text { items deleted? }\end{array}$ \\
\hline 1. Advancement (5 items) & .821 & Yes & No \\
\hline 2. Autonomy (4 items) & .063 & No & No \\
\hline $\begin{array}{ll}3 . & \text { Burnout- } \\
& \text { Depersonalization ( } 9 \\
\text { items, adjusted to } 8 \text { items) }\end{array}$ & $\begin{array}{l}.756 \\
\text { Remove 7m: .796 }\end{array}$ & Yes & $\begin{array}{l}\text { Yes } \\
\text { Remove item } 7 \mathrm{~m}\end{array}$ \\
\hline $\begin{array}{l}\text { 4. Burnout- } \\
\text { Emotional exhaustion (5 } \\
\text { items) }\end{array}$ & .919 & Yes & No \\
\hline $\begin{array}{ll}5 . & \text { Burnout- } \\
\text { Personal accomplishment } \\
\text { (8 items) }\end{array}$ & .825 & Yes & No \\
\hline 6. Job readiness (3 items) & .838 & Yes & $\begin{array}{l}\text { Yes, but no items } \\
\text { removed }\end{array}$ \\
\hline 7. Job satisfaction (7 items) & .753 & Yes & $\begin{array}{l}\text { Yes, but no items } \\
\text { removed }\end{array}$ \\
\hline 8. $\quad$ Peer support (5 items) & .852 & Yes & No \\
\hline $\begin{array}{l}\text { 9. Role clarity (5 items, } \\
\text { adjusted to } 4 \text { items) }\end{array}$ & $\begin{array}{l}.729 \\
\text { Remove 11d: .742. }\end{array}$ & Yes & $\begin{array}{l}\text { Yes } \\
\text { Removed item 11d }\end{array}$ \\
\hline 10. Role conflict (3 items) & .770 & Yes & No \\
\hline 11. Role overload (3 items) & .773 & Yes & No \\
\hline $\begin{array}{l}\text { 12. Supervisor competence (6 } \\
\text { items) }\end{array}$ & .921 & Yes & No \\
\hline $\begin{array}{l}\text { 13. Supervisor satisfaction } \\
\text { (10items) }\end{array}$ & .932 & Yes & No \\
\hline $\begin{array}{l}\text { 14. Supervisor Total } \\
\text { Satisfaction }\end{array}$ & .960 & Yes & No \\
\hline 15. Culture of caring & .891 & Yes & No \\
\hline
\end{tabular}


Table 11

Research Variables and Statistical Methodologies

Variable

Existing research

Measures

Methodology to determine correlation with intent to leave (DV)

\begin{tabular}{|c|c|c|c|}
\hline 1. Culture & $\begin{array}{l}\text { Mor Barak, Levin, } \\
\text { Nissly, \& Lane; } \\
\text { Glisson; Lawson, } \\
\text { Landsman; Jones \& } \\
\text { Sagmi. }\end{array}$ & $\begin{array}{l}24 \text { item scale } \\
\text { developed by CWP }\end{array}$ & $\begin{array}{l}\text { Backwards multiple } \\
\text { linear regression to } \\
\text { determine strength of } \\
\text { association between } \\
\text { items in culture scale } \\
\text { and DV }\end{array}$ \\
\hline 2. Climate & $\begin{array}{l}\text { Glisson, Dukes, Green, } \\
\text { \& Hemmelgar; } \\
\text { Lawson; Bednar; } \\
\text { James \& Sells. }\end{array}$ & $\begin{array}{l}42 \text { item scale } \\
\text { developed by CWP; } \\
\text { incorporates }\end{array}$ & $\begin{array}{l}\text { Backwards multiple } \\
\text { linear regression to } \\
\text { determine strength of } \\
\text { association between } \\
\text { items in climate scale } \\
\text { and DV }\end{array}$ \\
\hline 3. Supervision & $\begin{array}{l}\text { Landsman; Gibbs, ; } \\
\text { Bride, Jones; } \\
\text { MacMaster \& } \\
\text { Shatilaa; Rycraft; } \\
\text { Scannapieco, \& } \\
\text { Connell-Carrick }\end{array}$ & $\begin{array}{l}16 \text { item scale } \\
\text { developed by NC } \\
\text { Jordan Institute, } \\
\text { comprised of two } \\
\text { subscales }\end{array}$ & $\begin{array}{l}\text { Backwards multiple } \\
\text { linear regression to } \\
\text { determine strength of } \\
\text { association between } \\
\text { items in supervision } \\
\text { scale and DV }\end{array}$ \\
\hline 4. Job readiness & $\begin{array}{l}\text { Chernesky \& Israel; } \\
\text { Jordan Institute; } \\
\text { Breaugh; Buckley, } \\
\text { Veres, Fedor, Wiese, } \\
\text { \& Carraher }\end{array}$ & NC Jordan Institute & $\begin{array}{l}\text { Pearson's Chi Square to } \\
\text { determine variance } \\
\text { between JR workers } \\
\text { and DV at multiple data } \\
\text { points }\end{array}$ \\
\hline 5. Job role & $\begin{array}{l}\text { APHSA Study; Jordan } \\
\text { Institute; James \& } \\
\text { Sells }\end{array}$ & $\begin{array}{l}\text { Multiple choice } \\
\text { response containing } \\
7 \text { options based } \\
\text { upon Oregon's } \\
\text { position identifiers. }\end{array}$ & $\begin{array}{l}\text { Pearson's Chi Square } \\
\text { and Odds Ratio to test } \\
\text { for correlation and } \\
\text { determine the increased } \\
\text { odds of DV given PS } \\
\text { job role. }\end{array}$ \\
\hline 6. Intent to leave & $\begin{array}{l}\text { Outcome variable } \\
\text { supported as a } \\
\text { predictor of actual } \\
\text { turnover by: } \\
\text { Steel \& Ovalle; Mor } \\
\text { Barak, Nissly \& } \\
\text { Levin; Martin }\end{array}$ & $\begin{array}{l}3 \text { multiple-choice } \\
\text { questions based } \\
\text { upon Bluedorn } \\
\text { staying-or-leaving } \\
\text { index and } \\
\text { Schwartz/CWP } \\
\text { research } \\
\end{array}$ & $\begin{array}{l}\text { This is the dependent } \\
\text { variable (DV) }\end{array}$ \\
\hline
\end{tabular}




\section{CHAPTER VI}

\section{RESULTS}

The data were analyzed using quantitative statistical methodologies, as described in this section. In order to review the data, a correlation matrix of all the major dependent and independent variables was explored for a cursory review of relationships in the population of workers who intend to leave for preventable reasons for each hypothesis. According to Cohen, .10-.29 indicates a weak correlation, .30-.49 a moderate correlation, and .50-1 indicates a strong correlation (2003). This analysis includes all workers who are leaving for preventable reasons. When exploring cases of preventable turnover only, the $n=145$. Because cases are excluded pairwise, the final number of cases used in the regression models is 136.

\section{H1: Higher levels of worker satisfaction with organizational climate will be} significantly predictive of a worker's intent to leave the agency.

A brief review of the correlation matrix for Hypothesis 1 reveals that all scales are highly correlated with the outcome variable intent to leave. The correlations were run to test for one-tailed significance as the hypothesis is that relationships are directional, and the correlation matrix indicates that all the items are correlated in the expected direction. Note that on the Intent to Leave Scale, 0 indicates a very low intent and a score of 8 indicates a very high intent to leave. However, on the scales, 0 equals the most satisfied response and 5 equals the least satisfied response. Thus, negative correlations between the scales and intent to leave are expected. 
This scale demonstrates strong links between the dependent variable intent to leave and the variables for Role Clarity, Emotional Exhaustion, and Advancement. However, all of the explored variables demonstrate significant correlations at the p>.05 level. Not surprisingly, one of the strongest correlations is between role overload and emotional exhaustion, as demonstrated in Table 12.

Table 12

Correlation Matrix for Primary Independent and Dependent Variables for Hypothesis 1

\begin{tabular}{|c|c|c|c|c|c|c|c|c|c|}
\hline & $\begin{array}{l}\text { Advance } \\
\text { ment } \\
\text { Scale }\end{array}$ & $\begin{array}{c}\text { DP } \\
\text { Scale }\end{array}$ & $\begin{array}{c}\mathrm{EE} \\
\text { scale }\end{array}$ & $\begin{array}{c}\text { PA } \\
\text { scale }\end{array}$ & $\begin{array}{l}\text { Job } \\
\text { ready } \\
\text { scale }\end{array}$ & $\begin{array}{l}\text { Role } \\
\text { Clarity } \\
\text { scale }\end{array}$ & $\begin{array}{c}\text { Role } \\
\text { Confli } \\
\text { ct scale }\end{array}$ & $\begin{array}{l}\text { Role } \\
\text { Over } \\
\text { load }\end{array}$ & $\begin{array}{c}\text { Sup } \\
\text { Sat } \\
\text { scale }\end{array}$ \\
\hline \multirow{3}{*}{$\begin{array}{l}\text { Depersonalization } \\
\text { Scale }\end{array}$} & $.188^{*}$ & 1 & & & & & & & \\
\hline & .013 & & & & & & & & \\
\hline & 141 & 141 & & & & & & & \\
\hline \multirow{3}{*}{$\begin{array}{l}\text { Emotional } \\
\text { exhaustion scale }\end{array}$} & $.255^{* *}$ & $.444^{* *}$ & 1 & & & & & & \\
\hline & .001 & .000 & & & & & & & \\
\hline & 141 & 141 & 141 & & & & & & \\
\hline \multirow{3}{*}{$\begin{array}{l}\text { Personal } \\
\text { accomplishment } \\
\text { scale }\end{array}$} & .036 & $.310^{* * *}$ & $.329^{* * *}$ & 1 & & & & & \\
\hline & .337 & .000 & .000 & & & & & & \\
\hline & 141 & 141 & 141 & 141 & & & & & \\
\hline \multirow[t]{3}{*}{ Job readiness scale } & $.304^{* * *}$ & $.153^{*}$ & $.345^{* * 2}$ & .083 & 1 & & & & \\
\hline & .000 & .035 & .000 & .163 & & & & & \\
\hline & 141 & 141 & 141 & 141 & 141 & & & & \\
\hline \multirow[t]{3}{*}{ Role Clarity scale } & $.448^{* *}$ & $.186^{*}$ & $.336^{* *}$ & .128 & $.456^{* *}$ & 1 & & & \\
\hline & .000 & .014 & .000 & .065 & .000 & & & & \\
\hline & 141 & 141 & 141 & 141 & 141 & 141 & & & \\
\hline \multirow[t]{3}{*}{ Role Conflict scale } & $.380^{* * *}$ & $.339^{* *}$ & $.433^{* *}$ & $.196^{* *}$ & $.415^{* *}$ & $.427^{* *}$ & 1 & & \\
\hline & .000 & .000 & .000 & .010 & .000 & .000 & & & \\
\hline & 141 & 141 & 141 & 141 & 141 & 141 & 141 & & \\
\hline \multirow[t]{3}{*}{ Role Overload scale } & $.344^{* *}$ & $.273^{* *}$ & $.554^{* *}$ & $.141^{*}$ & $.274^{* * *}$ & $.360^{* * *}$ & $.487^{* *}$ & 1 & \\
\hline & .000 & .001 & .000 & .048 & .000 & .000 & .000 & & \\
\hline & 141 & 141 & 141 & 141 & 141 & 141 & 141 & 141 & \\
\hline \multirow{3}{*}{$\begin{array}{l}\text { Supervisor } \\
\text { satisfaction } \\
\text { combined scale }\end{array}$} & $.491^{* * *}$ & $.145^{*}$ & $.231^{* * *}$ & -.025 & $.395^{* * *}$ & $.731^{\text {*** }}$ & $.424^{* * *}$ & $.336^{* * *}$ & 1 \\
\hline & .000 & .043 & .003 & .386 & .000 & .000 & .000 & .000 & \\
\hline & 141 & 141 & 141 & 141 & 141 & 141 & 141 & 141 & 141 \\
\hline \multirow[t]{3}{*}{ Intent to leave scale } & $-.360^{* *}$ & $-.174^{*}$ & $-.389^{* *}$ & $-.222^{* *}$ & $-.254^{* *}$ & $-.410^{* *}$ & $-.288^{* *}$ & $-.240^{* *}$ & $-.302^{* *}$ \\
\hline & .000 & .021 & .000 & .005 & .001 & .000 & .000 & .002 & .000 \\
\hline & 137 & 137 & 137 & 137 & 137 & 137 & 137 & 137 & 137 \\
\hline
\end{tabular}


Testing Assumptions. The data was checked for assumptions required for multiple linear regression: data linearity, independence, normality, and equal variance. A test of correlation was performed to check the bivariate correlation of the variables for hypothesis 1 . The variables supervisor satisfaction and supervisor competence were very highly correlated (.893). Tabachnick and Fidel (2007) suggest one consider omitting or forming a composite variable of those variables that are correlated above the .70 level. Thus, a new Supervisor Satisfaction scale was created that combines the supervisor satisfaction and supervisor competence measures. Measures for tolerance, which would indicate how much of the variability of the independent variable is not explained by the other independent variables, indicates no high levels of multiple correlation (and therefore multicollinearity); all values are more than .10 for tolerance in each scale. A test of the Variance Inflation Factor, which indicates multicollinearity when results are more than 10 , demonstrated no multicollinarity.

A regression of the standardized residuals indicates that there are no major deviations from normality. The scatterplot indicates few outliers, and no standardized residuals of more than 3.3 or less than -3.3 (Tabachnick and Fidell, 2007). The data in Casewise Diagnostics indicate that only one case has a residual value above 3.0, and the residual is only -3.01 for that case. The measure of Cook's Distance indicates that this does not affect this model, as no values are larger than 1 (Tabachnick \& Fidell, 2007). 


\section{Regression Models}

Analysis of H1. Higher levels of worker satisfaction with organizational climate will be significantly predictive of a worker's intent to leave the agency.

A backwards stepwise regression of the climate measure's impact on intent to leave was calculated on the entire population of workers who intend to eventually leave for preventable reasons, consisting of the constructs for Supervisor Total Satisfaction, Role Conflict, Role Overload, Role Clarity, Depersonalization, Emotional Exhaustion, Personal Accomplishment, Advancement, and two questions "I like doing the things I do at work" and "I like my coworkers." This is measured against the full-scale ordinal score for time until intent to leave. The backward analysis does not suggest that removing any of the independent variables would increase the variance (R Square).

The regression results in Table 13 indicate that the model significantly predicts Intent to Leave $\left(\mathrm{R}^{2}=.297, \mathrm{R}_{\mathrm{adj}}=.248, F(9,127)=5.974, \mathrm{p}<.0001\right)$.

Table 13

Hypothesis 1 Regression Model of Climate Predicting Intent to Leave

\begin{tabular}{|c|c|c|c|c|c|c|c|c|c|}
\hline \multirow[t]{2}{*}{ Model } & \multirow[b]{2}{*}{$\mathrm{R}$} & \multirow[b]{2}{*}{$\begin{array}{c}\text { R } \\
\text { Square }\end{array}$} & \multirow[b]{2}{*}{$\begin{array}{l}\text { Adjusted } \\
\text { R Square }\end{array}$} & \multirow[b]{2}{*}{$\begin{array}{l}\text { Std. Error of } \\
\text { the Estimate }\end{array}$} & \multicolumn{5}{|c|}{ Change Statistics } \\
\hline & & & & & $\begin{array}{l}\text { R Square } \\
\text { Change }\end{array}$ & $\begin{array}{c}\mathrm{F} \\
\text { Change }\end{array}$ & df1 & df 2 & $\begin{array}{c}\text { Sig. F } \\
\text { Change }\end{array}$ \\
\hline 1 & $.545^{\mathrm{a}}$ & .297 & .248 & 1.65232 & .297 & 5.974 & 9 & 127 & .000 \\
\hline
\end{tabular}

The ANOVA score in Table 14 indicates an F-ratio of 5.974 for a significance value for the model of $.000(\mathrm{p}<.0001)$. 
Table 14

Hypothesis 1 ANOVA

\begin{tabular}{llrrrrr}
\hline Model & & Sum of Squares & df & Mean Square & F & Sig. \\
\hline 1 & Regression & 146.802 & 9 & 16.311 & 5.974 & $.000^{\mathrm{a}}$ \\
& Residual & 346.731 & 127 & 2.730 & & \\
& Total & 493.533 & 136 & & & \\
\hline
\end{tabular}

a. Predictors: (Constant), I like my co-workers. CLIMATE JOB SAT, I like doing the things I do at work. CLIMATE JOB SAT, Supervisor satisfaction combined scale, Role Overload scale, Personal accomplishment scale, Advancement Scale, Role Conflict scale, Emotional exhaustion scale, Role Clarity scale

b. Dependent Variable: Intent to leave scale

In this model, role clarity $t(127)=--2.161, p<.05, \beta-.209$, and emotional

exhaustion $t(127)=-2.046, p<.05, \beta-.249$, make statistically significant unique contributions when all other independent variables are held constant. The Part Correlation indicates that role conflict accounts for about $2.5 \%$ of the independent variance. The advancement scale approaches unique independent significance. See Table 15 for more information on the contribution of each independent variable.

Exploratory analysis. A backwards stepwise regression of the climate measure's impact on intent to leave was calculated on the entire population of respondents $(n=401)$, consisting of the same variables. While the model was still significant, it explained only $14 \%$ of variance. This indicates the model fits much better for workers who intend to leave for preventable reasons, consistent with the hypothesis. 
Table 15

Hypothesis I Coefficients for Climate Scales and Intent to Leave

\begin{tabular}{|c|c|c|c|c|c|c|c|c|c|}
\hline \multirow[t]{2}{*}{ Model } & & \multicolumn{2}{|c|}{$\begin{array}{l}\text { Unstandardiz } \\
\text { ed } \\
\text { Coefficients }\end{array}$} & \multirow[t]{2}{*}{$\begin{array}{c}\text { Stand. } \\
\text { Coeff } \\
\text { icts } \\
\end{array}$} & \multirow[b]{2}{*}{$\mathrm{T}$} & \multirow[b]{2}{*}{ Sig. } & \multicolumn{3}{|c|}{ Correlations } \\
\hline & & $\mathrm{B}$ & $\begin{array}{l}\text { Std. } \\
\text { Error }\end{array}$ & & & & $\begin{array}{l}\text { Zero- } \\
\text { order }\end{array}$ & $\begin{array}{c}\text { Partia } \\
1 \\
\end{array}$ & Part \\
\hline \multirow[t]{10}{*}{1} & (Constant) & 7.893 & .678 & & 11.647 & .000 & & & \\
\hline & $\begin{array}{l}\text { Supervisor satisfaction } \\
\text { combined scale }\end{array}$ & .035 & .271 & .015 & .129 & .898 & -.302 & .011 & .010 \\
\hline & Role Conflict scale & -.008 & .232 & -.003 & -.036 & .971 & -.288 & -.003 & -.003 \\
\hline & Role Overload scale & .217 & .238 & .088 & .912 & .364 & -.240 & .081 & .068 \\
\hline & Role Clarity scale & -.586 & .271 & -.249 & -2.161 & .033 & -.410 & -.188 & -.161 \\
\hline & Emotional exhaustion scale & -.334 & .163 & -.209 & -2.046 & .043 & -.389 & -.179 & -.152 \\
\hline & $\begin{array}{l}\text { Personal accomplishment } \\
\text { scale }\end{array}$ & -.108 & .196 & -.049 & -.552 & .582 & -.222 & -.049 & -.041 \\
\hline & Advancement Scale & -.400 & .218 & -.170 & -1.836 & .069 & -.360 & -.161 & -.137 \\
\hline & $\begin{array}{l}\text { I like doing the things I do } \\
\text { at work. }\end{array}$ & -.331 & .253 & -.130 & -1.310 & .193 & -.325 & -.115 & -.097 \\
\hline & I like my co-workers. & -.230 & .185 & -.102 & -1.243 & .216 & -.240 & -.110 & -.092 \\
\hline
\end{tabular}

a. Dependent Variable: Intent to leave scale

Discussion of results. The null hypothesis can be rejected. The hypothesis that organizational climate will account for significant variance in intent to leave is supported by the data. Although only about a quarter of total variance in intent to leave is explained, the hypothesis assumes other contributory factors, including personal characteristics that were not measured in this analysis, and culture, which will be measured as a separate analysis. The strongest impacts on climate for workers who intend to leave for preventable reasons are role conflict, emotional exhaustion, and opportunities for advancement. 
H2: Higher levels of worker satisfaction with organizational culture will be significantly predictive of a worker's intent to leave the agency.

A correlation matrix of the major variables related to this hypothesis reveals that all items correlate to the dependent variable in the expected direction (Table 16). All correlations are significant at the .01 level.

Table 16

Correlations for Hypothesis II Culture and Intent to Leave

\begin{tabular}{|c|c|c|c|c|c|c|}
\hline & $\begin{array}{l}\text { Peer } \\
\text { Support } \\
\text { scale }\end{array}$ & $\begin{array}{l}\text { Caring } \\
\text { Culture } \\
\text { Scale }\end{array}$ & $\begin{array}{c}\text { There is } \\
\text { only one } \\
\text { way }\end{array}$ & $\begin{array}{l}\text { This } \\
\text { agency } \\
\text { rewards } \\
\text { expertise. }\end{array}$ & $\begin{array}{l}\text { This agency } \\
\text { emphasizes } \\
\text { growth and } \\
\text { development }\end{array}$ & $\begin{array}{l}\text { Intent to } \\
\text { leave } \\
\text { scale }\end{array}$ \\
\hline \multirow[t]{3}{*}{ Peer Support scale } & 1 & $.533^{* *}$ & $.261^{* *}$ & $.463^{* *}$ & $.484^{* *}$ & $-.244^{* *}$ \\
\hline & & .000 & .001 & .000 & .000 & .002 \\
\hline & 141 & 141 & 139 & 141 & 141 & 137 \\
\hline \multirow[t]{3}{*}{ Caring Culture Scale } & $.533^{* * *}$ & 1 & $.177^{*}$ & $.286^{* *}$ & $.377^{* *}$ & $-.258^{* * *}$ \\
\hline & .000 & & .019 & .000 & .000 & .001 \\
\hline & 141 & 141 & 139 & 141 & 141 & 137 \\
\hline \multirow{3}{*}{$\begin{array}{l}\text { There is only one } \\
\text { way to do the job --- } \\
\text { the boss's way. }\end{array}$} & $.261^{* * *}$ & $.177^{*}$ & 1 & $.191^{*}$ & $.364^{* *}$ & $-.207^{* * *}$ \\
\hline & .001 & .019 & & .012 & .000 & .008 \\
\hline & 139 & 139 & 139 & 139 & 139 & 135 \\
\hline \multirow{3}{*}{$\begin{array}{l}\text { This agency rewards } \\
\text { expertise. }\end{array}$} & $.463^{* *}$ & $.286^{* *}$ & $.191^{*}$ & 1 & $.514^{* *}$ & $-.315^{* *}$ \\
\hline & .000 & .000 & .012 & & .000 & .000 \\
\hline & 141 & 141 & 139 & 141 & 141 & 137 \\
\hline \multirow{3}{*}{$\begin{array}{l}\text { This agency } \\
\text { emphasizes } \\
\text { professional growth } \\
\text { and development. }\end{array}$} & $.484^{* * *}$ & $.377^{* * \%}$ & $.364^{* * *}$ & $.514^{* * *}$ & 1 & $-.333^{* * *}$ \\
\hline & .000 & .000 & .000 & .000 & & .000 \\
\hline & 141 & 141 & 139 & 141 & 141 & 137 \\
\hline \multirow[t]{3}{*}{ Intent to leave scale } & $-.244^{* * *}$ & $-.258^{* * *}$ & $-.207^{* * *}$ & $-.315^{* * *}$ & $-.333^{* *}$ & 1 \\
\hline & .002 & .001 & .008 & .000 & .000 & \\
\hline & 137 & 137 & 135 & 137 & 137 & 137 \\
\hline
\end{tabular}

**. Correlation is significant at the 0.01 level (1-tailed).

*. Correlation is significant at the 0.05 level (1-tailed).

Testing Assumptions. The data was checked for assumptions required for multiple linear regressions: data linearity, independence, normality, and equal variance. 
A test of correlation was performed to check the bivariate correlation of the variables for H2. No items are correlated above .70 (Tabachnick and Fidel (2007). Measures for tolerance, which would indicate how much of the variability of the independent variable is not explained by the other independent variables, indicate no high levels of multiple correlation (and therefore multicollinearity); all values are more than .10 for tolerance. A test of the Variance Inflation Factor, which indicates multicollinearity when results are more than 10 , demonstrated no multicollinarity.

A regression of the standardized residuals indicates that there are no major deviations from normality. The scatterplot indicates few outliers and no standardized residuals of more than 3.3 or less than -3.3 (Tabachnick \& Fidell, 2007). The data in Casewise Diagnostics indicate that only one case has a residual value above 3.0, and the residual is only -3.01 for that case. The measure of Cook's Distance indicates that this does not affect the model, as no values larger than 1 (Tabachnick \& Fidell, 2007).

Analysis. Backwards multiple linear regression was again used to estimate the relationship between the independent variables in the construct of "culture" and the dependent variable scale for "intent to leave." The culture construct is made up of the Peer Support Scale, a Culture of Caring scale, and three other stand-alone questions. The scale for autonomy was eliminated because the scale did not correlate with the dependent variable and did not seem to be measuring the desired construct, but a question from the original autonomy scale was left in the measure because it was correlated and theoretically useful in attempting to capture the construct of autonomy. 
These items and scales were measured against the full-scale ordinal score for time until intent to leave.

The backward analysis does not suggest that removing any of the dependent variables would increase the R Square. This model explains $13 \%$ of the variance in the dependent variable Intent to Leave, according to the adjusted R Square, which is a conservative R square estimate that adjusts for the amount of variables and the sample size (see Table 17).

Table 17

Hypothesis II Regression Model of Culture Predicting Intent to Leave

\begin{tabular}{|c|c|c|c|c|c|c|c|c|c|}
\hline \multirow[t]{2}{*}{ Model } & \multirow[b]{2}{*}{$\mathrm{R}$} & \multirow[b]{2}{*}{$\begin{array}{c}\text { R } \\
\text { Square }\end{array}$} & \multirow[b]{2}{*}{$\begin{array}{l}\text { Adjusted } \\
\text { R Square }\end{array}$} & \multirow{2}{*}{$\begin{array}{l}\text { Std. Error } \\
\text { of the } \\
\text { Estimate }\end{array}$} & \multicolumn{5}{|c|}{ Change Statistics } \\
\hline & & & & & $\begin{array}{l}\text { R Square } \\
\text { Change }\end{array}$ & $\begin{array}{c}\mathrm{F} \\
\text { Change }\end{array}$ & df1 & $\mathrm{df} 2$ & $\begin{array}{c}\text { Sig. F } \\
\text { Change }\end{array}$ \\
\hline 1 & $.403^{\mathrm{a}}$ & .162 & .130 & 1.77708 & .162 & 4.996 & 5 & 129 & .000 \\
\hline
\end{tabular}

a. Predictors: (Constant), There is only one way to do the job --- the boss's way, Caring Culture Scale, This agency rewards expertise., This agency emphasizes professional growth and development, Peer Support scale

The ANOVA score in Table 18 indicates an F-ratio of 4.996 for a significance value for the model of $.000(\mathrm{p}<.0005)$.

Table 18

Hypothesis II ANOVA

\begin{tabular}{llrrrrr}
\hline Model & & Sum of Squares & Df & Mean Square & F & \multicolumn{1}{c}{ Sig. } \\
\hline 1 & Regression & 78.891 & 5 & 15.778 & 4.996 & $.000^{\mathrm{a}}$ \\
& Residual & 407.384 & 129 & 3.158 & & \\
& Total & 486.275 & 134 & & & \\
\hline
\end{tabular}

a. Predictors: (Constant), This agency emphasizes professional growth and development, How things are done around here is left pretty much up to the person doing the work., Caring Culture Scale, This agency rewards expertise, Peer Support scale

b. Dependent Variable: Intent to leave scale 
The strongest unique contribution to this model, when all other items are held constant, is the response to the statement "This agency rewards expertise," $t(129)=-$ $1.868, p<.10, \beta-.183$. However, none of the independent variables in this model made a significant individual impact on the outcome variable, which suggests that these items vary together with intent to leave. The peer support measure made the smallest independent contribution to the model, although it was fairly strongly correlated to the outcome variable in the direct correlation matrix (see Table 19).

\section{Table 19}

Model Coefficients for Hypothesis II

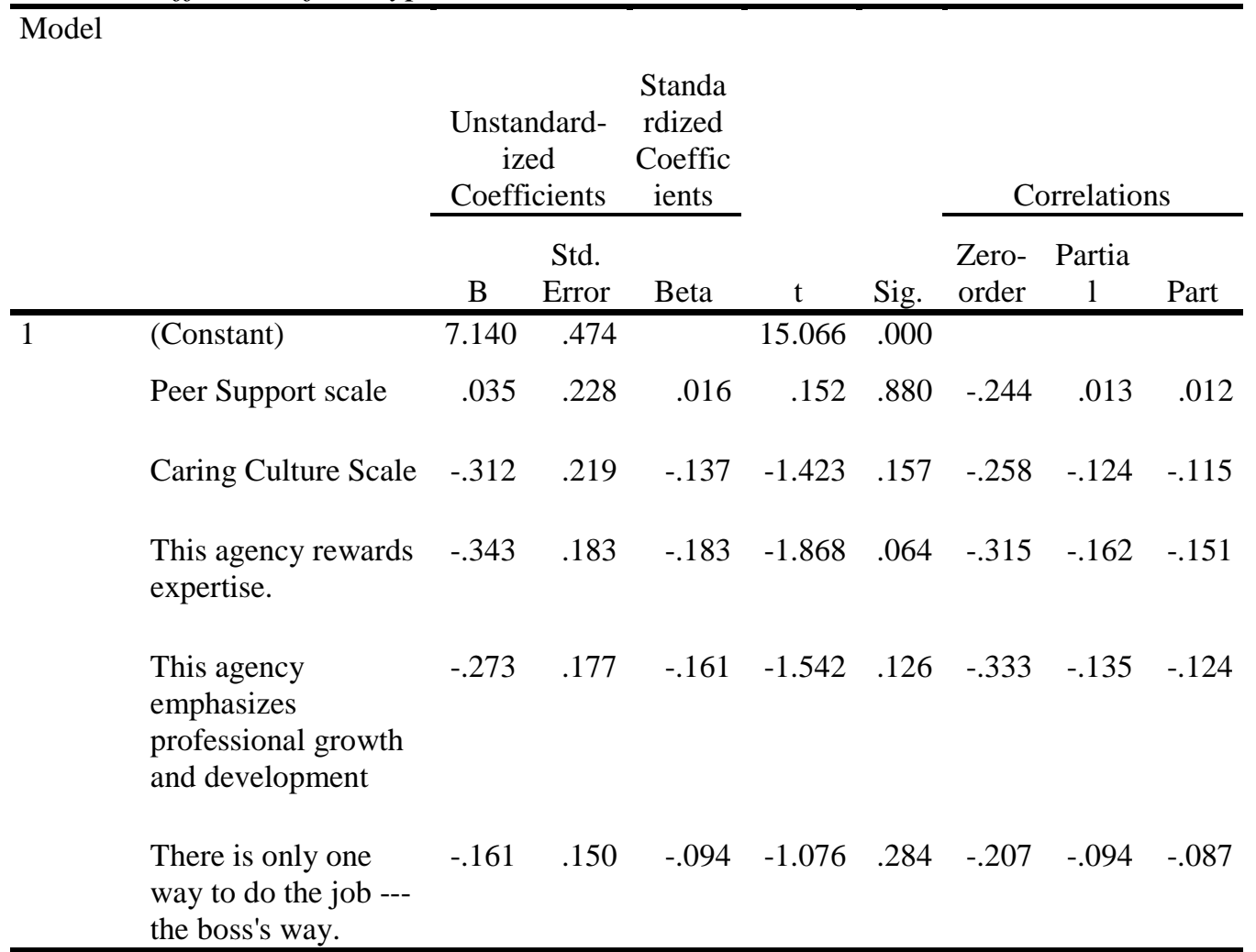

a. Dependent Variable: Intent to leave scale 
Discussion of Results. The data suggests that culture does have an effect on intent to leave. The null hypothesis can be rejected. As expected, the model for climate better explains intent to leave than the model for culture. The construct of climate speaks to an employee's psychological experience with their work environment and how it affects them personally, while culture describes the way work is approached by people in the workplace. In this study, the shared employee experience of climate and culture is not measured; only the direct effects of climate and culture on the individual's personal intent to leave is assessed. Different findings may result from an exploration of shared climate and culture on intent to leave.

\section{H3: Worker satisfaction with supervision will be inversely correlated with intent to} leave the agency.

To test this hypothesis, the mean for two supervisor scales was added together for each person in order to ascertain a greater range of satisfaction with supervision for each respondent. Pearson's correlation was used to test the relationship between the rank-scaled supervisor satisfaction measures and intent to leave. These items were measured against the scaled variable, intent to leave, to see if a worker's perception of their organizational climate can predict whether workers' supervisor satisfaction explains variance around workers who intend to eventually leave the agency for preventable reasons. Relationships are considered significant at the $\mathrm{p}<.05$ level.

The data was first checked for assumptions of linearity and homoscedasticity. A scatterplot was explored for the presence of outliers. There were no significant 
outliers. The data was even from one end to the other. The scatterplot does not suggest a very strong relationship between the variables. The relationship between the variables does appear to be roughly linear, as evidenced by the figure below. The scores are more strongly clustered in the area that indicates intent to leave is low (as indicated by high scores) and supervisor satisfaction is high (as indicated by low scores.)

Figure 3

Scatterplot of Supervision Satisfaction and Intent to Leave

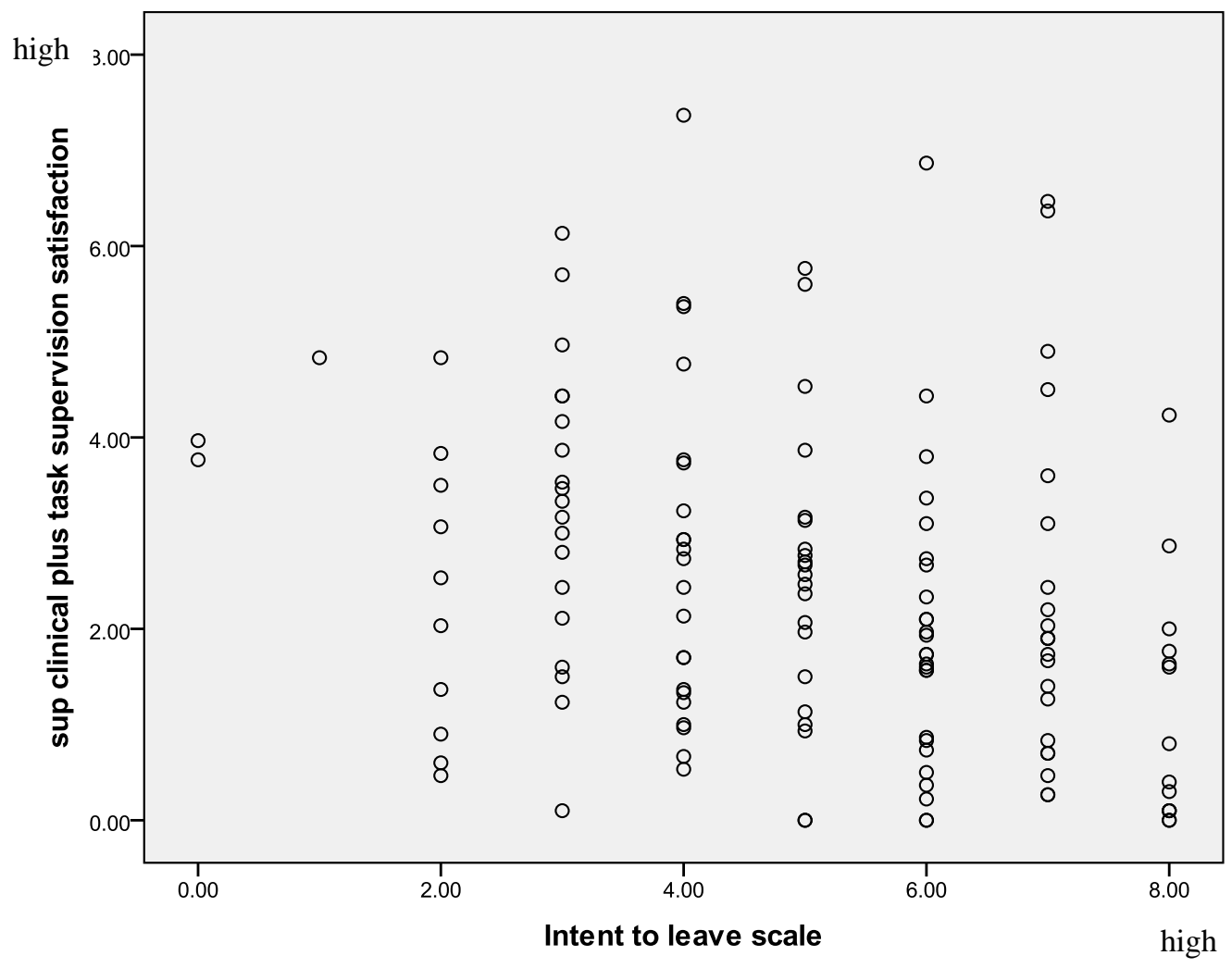

This test is computed on workers leaving for preventable reasons. Missing data are excluded pairwise. The $n=137$ for this test. This is a one-tailed analysis with the theoretical assumption that supervisor satisfaction is negatively correlated with intent 
to leave. The Pearson's Correlation reveals a correlation coefficient of -..302. The more satisfied people are with supervision, the less likely their intent to leave. This test is significant at the .0005 level. The observed $\rho$ was compared with published tables to determine levels of significance. The correlation coefficient suggests that the strength of the association is moderate (Cohen, 2003). A calculation of shared variance reveals that 9 percent of the variance in these two scales is shared.

Results. The null hypothesis can be rejected. There is statistical support for the hypothesis that supervisor satisfaction and intent to leave are inversely correlated. The relationship between supervisor satisfaction (as measured by the combined task and clinical supervision satisfaction scale) and intent to leave (as measured by the combined time until leaving and intent behaviors scale) was investigated using Pearson product-moment correlation coefficient. Preliminary analyses were performed to ensure no violation of the assumptions of normality, linearity and homoscedasticity. There was a moderate negative correlation between the two variables $[r=-.302, n=137$, $\mathrm{p}<.0005$ ], with high supervisor satisfaction associated with lower levels of intent to leave.

H4: Job readiness will be inversely correlated with intent to leave the agency.

Pearson's correlation was used to test the relationship between the rank-scaled job readiness measure and intent to leave. Job readiness is a 3-item construct on a 5point scale and was compared to workers' Intent to Leave score. Missing data are 
excluded pairwise. The observed $\rho$ was compared with published tables to determine levels of significance.

This test is administered for workers leaving for preventable reasons. A onetail test was run, with the assumption that as job readiness increases, intent to leave decreases. This test is significant at the .001 level. The analysis reveals a correlation coefficient of -.254 . The higher scores on the job readiness scales lead to lower intent to leave scores $[\mathrm{r}=-.254, \mathrm{n}=137, \mathrm{p}<.005$.$] The correlation coefficient suggests that the$ strength of the association is weak, but the strength approaches a medium association (Cohen, Cohen, West, \& Aiken, 2003). A calculation of shared variance reveals a shared variance of 6.4 percent. The null hypothesis can be rejected.

Subanalysis. It was hypothesized that Job Readiness would have a greater effect in those who have not worked at the agency as long. Therefore, a Pearson's Correlation was run on workers who have worked for child welfare for 24 months or less. This test revealed a slightly higher Pearson's Correlation of -.275 and a p value of .002 , and accounts for 7.5 percent of shared variance, and approached a moderate association $[\mathrm{r}=-.275, \mathrm{n}=112, \mathrm{p}<.005]$. There is not much difference between newer workers and those with longer tenure.

H5: Workers in protective services roles will express significantly greater intent to leave than workers in case management roles.

An independent-samples T-test was conducted to compare the intent to leave of Protective Services Workers to Ongoing workers. The dependent variable intent to 
leave is measured on the scaled score for time until leaving. Significance was measured at the $\mathrm{p}<.05$ level.

For this test, the sample was filtered to include only those who are either in protective service roles $(n=51)$ and ongoing $(n=73)$ workers. Because of items eliminated pairwise, the final analysis group is $n=39$ protective services workers, and $\mathrm{n}=62$ ongoing workers, for a total sample of 101 workers.

The intent to leave scale, which ranges from 0 (very high intent to leave) to 8 (very high intent to stay), utilizes the combined responses reported to questions of time until planned agency departure and the worker's participation in job-seeking behaviors.

Assumptions for this testing technique were met: the data are continuous and interval level. Although the data are not from a random sample from the population, it does represent approximately $30 \%$ of workers from selected districts. Each score is independent. The Holmogorov-Smirnov test for normality suggests that the data are not normally distributed, which is common for this size sample. However, an inspection of the Normal Q-Q Plots demonstrates a reasonably straight line along the expected values. The sample is reasonably normally distributed for the sample size. The boxplot does not indicate any outlier scores. The Trimmed Mean scores (with the $5 \%$ highest and lowest scores removed) were very close to the full scale means, indicating that extreme scores do not have a strong influence on the mean. The 
Levene's Test for Equality of Variances assumes equal variance (sig value .13). The effect size was calculated using the formula for Eta squared, and equaled .009.

The results of the T-test demonstrate no significant difference between the two groups. The null hypothesis cannot be rejected. There was no significant difference in scores for protective services workers $(\mathrm{M}=4.34, \mathrm{SD} 2.58)$ and ongoing workers $(\mathrm{M}=4.79, \mathrm{SD}=2.18 ; t(111)=-1.014, p=.31)$. The magnitude of the differences in the means was very small (eta squared=.009), indicating only .9 per cent of the variance in intent to leave is explained by job role.

\section{Additional Analysis}

Shared effect of climate and culture on intent to leave. A statistical test was run to see if culture and climate together better explain intent to leave than either does separately. Because the Culture and Climate scale both predicted variance in intent to leave, a combined model was tested that combined all of the items from climate and culture measures to see how much variance in Intent to Leave was accounted for when culture and climate were combined. All the items for culture and climate were added simultaneously to the linear regression model in the sample of only workers who intend to leave for preventable reasons, and assumptions were checked for linear regression.

The sample size used for this model pushes the limits of assumption of a large enough sample size for the number of independent variables used. The sample size is $\mathrm{n}=145$. A sample size calculation, which assumes a medium effect size (.15) and a 
statistical power level of .80 (Cohen et al., 2003) suggests that this test requires a minimum sample of 190 , for which the actual sample falls short. Although using a sample this size may result in underestimating association, the test was run to see if culture appeared to increase the variance explained.

To test the effect of the culture and climate constructs together on the dependent variable Intent to Leave, the independent variables from both of these measures were added to a regression model. The model indicates that the two groups, when combined together, account for $22.8 \%$ of variance in the dependent variable, which is slightly less than the model for climate alone explains. The effect is smaller due to the number of independent variables, but also suggests that the same variance caused by climate also affects culture.

Effects of supervision on intent to leave. Previous hypothesis testing demonstrates that satisfaction with supervision has a significant effect on Intent to Leave. Additional testing was done to see what questions in the supervision scales were most correlated with Intent to Leave.

For further exploration, each scale was explored to see what specific questions were most highly correlated to intent to leave in each scale. The results are somewhat surprising, in that for the Supervisor Clinical Satisfaction scale, "my supervisor encourages workers to spend time mentoring new employees" is the most highly correlated item, followed by “...reinforces the training I receive.” See Table 20 for correlations. 
A second correlation analysis was run on the items in the Supervisor Competence and Task Supervision scale. The statements "My supervisor provides the expert help I need to do my job," and "My supervisor has expectations for my work that are challenging but reasonable" are most highly correlated with intent to leave, as seen in Table 21.

A correlation was run that included the scales from the supervision competence/task satisfaction scale and the supportive/clinical supervision scale (Table 22). The two scales are very highly correlated with each other, indicating that when a person is satisfied with supervision, they likely see their supervisor as skillful (or not) on both competence and supportive areas. However, the Supervisor Competence scale has a slightly higher correlation to intent to leave. This is an unexpected finding. 


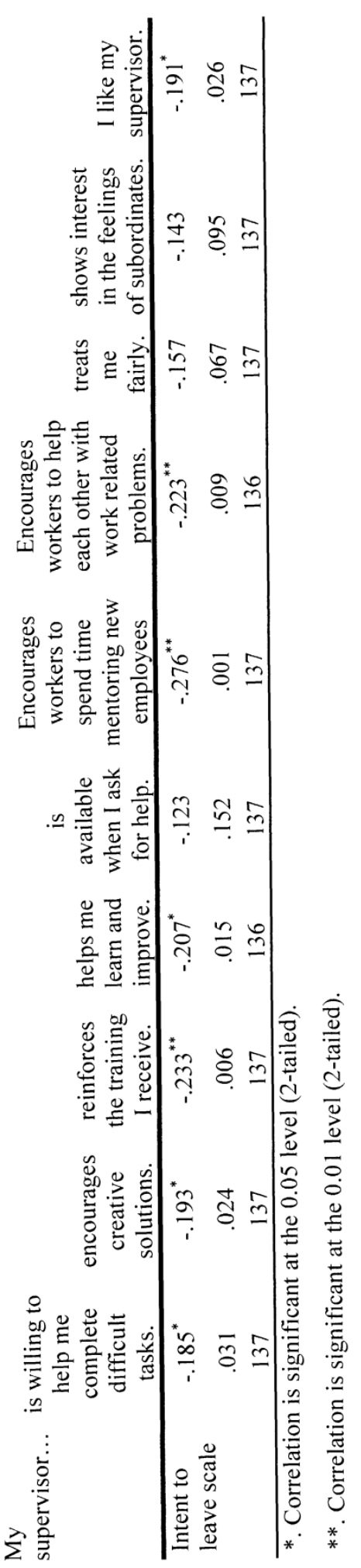


Table 20

Supervisor Competence Items Correlations with Intent to Leave

\begin{tabular}{|c|c|c|c|c|c|c|}
\hline $\begin{array}{c}\text { My } \\
\text { supervisor... }\end{array}$ & $\begin{array}{l}\text { provides the } \\
\text { expert help I } \\
\text { need to do my } \\
\text { job. }\end{array}$ & $\begin{array}{l}\text { knows } \\
\text { effective ways } \\
\text { to work with } \\
\text { children and } \\
\text { families. }\end{array}$ & $\begin{array}{l}\text { has expectations } \\
\text { for my work that } \\
\text { are challenging } \\
\text { but reasonable. }\end{array}$ & $\begin{array}{c}\text { gives me clear } \\
\text { feedback on my } \\
\text { job performance. }\end{array}$ & $\begin{array}{l}\text { has helped my } \\
\text { unit develop } \\
\text { into an } \\
\text { effective work } \\
\text { team. }\end{array}$ & $\begin{array}{c}\text { is quite } \\
\text { competent at } \\
\text { doing his/her } \\
\text { job }\end{array}$ \\
\hline \multirow{3}{*}{$\begin{array}{l}\text { Intent to } \\
\text { leave scale }\end{array}$} & $-.347^{* *}$ & $-.186^{*}$ & $-.337^{* *}$ & $-.253^{* * *}$ & $-.281^{* *}$ & $-.242^{* * *}$ \\
\hline & .000 & .030 & .000 & .003 & .001 & .004 \\
\hline & 137 & 137 & 137 & 137 & 137 & 137 \\
\hline
\end{tabular}

**. Correlation is significant at the 0.01 level (2-tailed).

*. Correlation is significant at the 0.05 level (2-tailed).

Table 22

Supervisor Satisfaction Correlations with Intent to Leave

\begin{tabular}{llrrr}
\hline & & $\begin{array}{c}\text { Supervisor } \\
\text { clinical role } \\
\text { scale }\end{array}$ & $\begin{array}{c}\text { Supervisor } \\
\text { competence } \\
\text { scale }\end{array}$ & $\begin{array}{c}\text { Intent to } \\
\text { leave scale }\end{array}$ \\
\hline supervisor clinical role scale & Pearson Correlation & 1 & $.896^{* * *}$ & $-.256^{* *}$ \\
& Sig. (2-tailed) & & .000 & .003 \\
& $\mathrm{~N}$ & 141 & 141 & 137 \\
\hline Supervisor competence scale & Pearson Correlation & $.896^{* *}$ & 1 & $-.327^{* *}$ \\
& Sig. (2-tailed) & .000 & 141 & .000 \\
& $\mathrm{~N}$ & 141 & 137 \\
\hline Intent to leave scale & Pearson Correlation & $-.256^{* * *}$ & $-.327^{* *}$ & 1 \\
& Sig. (2-tailed) & .003 & .000 & 137 \\
& $\mathrm{~N}$ & 137 & 137 \\
\hline
\end{tabular}

**. Correlation is significant at the 0.01 level (2-tailed).

Emotional exhaustion by job role. Previous analysis revealed that the mean score for intent to leave was not different depending on whether a worker performed investigations or ongoing case management. The intent to leave was hypothesized to be different between these two job roles. A follow-up analysis was conducted to see if 
there is a difference between these job roles when emotional exhaustion is used as the dependent variable. Emotional exhaustion is thought to be the predecessor for burnout (Maslach, 2002), and was also found to be a significant predictor of intent to leave in the climate scale.

An independent-samples t-test was conducted to compare the emotional exhaustion scores for protective services workers and ongoing workers. There was no significant difference in scores for protective services workers $(M=2.18, S D=1.27)$ and ongoing workers $[\mathrm{M}=2.04, \mathrm{SD}=1.14 ; \mathrm{t}(96)=.578, \mathrm{p}=.565]$ The magnitude of the differences was very small (eta squared=.0003).

Advancement. Scores were lower for satisfaction on the advancement scale than for any other scale. Workers generally report poor satisfaction with their opportunities for advancement. In this scale, which ranged from "strongly agree" (indicating greatest satisfaction) to "strongly disagree," $65 \%$ of workers had total scale scores that indicated scores ranging from "strongly disagree" to "neither agree or disagree" in the measure of satisfaction. A one-tailed correlation of the Advancement scale with the Intent to Leave scale indicates a moderately strong correlation $(p=-$ $.360)$.

Descriptive variables and Intent to Leave. A number of descriptive variables were collected. Although they are not linked to specific hypotheses, other studies have analyzed the effect of employee descriptive information, such as degree type, race, and gender, on intent to leave. Surprisingly, none of these variables were highly correlated 
with the intent to leave scale. This lends support to a hypothesis that personal demographics play a less significant role than organizational factors.

There was some variation in Intent to Leave in degree type, but several t-tests showed no significant differences in means between masters versus bachelors education, or in social work versus non-social work degree recipients. Figure 5, below, shows the mean for intent to leave by degree type in the preventable turnover sample. As the graph demonstrates, the mean intent to leave score is slightly lower for MSW graduates. (Lower scores indicate highest intent to leave.) The mean for other BSW's and workers with bachelors or masters in other fields is about the same.

Figure 4

Intent to Leave by Degree Type

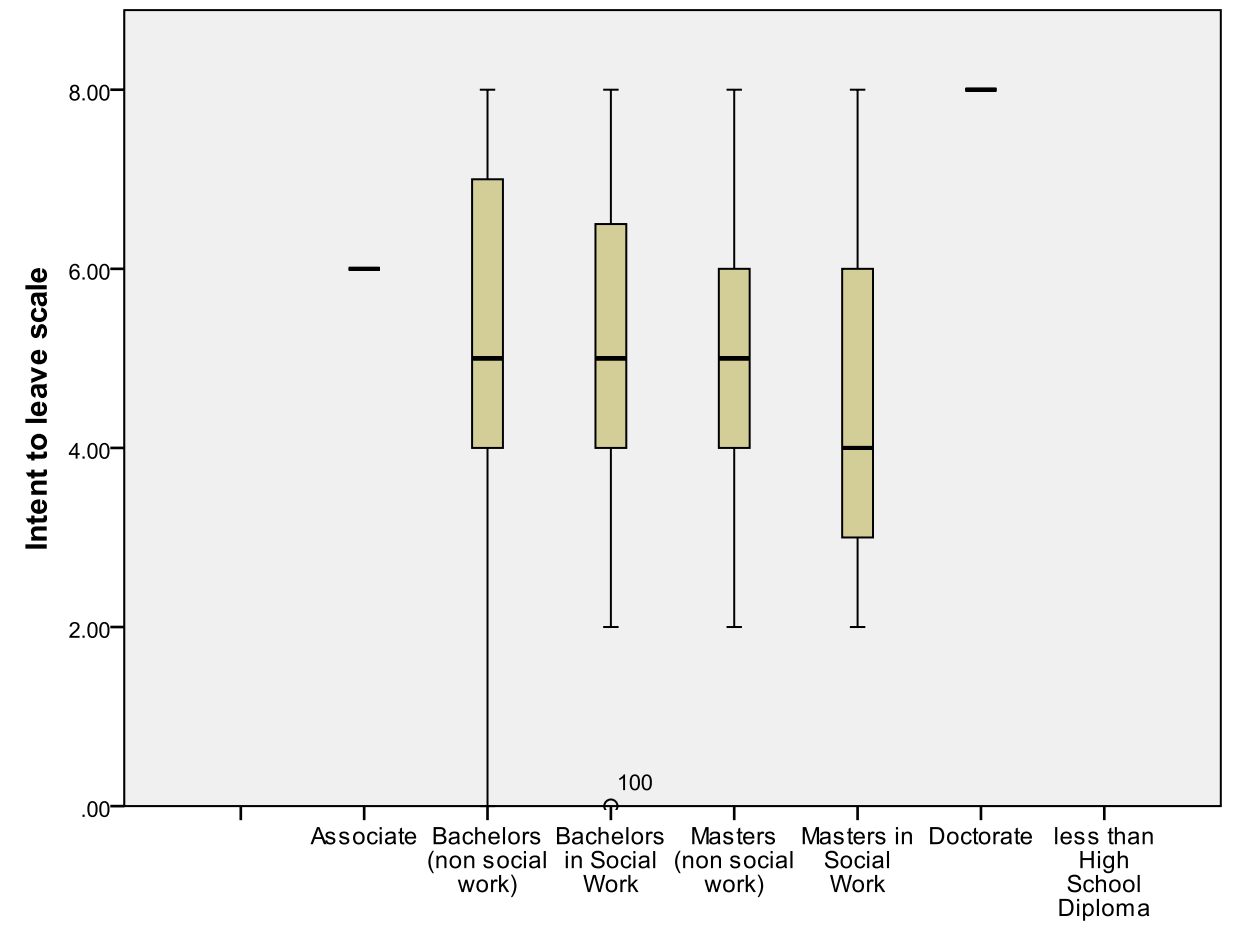

What is your highest degree? 


\title{
CHAPTER VII
}

\section{FINDINGS, IMPLICATIONS, LIMITATIONS, AND DISSEMINATION}

\author{
Major Findings
}

This study investigates the relationship of culture and climate, supervisor satisfaction, job readiness, and job role with intent to leave. Findings support that climate and culture, supervisor satisfaction, and job readiness all have significant roles in intent to leave for workers who are exiting for preventable reasons.

Foremost, this research reveals that the child welfare organization has a significant impact on the wellbeing of workers who are called upon to serve the most vulnerable children and families in our community, an issue that must be addressed to ensure workforce stability and provide services. Lambert, Cluse-Tolar, Pasupuleti, Hall, \& Jenkins (2005) express this sentiment clearly, "Social service employees deserve organizational justice, especially in light of the fact that they are called upon to deliver social justice to the clients and public they serve."

Climate and Culture. The research findings demonstrate that organizational climate accounts for approximately $25 \%$ of the variance in intent to leave for workers who will eventually leave for preventable reasons. Organizational culture accounts for approximately $13 \%$ of the variance of intent to leave. However, the shared effects of climate and culture account for $23 \%$ of variance in intent to leave, which suggests a strong shared relationship between climate and culture constructs. Workers who are 
likely to express intent to stay or leave due to climate are the same workers who express intent to stay or leave due to culture, and climate more strongly predicts intention to stay or leave.

The climate measure suggests that role clarity and emotional exhaustion make the strongest significant contributions to variance in intent to leave. Role clarity includes statements about getting clear work feedback and knowing where to go for help, as well as having a clearly defined role and knowing what is expected of you. This is an area for continued research and attention. Glisson \& Hemmelgarn (1998) have identified role clarity, along with personalization and low conflict, as key indicators of organizational functioning. Lawson and colleagues have additionally identified clarity of practice as a significant hallmark of lower-turnover child welfare counties (Lawson et al., 2006). Emotional exhaustion measures feelings of being over extended and exhausted by work (Maslach, Schaufeli, \& Leiter, 2001); it is thought to be the precursor to depersonalization of clients and reduced feelings of personal accomplishment (Matheny, Gfroerer, \& Harris, 2000), and burnout is linked in multiple studies to intent to leave in child welfare populations (Maslach et al., 2001) and has dangerous contagious effects on others in the workplace (Bennett, Plint, \& Clifford, 2005).

Research by Glisson et al. indicates that climate has the most significant impact on outcomes of children (2008). Fortunately, climate is thought to be easier to affect than the more rigid culture of an agency (Glisson \& Green, 2005; Glisson, 
Dukes \& Green, 2006). This dissertation research indicates that climate explains much of a worker's eventual intent to leave. The climate findings also suggest special attention to advancement issues; workers indicate that the construct of advancement and feelings about how well the agency rewards expertise are both significant independent contributors to variance in intent to leave. This supports previous findings that link advancement opportunities to intent to leave in child welfare populations (ie Institute for the Advancement of Social Work Research, 2008; Pecora, Whittacker, Maluccio, \& Barth, 2000). This study's measure of advancement resulted in a high reliability score (.821) for Cohen's Alpha (2003). Previous studies (i.e. Westbrook, Ellett, \& Deweaver, 2009) found advancement to be amongst those constructs difficult to conceptualize in a child welfare worker population. Thus, this study offers a unique contribution to measuring constructs in this group.

A surprising finding is that the autonomy scale, as conceptualized in the original survey and developed from the review of literature, offered a poor reliability score and was not correlated to intent to leave. Previous research suggests that child welfare organizations provide a bureaucratic system of monitoring work that does not allow workers with advanced training to make independent case decisions (i.e. Annie E Casey Foundation, 2003). Although a single item from the autonomy measure was used in the culture scale, and did make a significant independent contribution to variance in the culture regression model, more exploration should be done into the meaning of this finding, and other measures of autonomy explored. 
It is expected that findings for climate (how work impacts an individual) explain more variance than the culture measure because workers are more comfortable reporting scores at the extremes of the scale related to how work impacts them versus how it impacts others in the organization, and also because the climate measure spans a wider range of variables. These are issues for future research consideration.

Supervisor Satisfaction. The research findings demonstrate that satisfaction with supervision does have a significant impact on a worker's intention to stay or leave. Supervisor satisfaction is one component of organizational climate, and has a role in what it feels like to work in the child welfare organization. Although supervision does not offer the strongest independent contribution to variance in intent to leave, it does play a role. The analysis suggests that $9 \%$ of variance in supervisor satisfaction and intent to leave is shared for workers who intend to leave the agency for preventable reasons. The findings reveal that workers prioritize competent supervision over supportive supervision, but both types of supervision are significantly associated with a worker's intention to leave.

Overall, workers were more satisfied with supervision than was expected. On a scale of $0-5$, with a score of 0 indicating "strongly agree" with questions related to supervisor satisfaction and competence, respondents had an overall score of 1 . If workers were less satisfied with supervision, perhaps more variance in intent to leave would be explained. However, this finding indicates that even workers who are 
relatively satisfied with supervision are still dissatisfied with organizational variables to the extent that it influences their intent to leave.

Job Readiness. The research findings demonstrate that workers who perceive that they understood the job role before they took it are less likely to express intent to leave. This is no different in new workers than long-time workers. The job readiness and intent to leave measure share variance of about $6 \%$ in workers who eventually intend to leave for preventable reasons. Although job previews are increasingly offered to child welfare workers, there has been little empirical support for the need of this intervention in this specific population. This research supports continued interventions in the area.

Job Role. Findings from this study demonstrate no differences in intent to leave or emotional exhaustion in protective services workers versus ongoing case workers. Little research has been done around differences in job role in this specific population, and these results are significant in improving what is known about the child welfare workforce and how to best target services that improve organizational culture and climate.

\section{Implications for Child Welfare Administrators}

It is exhausting to continually have new people in our workplace. Just when you think it is all going smoothly people leave. It is difficult for families as even under the best circumstances families can be left for periods of time without their own worker to stay on top of their case. There is more often significant discord and dropped balls when cases 
have been transferred repeatedly to new workers due to turnover. Oregon Child Welfare Worker

Culture and Climate. Agency administrators can reduce preventable turnover and increase organizational justice by improving organizational culture and climate. Administrators should prioritize exploring workers' needs for opportunities for advancement and growth. Workers should feel that the organization cares about their development and wellbeing. One worker who participated in this study shares, "I would like offsite time for truly motivational and clinical training and self care. I'd like a chance for teambuilding with coworkers, and to attend regional conferences pertaining to my field of casework." This research indicates that workers want to work in an agency that rewards personal development and expertise. Many workers shared similar feedback about advancement and career ladders:

There is no middle step for caseworkers to get promotions. In addition, I often feel that I am being given more work by my supervisor for being a competent employee, but also being held back from opportunities I request as it may take away from my casework responsibilities. I am being told I am a competent caseworker and still am not able to pursue opportunities for myself that would encourage professional development.

Oregon is one of several states that has no structured career ladder within the caseworker role, and offers no compensation or advancement for workers with advanced degrees. A 2001 APHSA survey of 43 states indicated that two thirds of states had career ladders within the CPS and direct services roles for child welfare workers (2004). Several respondents of this survey 
indicated they believed initiation of career ladders was helpful with recruitment or retention efforts.

Additionally, these findings suggest that administrators should improve role clarity for workers by ensuring they receive clear feedback about their performance, know where to find answers, and have clear expectations about their roles and priorities.

A caseworker offers this feedback: (There are) inconsistent policy changes, changes to court report forms and guidelines and such, on going --nothing is consistent. One person states that you have to do it a certain way, then they turn around and allow exceptions to the same policy -- it's irritating.

Role clarity was more highly correlated with intent to leave than any other scale (.41).

While performance appraisals may be a neglected paperwork burden, this is one opportunity for workers to get valuable feedback about their performance, including opportunities for growth and advancement and clarification of performance priorities. One worker shares, "I have been working here for five years and have only had one employee evaluation, and that was when I passed probation. ” Additionally, some research indicates that workers can better handle high-pressure jobs when role clarity is improved (Bliese \& Castro, 2000).

Agency administrators interested in improving workforce stability can continue to advocate for reasonable workloads to increase justice for their 
workers so that workers can advocate and serve their clients. Workers endorse high levels of emotional exhaustion in relationship to intent to leave, which includes feelings of being drained by their work. Some workers who participated in the survey shared qualitative feedback about feeling blamed for their exhaustion and stress:

I have worked at the same branch for several years. I and other coworkers have been told by supervisors and the branch manager during times of great stress statements such as 'maybe PS just isn't for you' or 'this is the cold hard reality of PS.' The preceding have been said in terms of job performance rather than commiseration about how hard the work, or more aptly, the work demands can be. When good workers leave, management simply feels that they were 'burnt out' rather than putting time and energy into making the job of PS more doable. As workers, we are consistently told that this job is 'doable' and that we just need to work better/faster/ect... THIS IS NOT TRUE!!!

The findings from this survey that link emotional exhaustion to job exit are supported by previous research (i.e. Potter et al., 2009; Maslach et al., 1996). This research finds that role overload is highly correlated to emotional exhaustion (.54), and research supports that role overload leads to exhaustion (Yip \& Rowlinson, 2009; Pasupuleti, Allen, Lambert, \& Cluse-Tolar, 2009). Reducing turnover allows agency funds to be redirected toward goals of lowering caseloads, and presents an opportunity for significant savings in Oregon. One quarter of Oregon child welfare workers who participated in this study anticipate leaving the child welfare agency within the next two years. Administrators charged with making an efficient use of agency resources can explore the prevention of costly workforce turnover as a way to meet cost- 
saving goals. Reducing turnover would likely have effects that include reduced caseload sizes, beneficial outcomes for families, and increased worker satisfaction (Cornerstones, 2006).

Rapid Process Improvement, a philosophy recently adopted by Oregon Department of Human Services as part of the Transformation Initiative, calls for regular and continued assessment of work processes and includes a goal of boosting worker morale (DHS, accessed 2010). One way to meet this goal is to dedicate resources to continued assessment of factors such as organizational climate and culture, and using the results to make organizational changes. Although surveys may seem time consuming for workers, they offer an opportunity for participation in the change process and raises awareness about organizational well-being. Surveying workers, and sharing the survey feedback with workers, becomes part of an intervention process. One survey respondent shares, "I would recommend offering these surveys to workers on a regular basis. " However, workers want to know how surveying is used to improve the workforce. Several workers share frustration with not hearing about how their survey results impact system change. For example, one caseworker shares, "We have had several surveys and I imagine the same sort of questions are asked on each. We give the same answers and express the same concerns, but nothing changes and we get more surveys asking for our input." 
Supervision. The research findings from this study indicate that task supervision and expertise are valued by workers and influence workers' intent to leave. Although previous studies indicate that workers tend to be slightly more impacted by clinical supervisor qualities (Gibbs, 2001; Jacquet et al., 2007), the way the supervisor variables were conceptualized in this study demonstrates that supervisor competency has a slightly higher correlation with intent to leave than tasks that are thought to be more clinical in nature (correlations are most significant for questions related to "expert help" and "reasonable expectations"). Oregon has recently invested in training for supervisors to increase their capacity for clinical supervision, which is an intervention supported by existing research (e.g. Landsman, 2007; Gibbs, 2001; Bride et al., 2003). Findings were significant for the value of a supervisor's skill in supporting teamwork within a unit. Supervisor training should incorporate these types of skill building as well as providing clinical support.

Job Readiness. This research suggests an inverse relationship between intent to leave and job readiness, and supports previous findings in this area (Jordan Institute, 2008). Agency administrators should consider the use of a Realistic Job Preview or consider other ways of providing clear expectations about the role of a child welfare worker prior to hire. Realistic Job Previews have been employed as part of an internet application video hosted on a website, and also as a site-based pre-interview video in some child welfare agencies. The relationship between realistic understanding of the job and intent to leave suggests that spending money on Realistic Job Preview tools 
may be a fiscally useful investment, given the costs associated with turnover.

Although there was an expectation that job readiness would have greater impact for early-career workers, this was not a supported finding. Survey feedback from workers indicate that they would like greater investment in screening workers,

Within my domain, protective services, a worker will often require 12-18 months to reach a level of proficiency and comfort with the work. When staff who have recently been hired leave, or long-time staff depart because they do not feel valued, this leaves a huge hole in the unit's cohesion and often leads to breakdowns in communication, morale, and productivity. I am often amazed at how tone-deaf management is with regard to the impact changes they make will have on units. Improving management training on interviewing, hiring, and coaching employees would be of benefit here.

Job role. This evidence does not support a differential intervention need for

worker retention based on job role. It is likely that protective services workers and ongoing case workers experience many of the same organizational-level needs and stressors. Continuing attention should be given to improving organizational issues for workers in all job roles. Although there is limited research on the effect of job role on turnover in the child welfare population, some previous research indicates higher turnover for investigative roles (Jordan Institute, 2000; APHSA, 2004). This issue requires further exploration.

\section{Implications for Research}

Culture and Climate. The findings of this study indicate that workers are significantly impacted by issues of culture and climate. Additional work should be undertaken to perfect consistent measures of culture and climate through a systematic review of existing research. The tests of reliability used in this study provide valuable 
contributions from which to further consider measurement of constructs for child welfare. Reliability for measures of burnout in this population closely matched those of wide international samples studied by Maslach, Jackson, \& Leiter (1996). Reliability of other constructs used in this measure is better, in some cases, than those used in other culture and climate measures. For instance, the advancement scale was much more reliable in this measure than that used in a large sample of child welfare workers (Westbrook et al., 2009).

This survey establishes the connection between organizational variables and intent to leave, and supports previous findings that suggest the same. Continued research is necessary to establish effective interventions that address organizational issues in an empowering and accessible way, especially in child welfare organizations where resources are limited and workers are often overburdened.

Supervision. This research supports the work of several studies (e.g., Gibbs, 2001; Jacquet et al., 2007; Rycraft, 1994; Scannapieco \& Connell-Carrick, 2007), that indicate supervisors play an important role in the support and retention of child welfare workers. Further research is needed to explore what specific supervisory tasks best support worker retention, and what interventions are successful in improving retention in longitudinal studies. Although the afore-mentioned studies suggest that clinical supervision is most important, the findings from this research slightly favor the highly knowledgeable supervisor as playing a role in reducing turnover intentions. This study supports previous research findings (ie Nissly, Mor Barak, \& Levin, 2005) 
that supervisor support is more important than peer support in impacting intent to leave. Further research should explore interactions between supervision and other variables, and analyze pathways between supervision and burnout and satisfaction with intent to leave.

Job Readiness. Future research should investigate whether job preview interventions are successful by using control groups and/or longitudinal studies to explore the effects of job readiness on intent to leave. Little empirical support for the use of Job Preview tools exists in child welfare populations, but the results of this study, and research in other fields (Breaugh, 1983; Buckley et al., 1998; Wanous, 1973), supports continue research and interventions in this area. Findings also support the intervention work being done in some child welfare agencies. This study also finds a high correlation between job readiness and role clarity (.46), an association that should be explored further.

Job role. There is little known about the different experiences of workers based on job roles. In a review of the literature, it appears that often many types of workers are examined together. Researchers should continue to explore the impact of job role on various outcome variables to better understand the needs of the workforce.

Implications for Social Work Education

Culture and Climate. Social workers tend to be well-educated in ways of dealing with clients and the difficult barriers they face. The social work curriculum places less emphasis on navigating difficult bureaucratic systems as an employee, 
advocating for reasonable caseload sizes and work expectations (as would be indicated by findings related to emotional exhaustion and supervisor satisfaction in this research), or using empowerment theory to help the workforce collaborate for system change. This focus in social work education would raise the level of conversation about organizational change in a personal way that affects workers whether they choose micro or macro paths, and at the same time raise awareness about issues of organizational social justice and the parallel benefits of service to clients.

Supervision. Social workers often rise to levels of leadership in child welfare agencies, and should be educated in issues related to effective supervision practices and the links between supervision and turnover. Education about the value of effective supervision can also prepare social workers to advocate for supervision within their agencies. When offered evidence about the links between supervision and turnover, such as the research findings of this study, it becomes easier to justify the investment of agency resources in supervision and training.

Many BSW and MSW-educated workers, especially in the child welfare field, will move on to positions of increasing responsibility. It is important for these workers to understand the impact of the organization on employees and be knowledgeable in interventions that create organizational change in a way that is empowering and supportive. These workers have the potential to impact future worker turnover, and should understand the links between supervision and intent to leave. Although workers are trained in broad policy issues and macro contributions to human behavior, issues 
related to organization and supervision skills are often relegated to elective coursework.

Job Readiness. Approximately $50 \%$ of workers in this sample have either a BSW or MSW degree (see Table 8). However, most of these students were not recipients of child welfare related tuition assistance, and may have had limited exposure to child welfare prior to entering the field. Given that half this sample has a social work degree, efforts should be made to introduce the roles and a realistic job preview for child welfare to all social work students, at least in a cursory way. The National Association of Social Workers (NASW), suggest that child welfare administrators and supervisors have MSWs and that case workers have BSWs at minimum (NASW, 2008). Realistic job preview videos are often only an hour in length. Workers in a variety of professions will serve in roles as mandated reporters and would benefit from knowledge about the role and work of child welfare workers. It may also broaden the perspective of students about the types of work that child welfare workers perform and open the opportunity of considering this profession to those who had negative feelings about the work.

The links between job readiness and intent to leave are supported by research in other fields, and these findings may suggest that realistic job previews are likely good training tools for agencies that are major employers of social workers. Because child welfare organizations do not always have the expertise or funding for projects 
such as Realistic Job Previews, there may be opportunities for universities to partner in the creation of Realistic Job Preview tools.

Job Role. Social work students who are interested in child welfare may assume that there is a difference in the amount of burnout or stress between protective services or ongoing case management roles. This research is contrary to practice wisdom and does not support that idea. Social work students who are considering child welfare should know that the effects of organizational well-being are similar across these job roles.

\section{Limitations and Strengths}

Interpretation of findings must take in to account several limitations and strengths of these data, beginning with the size and composition of this particular sample. This was a convenience sample that consisted of many, but not all, regions in Oregon. An average of $30 \%$ of workers opted to take the survey, but it is unknown how their personal perspectives on issues related to retention and organizational issues influenced whether they took the survey.

Investigator Bias. This study was specifically designed to focus on organizational issues in child welfare, with an assumption that these factors have greater impact on worker retention than personal demographic factors. This assumption is based partly upon this investigator's personal experience working in the child welfare field and bias toward providing better support to child welfare workers. A background in child welfare social work biases this investigator towards 
empowerment and system perspectives for understanding this complex problem. Additionally, as a participant in the original Oregon Child Welfare Workforce research team, I am an insider to the survey design, which offers a nuanced perspective of the original survey. These issues are mitigated in part through review by the dissertation committee.

Survey and Data. This study relies on secondary data of a pilot survey that has not been previously analyzed. In most secondary research analyses, some reporting about the sample has been done previously. However, this is an original analysis of secondary data. The tool has not been tested or normed outside of this analysis. The items on the tool are meant to be exploratory, and the actual relationships between the items and the constructs have not been established in this particular survey, although face validity exists based upon an extensive literature review. The survey was delivered over several months and not at a single point in time for all respondents. At least one Service Delivery Area that was experiencing organizational difficulties and media scrutiny opted out of the survey, which may skew results. Despite these drawbacks, little is known about the population studied in this survey, and the information contributes to new knowledge generation. The pilot survey analysis allows for further survey refinement in the future.

Although participation was anonymous, about $10 \%$ of workers opted to skip questions that were potentially controversial, related to their experiences with depersonalization and exhaustion. It is likely that they skipped these questions due to 
strong feelings related to the issue, and their responses would have likely affected the data. This knowledge allows future researchers to study whether additional or different questions could be asked in the future to address issues of depersonalization or exhaustion, and suggests it may be beneficial to explore whether respondents feel secure in measures taken to address confidentiality.

As is the case with much correlational research, mediating and moderating variables were not explored in this analysis. It is unknown whether constructs such as emotional exhaustion are affected by constructs such as supervisor satisfaction, thus impacting intent to leave. Modeling could provide a more thorough examination of the paths of relationships between variables in future research. The exploratory nature of these data, as well as time limitations, did not allow for this type of analysis.

Although all the constructs were explored, and reliability was measured, the unique contributions of individual survey items were not explored in this analysis. It would be of interest to explore the individual impact of each question on each of the scales in future analysis. Although it would provide no additional information to the findings of this analysis, it would be useful to conduct a factor analysis to see if items can be eliminated before the survey is used again. These are tasks best left to survey refinement, which was not the main goal of this analysis.

Methodology. This study draws from the existing research and literature, but suffers from several of the same barriers as past child welfare workforce research. The limitations pertain to the non-random convenience sample and external validity, the 
survey design's impact on internal validity, and limitations created by the type of data collected.

These data were collected at a single point in time, and rely on the report of the respondent who shares conditions about the work environment. From a constructivist perspective, the data collection method would be recognized as flawed, as an everchanging environment cannot be measured at a single point in time, and it is impossible to measure a shared perspective of "culture" or "climate." This survey did not account for the systems exchanges at many different levels of individual to community and society. Linear data collection tools used to collect and analyze these data only begins to suggest a roadmap, and is not a definitive guide for solving the problem of worker turnover. Multiple methodologies and perspectives are useful when exploring such a dynamic issue. This research provides a starting point for considering the topic from other methodological perspectives.

Web-based surveys pose a limitation in that a person who is more technologically inclined might be more likely to take a survey. This also potentially introduces an age selection bias, as users more adept at technology may be more likely to be young, thereby reducing internal validity. Additional problems include technology errors, and a computer crash or survey issue could cause a data loss that would never be known by the researchers. However, child welfare caseworkers perform much of their work on computers now, and computer-based data collection is 
the primary method for inputting case information, so the impact of this limitation is likely small.

Computer-based surveys cannot afford all the opportunities of an in-person interview. Workers were not able to explain their answers, and in many cases were not offered the option of an "other" response. There were limited options by way of openended questions to explain meaning. Although time constraints did not allow for further qualitative review, follow-up qualitative interviews would likely better explain some of the responses received.

This is a cross-sectional design. There is no experimental group, and no pre/post tests were administered. The design would benefit from a longitudinal study that polls workers over time using multiple data collection methods, offers interventions, and tracks other organizational impact factors, such as policy/administration change or change in the political climate, all which are expected to impact the culture and climate of the workplace, as well as workers' feelings about intent to leave the agency, and only captures a single moment in time. All the data was collected directly from workers, thus no triangulation of data support the perception of the workers, and the survey relies on the worker's ability to report information. This pilot could be the start of regular polling for DHS workers, and offers a valuable starting point.

The constant change of policy and practice in child welfare makes it difficult to determine the effects of confounding variables. While this survey was taking place, 
the State of Oregon was engaged in a roll-out of a new child welfare safety model. Some workers have expressed frustration or appreciation for the new model, which may also affect survey outcomes. Other extraneous variables to the design include budget shortfalls, changes in the local mental health service delivery system, other research being conducted, a hiring freeze/slow down, and new supervision training. Locally, issues such as a child's death, negative media coverage, high-profile cases, or management changes also impact the experiences of workers. Invariably, there were other issues that escaped attention of the research team who collected the data. Future qualitative research may be able to capture some of the external forces that were unnamed in these data.

Some irony comes with the fact that workers, who are overwhelmed with their current responsibilities, were asked to take on the additional task of completing an online survey. It could be that workers who felt the most passion about the issue were more likely to complete the survey, or just as likely that those most impacted by the issues presented in the survey were less likely to find time to complete it. Because of how little is known about workers in Oregon, it is very difficult to determine whether the sample of workers who participated in this survey are representative of the workers in the target population.

The Oregon Child Welfare Workforce questionnaire relied mostly on practice experience and a literature review. Some questions were borrowed from the literature, but most have not been normed to a population, and there are no scores with which to 
compare the outcomes. This survey would benefit from a factor analysis and further testing and exploration of the measure to improve the construct validity, and indeed the Child Welfare Partnership intends to take some of those steps. They were not possible to explore within the context of this dissertation because this would require longitudinal testing over several years, which falls outside of the time limitations of this dissertation research.

Generalizability. To generalize these findings to workers outside of Oregon poses problems, in that each state has different criteria for minimum education, offers different benefits, and has different organizational configurations. Many states do not have state-run systems like Oregon, and findings may be significantly different in states with county-administered or private-sector child welfare programs. Additionally, this sample did not contain much diversity in race and ethnicity; reflective of the population demographics in Oregon. It is unknown how race and ethnicity impact findings related to workforce retention; thus, generalizability is further limited.

Much of the research in organizational culture and climate has investigated agency employees' shared perceptions of culture and climate within a particular office setting, and compared those across other settings in the region. This study looked at individual-level experiences with culture and climate. There is a theoretical assumption that culture, and to a lesser extent, climate, are shared experiences within an organization. It is unknown whether this is true in this sample. This would be an 
interesting viewpoint from which to explore the dependent variable. Other researchers, such as Lawson et al., (2006) and Glisson et al. (2006), have studied and designated regions as either having high functioning or low functioning culture and climates, and have mapped job exit from these agencies based on their designation. However, because of the small number of child welfare caseworkers who work in some Oregon offices, as well as the number of offices spread across the state, it would be very difficult to collect and compare office-based climate and culture demographics. These data did not provide information about the specific office in which the worker is employed.

Unfortunately, the timeframe for this research did not allow a more active participation of those that are most impacted by its results. Ideally, child welfare workers and other stakeholders would have greater involvement in the design, dissemination, ownership, and use of results. Future dissemination plans that will be carried out by the Child Welfare Partnership will work to make this information as accessible and useful as possible by those most affected.

There was a relatively high response to this survey, which suggests that workers are willing to continue to share feedback about their experiences. The survey itself hopefully becomes an intervention in raising awareness about organizational issues that affect workers. This research was the first to explore the data collected by the Workforce Survey, and found the measures were generally reliable and consistent with similar research across the nation. Oregon managers were generally agreeable to 
allowing workers to reflect upon their work environment in this type of survey, which opens a door to future collaboration, consideration, and intervention. The expected hypotheses were generally well supported. The knowledge gained is significant in its contribution to the current literature in this field.

\section{Dissemination Planning}

The goal of this dissertation research is not only to create findings that are significant to scholarship, but also that are applicable to the field. The findings of this research will assist Portland State University's Child Welfare Partnership in providing feedback to the child welfare agency and local stakeholders. The data from this dissertation will be used by the Child Welfare Partnership to develop White Papers, and be shared with other scholars conducting similar research. Outcome data from this dissertation can be paired with interventions in the literature that have been proven successful for tackling identified problems so that this research can support action planning within local agencies.

Follow-up research is planned by this author, including further qualitative exploration of these dissertation findings. The analysis will be shared through publication and presentation at social work and child welfare conferences.

\section{Conclusion}

Workforce turnover is a significant and costly problem in child welfare nationally. This study was designed to address this important problem through the lens of social work's most central theory bases (systems theory and empowerment theory) 
by investigating the impact of organizational issues on retention of Oregon's child welfare case workers.

As the literature review in Chapter III demonstrates, much of the research on this problem has focused on individual worker traits and interventions that 'fix' (and by implication 'blame') workers. For example, previous research has studied worker burnout or vicarious trauma, or a worker's level of training. Systems theory would predict that aspects of the organizational system such as culture and climate, not just individual traits such as burnout or education, would impact worker behavior and intent to leave. Empowerment theory would suggest intervening by engaging workers in finding solutions. The statistical analyses revealed significant findings; as expected, a worker's perception of organizational conditions does impact the worker's intention to leave the agency.

Systems theory and empowerment theory, within an ecological framework, predict the behavior of workers as they consider whether they will maintain employment as case managers in child welfare. In Oregon's child welfare system, systemic characteristics, specifically culture and climate, have impact on the behavior of individual members of the system, and specifically child welfare workers. Up to a quarter of workers who plan to leave the agency report that organizational climate or culture impact their expected employment longevity. Additionally, workers' perceived access to resources and support impacts their expectation of how long they will stay at the agency, as explained by empowerment theory. 
The first research question asked whether organizational culture affects caseworkers' intention to leave in Oregon's public child welfare system, and what organizational culture issues most impact caseworkers' intention to leave. This research found that amongst workers who intend to leave the agency for preventable reasons, a worker's perception of how things are done within the agency predicts how likely a worker is to stay in $13 \%$ of cases. The strongest unique predictor was whether the agency is perceived to reward worker expertise, although all items in the culture scale were correlated with intent to leave in the expected directions. The higher a worker's satisfaction with workplace culture, the less likely they were to report intent to leave.

Secondly, this dissertation research explored whether climate affects caseworkers' intention to leave in Oregon's public child welfare system, and what organizational climate issues most impacts caseworkers' intent to leave. This analysis found that, amongst workers who intend to leave the agency for preventable reasons, a worker's perception of how it feels for them to work within the organization predict how likely a worker is to stay in $25 \%$ of cases. Role clarity, role conflict, and emotional exhaustion are all uniquely significant predictors of this model. Advancement also contributes to a worker's decision to stay or leave. The higher a worker's satisfaction with organizational climate, the less likely they are to intend to leave. 
This research analyzed whether workers' intention to leave is impacted by their satisfaction with supervision. The data analysis found that supervisor satisfaction is linked to intention to stay or leave. The research found that Oregon workers, on average, agree that their supervisors provide good support. The more satisfied workers are with supervision, the less likely their intent to leave. A worker's satisfaction with supervision predicts intent to leave in $9 \%$ of cases. A worker's perceptions that their supervisor encourages mentorship amongst employees, reinforces training, provides expert help, and has reasonable expectations are the supervisor-related questions that were most highly correlated with intent to leave. The construct of task supervision was found to be slightly more predictive of intent to leave than the construct of clinical supervision.

This research also explored whether workers who perceived that they had greater knowledge of what child welfare work entails before being hired was related to intent to leave. The analysis found that workers, indeed, have greater intent to stay at the agency if they report they understood the role of a child welfare worker prior to accepting the position. A worker's perception of job readiness predicted intent to leave in $6 \%$ of cases. Although it was expected that correlations between a worker's experience of job readiness and intent to leave would be strongest in early-career workers, this was not found to be the case. The correlation between job readiness and intent to leave in workers with less than two years experience is no different than workers with more than two years of experience. 
Finally, this dissertation investigated whether protective services investigators differed from ongoing caseworkers in intent to leave. In a break from conventional wisdom, this analysis found no difference in intent to leave between workers in these job roles. Workers in each of these two job categories expressed similar intent to leave. Amongst all workers who say they are leaving for preventable reasons, $46 \%$ plan to do so within two years, and $71 \%$ plan to leave within five years.

Workplace culture and climate do offer unique contributions to a worker's commitment to the agency. Qualitative feedback from workers, as well as the rate of participation in the voluntary survey from which this research data was collected, support the theory that workers want to be included in organizational system monitoring.

Scholars interested in culture and climate in the child welfare workplace have much to learn about the complex system issues that impact the organization and how to best address the dynamic problem of workforce turnover. This research supports continued investigation in to organizational impacts on worker turnover.

These research findings offer good news to child welfare advocates and administrators. These data support that agencies are not powerless to high worker turnover. There are clear ways to elicit information from workers about what organizational factors most need attention. Organizational interventions supported by the literature include targeted measures to address specific organizational problems, such as satisfaction with role clarity, career ladders, or supervision. Additionally, 
agencies can improve retention by educating potential employees about the roles and responsibilities of a child welfare caseworker, and a realistic job preview may help prepare and screen workers. Tertiary benefits to improving workforce retention likely include cost-savings, improved morale, and improved outcomes for children and families served by the agency. Caseworkers are best equipped to answer the questions about what will make them want to remain on the job, and a growing pool of research indicates that committed workers who stay are best equipped to meet agency goals of child and family well-being in the community. 


\section{REFERENCES}

American Public Human Services Association. (2005). Report from the 2004 child welfare workforce survey. Washington, DC: American Public Human Service Association. Retrieved from http://www.aphsa.org/Home/Doc/Workforce\%20Report\%202005.pdf.

Anderson, D. (2000). Coping strategies and burnout among veteran child protection workers. Child Abuse \& Neglect, 24(6), 839-848.

Anderson-Butcher, D., Lawson, H., \& Barkdull, C. (2002). An evaluation of child welfare design teams in four states. Journal of Health \& Social Policy, 15(3/4), $131-161$

Annie E. Casey Foundation. (2003). The unsolved challenge of system reform: the condition of the frontline human services workforce. Baltimore, MD: Annie E Casey Foundation. Retrieved from http://www.aecf.org/upload/publicationfiles/the\%20unsolved\%20challenge.pdf

Bales, R. F. (1950). Interaction process analysis. Cambridge: Addison-Wesley.

Barbee, A., Antle, B., Sullivan, D., Huebner, R., Fox, S., \& Hall, J. (2009). Recruiting and retaining child welfare workers: Is preparing social work students enough for sustained commitment to the field? Child Welfare, 88(5), 69-86.

Barber, G. (1986). Correlates of job satisfaction among human service workers. Administration in Social Work, 10(1), 25-36. 
Barker, R. L. (1995). The social work dictionary. (3rd Ed.). Washington: NASW Press.

Bednar, S. G. (2003). Elements of satisfying organizational climates in child welfare agencies. Families in Society, 84(1), 7-12.

Bennett, S., Plint, A., \& Clifford, T. (2005). Burnout, psychological morbidity, job satisfaction, and stress: A survey of Canadian hospital based child protection professionals. Archives of Disease in Childhood, (90), 1112-1116.

Bluedorn, A. C. (1981).The theories of turnover: Causes, effects and meanings. In S. Bacharach (Ed.), Perspectives in organizational sociology: Theory and research. Greenwich: Jai Press.

Bliese, P., \& Castro, C. (2000). Role clarity, work overload and organizational support: Multilevel evidence of the importance of support. Work \& Stress, 14(1), 65-73.

Breaugh, J.A. (1983). Realistic job previews: A critical appraisal and future research directions. The Academy of Management Review, 8(4), 612-619.

Breton, M. (2004). An empowerment perspective. In C.D. Garvin, L.M.. Gutiérrez, \& J. Galinsky (Eds.), Handbook of social work with groups. (pp. 58-75). New York: The Guilford Press.

Bride, B., Jones, J., \& MacMaster, S. (2007). Correlates of secondary traumatic stress in child protective services workers. Journal of Evidence-Based Social Work, $4(3 / 4), 69-80$. 
Bride, B., Jones, J. L., MacMaster, S. A., \& Shatila, S. (2003). The Tennessee child protective services supervisors' development project: Evaluating process, outcome, and the role of secondary traumatic stress and burnout. Professional Development, 6(1/2), 79-84.

Byrne, B. M. (1994). Burnout: Testing for the validity, replication, and invariance of causal structure across elementary, intermediate, and secondary teachers. American Educational Research Journal, 31(3), 645-673.

Buckley, M., Veres, J., Fedor, D., Wiese, D., Carraher, S. (1998). Investigating newcomer expectations and job-related outcomes. Journal of Applied Psychology, 83(3), 452-461.

Bureau of Labor Statistics. Annual total separations rates by industry and region, not seasonally adjusted. (2008). Washington, DC: Bureau of Labor Statistics.

Caringi, J., Strolin-Goltzman, J., Lawson, H., McCarthy, M., Briar-Lawson, K., \& Claiborne, N. (2008). Child welfare design teams: An intervention to improve workforce retention and facilitate organizational development. Research on Social Work Practice, 18(6), 565-574.

Chenot, D., Benton, A., \& Hansung, K. (2009). The influence of supervisor support, peer support, and organizational culture among early career social workers in child welfare services. Child Welfare, 88(5), 129-147.

Chernesky, R., Israel, M. (2009). Job expectations and intention to leave in a state child welfare agency. Journal of Public Child Welfare, 3(1), 23-39. 
Child Welfare League of America. (2001a). 2001 Salary Study. Washington, DC.

Child Welfare League of America. ( 2001b). The child welfare workforce challenge: Results from a preliminary study. In conjunction with Alliance for Children and Families and American Public Human Services Association. Washington, DC. Retrieved from http://www.alliance1.org/Research/Workforce\%20survey\%20results\%20\%20final.PDF.

Clark, S., Smith, R., \& Mathias, C. (2009). The 2008 California public child welfare workforce study. Berkeley, CA: University of California, Berkeley, School of Social Welfare, California Social Work Education Center.

Cohen, J., Cohen, P., West, S. G., Aiken, L. S. (2003). Applied multiple regression/ correlational analysis for the behavioral sciences (3rd ed.). Mahwah: Lawrence Erlbaum Associates.

Cornerstones for Kids. (2006) Relationship between staff turnover, child welfare system functioning, and recurrent child abuse. Retrieved from Cornerstones for Kids Web site: http://www.cornerstones4kids.org/images/nccd_relationships_306.pdf.

Cox, E. (1988). Empowerment of low income elderly through group work. Social Work with Groups, 39(3), 262-268. 
Daly, D., Dudley D., Finnegan, D., Jones, L., \& Christiansen, L. (2000, June). Staffing child welfare services in the new millennium. San Diego: Academy for Professional Excellence in Human Services.

Davies, M. (1977) Support Systems in Social Work. London: Heinemann Educational Books/Community Care.

DeVellis, R. F. (2003). Scale development: Theory and applications, Second Edition. Thousand Oaks: Sage Publications.

Dickinson, N., \& Painter, J. (2009). Predictors of undesired turnover for child welfare workers. Child Welfare, 88(5), 187-208.

Dorch, E. (2007). Costing Turnover in New York State County Social Services Systems. Albany: Social Work Education Consortium.

Dorch, E., McCarthy, M., \& Denofrio, D. (2008). Calculating child welfare separation, replacement, and training costs. Social Work in Public Health, 23(6), 39-54.

Drake, B., \& Yadama, G. N. (1996). A structural equation model of burnout and job exit among child protective services workers. Social Work Research, 20(3), 179-188.

Ducharme, L., Knudsen, H., \& Roman, P. (2008). Emotional exhaustion and turnover intention in human service occupations: the protective role of coworker support. Sociological Spectrum, 28(1), 81-104.

Ellett, A., Ellett, C., \& Rugutt, J. (2003). A study of personal and organizational factors contributing to employee retention and turnover in child welfare in 
Georgia: Executive summary and final project report. Athens, GA. University of Georgia School of Social Work.

Ellett, A., Ellis, J., Westbrook, T., \& Dews, D. (2007). A qualitative study of 369 child welfare professionals' perspectives about factors contributing to employee retention and turnover. Children and Youth Services Review, 29(2), 264-281.

Ellis, J. I., Ellett, A. J., \& Deweaver, K. (2007). Human caring in the social work context: Continued development and validation of a complex measure. Research on Social Work Practice, 17(1), 66-76.

Flowers, C., McDonald, J., \& Sumski, M. (2005). Review of turnover in Milwaukee County private agency child welfare ongoing case management staff Milwaukee, WI: Bureau of Milwaukee Child Welfare.

Folman, R. (2000). Assessing well-being among traumatized children in foster care: The reality behind the numbers. Paper presented at the Research Symposium on Child Well-being, September 21-22, Institute of Government and Public Affairs, University of Illinois.

Freire, Paulo. (1973). Education for critical consciousness. San Francisco: Harper.

Garvin, C. (1987). Contemporary group work, 2nd edition. Englewood Cliffs: Prentice Hall.

Gibbs, J. A. (2001). Maintaining front-line workers in child protection: A case for refocusing supervision. Child Abuse Review, 10(5), 323-335. 
Glisson, C. (2007). Assessing and changing organizational culture and climate for effective services. Research on Social Work Practice, 17(6), 736-747.

Glisson, C., Dukes, D., \& Green, P. (2006). The effects of the ARC organizational intervention on caseworker turnover, climate, and culture in children's service systems. Child Abuse \& Neglect, 30(8), 849-880.

Glisson, C., \& Green, P. (2006). The effects of organizational culture and climate on the access to mental health care in child welfare and juvenile justice systems. Administration \& Policy in Mental Health, 33(4), 433-448.

Glisson, C., \& Hemmelgarn, A. (1998). The effects of organizational climate and interorganizational coordination on the quality and outcomes of children's service systems. Child Abuse \& Neglect, 22(5), 401-421.

Glisson, C., \& James, L. (2002). The cross-level effects of culture and climate in human service teams. Journal of Organizational Behavior, 23(6), 767-794.

Glisson, C., \& Schoenwald, S. K. (2005). The ARC organizational and community intervention strategy for implementing evidence-based children's mental health treatments. Mental Health Service Research, 7(4), 243-259.

Graef, M., \& Hill, E. (2000). Costing child protective services staff turnover. Child Welfare, 79(5), 517-533.

Gray, W., \& Rizzo, N. (Eds.) (1973). Unity through Diversity: A Festschrift for Ludwig von Bertalanffy. New York: Gordon and Breach Science Publications. Greene, Roberta. (1994). Human behavior theory. Piscataway: Aldine Transaction. 
Gunderson, D., \& Osborne, S. (2001). Addressing the crisis in child welfare social worker turnover. North Carolina Journal for Families and Children, (Winter), 2-6.

Gutiérrez, L. (1990). Working with women of color: An empowerment perspective. Social Work, 35(2), 149-153.

Gutiérrez, L (2001). Working with women of color: An empowerment perspective. Rothman, J., Erlich, J.L., and Troyman, J.E. (Eds.). In Strategies of Community Intervention. Itasca: F.E. Peacock Publisher, Inc.

Gutiérrez, L., \& Lewis, E. (1999). Empowering women of color. New York: Columbia University Press.

Hill, R.B. (2006). Synthesis of research on disproportionality in child welfare: An update. Washington, DC: Casey Center for the Study of Social Policy Alliance for Racial Equity. Casey/Center for the Study of Social Policy Alliance for Racial Equity.

Homans, G. C. (1958). Social behavior as exchange. American Journal of Sociology, 63(6), 597-606.

Hutchison, E., (2007). Dimensions of Human Behavior: Person and Environment. Thousand Oaks: Sage Publications, Inc.

Institute for the Advancement of Social Work Research. (2008). IASWR Child Welfare Workforce Initiative. Retrieved February 22, 2010 from http://www.aecf.org/upload/publicationfiles/hs3622h638.pdf 
Ivancevich, J., \& Matteson, M. (1980). Optimizing human resources: A case for preventative health and stress management. Organizational Dynamics, 9(2), 425.

Jacquet, S., Clark, S., Morazes, J., \& Withers, R. (2007). The role of supervision in the retention of public child welfare workers. Journal of Public Child Welfare, $1(3), 27-54$.

James, L., \& Sells, S. (1981). Psychological Climate: Theoretical perspectives and empirical research. In D. Magnusson (Ed.), Toward a psychology of situations: An interactional perspective. (pp. 275-450). Hillsdale: Lawrence Erlbaum Associates.

Jaskyte, K. (2005). The impact of organizational socialization tactics on role ambiguity and role conflict of newly hired social workers. Administration in Social Work, 29(4), 69-87.

Johnson, K., \& McIntye, C. (1998). Organizational culture and climate correlates of job satisfaction. Psychological Reports, 82(3), 843-850.

Jones, J. L., \& Cho, S. (2006). The impact of organizational culture on intention to remain in public child welfare: A case study in Tennessee. Professional Development, 9(2/3), 78-90.

Jones, M. (1993). Role conflict: Cause of burnout or energizer? Social Work, 38(2), 136-141. 
Jordan Institute for Families. (2008, March). The Recruitment and retention project. Retrieved from http://ssw.unc.edu/jif/rr/research.htm.

Kast, F., \& Rosenzweig, J. (1972). General systems theory: Applications for organizations and management, The Academy of Management Journal, 15(4), 447-465.

Katz D., \& Kahn R. (1966). The social psychology of organizations. New York: Wiley.

Keffer, C. (1984). Citizen empowerment: A developmental perspective. Prevention in Human Services, 3(2/3), 9-36.

Kirst-Ashman, K., (2008). Human behavior, communities, organizations, and groups in the macro social environment. South Melbourne: Thomson/Brooks/Cole.

Koeske, G., \& Koeske, R. (1993). A preliminary test of stress-strain-outcome model for reconceptualizing the burnout phenomenon. Journal of Social Research, $17,107-135$.

Kreitner, R., \& Kinicki, A. (2000). Organizational behavior. Dubuque: McGraw Hill. Lambert, E., Cluse-Tolar, T., Pasupuleti, S., Hall, D., \& Jenkins, M. (2005). the impact of distributive and procedural justice on social service workers. Social Justice Research, 18(4), 411-427.

Landsman, M. (2007). Supporting child welfare supervisors to improve worker retention. Child Welfare, 86(2), 105-124. 
Lauderdale, M. (1982). Burnout, strategies for personal and organizational life: Speculations on evolving paradigms. Austin: Learning Concepts. San Diego: University Associates.

Lawson, H. (2005). A theoretical foundation for design teams in public child welfare. Unpublished manuscript.

Lawson, H., \& Claiborne, N. (2005). Retention planning to reduce workforce turnover in New York State's public child welfare systems: Developing knowledge, lessons learned, and emergent priorities. New York State Social Work Education Consortium. Albany: University of Albany.

Lawson, H. A., McCarthy, M., Briar-Lawson, K., Miraglia, P., Strolin, J., \& Caringi, J. (2006). A complex partnership to optimize and stabilize the public child welfare workforce. Professional Development (10974911), 9(2/3), 122-139.

Lee, J. (2001). The Empowerment Approach to Social Work Practice. New York: Columbia University Press.

Luongo, G. (2007). Re-thinking child welfare training models to achieve evidencebased practices. Administration in Social Work, 31(2), 87-96.

McKinsey \& Co. (2008). Transformation Roadmap. Oregon DHS. Retrieved April 12, 2010, from http://www.oregon.gov/DHS/transformation/docs/roadmap.pdf.

McMichael, P. (2006). Development and social change: A global perspective. Routledge: Pine Forge Press. 
McMurtry, S., \& Rose, S. (2005). Workforce recruitment and retention in the bureau of Milwaukee child welfare: Results from staff surveys and focus groups. Helen Bader School of Social Welfare, University of Wisconsin-Milwaukee.

Martin, T. (1979). A contextual model of employee turnover intentions. Academy of Management Journal, 22(2), 313-324.

Maslach, C. (1976). Burned-out. Human Behavior, 9(5), 16-22.

Maslach, C., \& Jackson, S. (1981). The measurement of experienced burnout. Journal of Occupational Behavior, 2(2), 99-113.

Maslach, C., Jackson, S., \& Leiter, M. (1996). The Maslach Burnout Inventory (3rd ed.). Palo Alto: Consulting Psychologists Press.

Maslach, C., \& Leiter, M. (2008). Early predictors of job burnout and engagement. Journal of Applied Psychology, 93(3), 498-512.

Maslach, C., Schaufeli, W., \& Leiter, M. (2001). Job burnout. In S. Fiske, D. Schacter \& C. Zahn-Waxler (Eds.), Annual Review of Psychology (pp. 397-422).

Masternak, M. (2004). Realistic Job Preview: A review of the literature and recommendations for Michigan family independence agency. Retrieved from CPS Human Resource Services Web site: http://cps.ca.gov/ConsultingServices/HSRC/MIFIAAppendices/Append_G_FI A_CCHP_Realistic_Job_Preview.pdf. 
Matheny, K., Gfroerer, C., \& Harris, K. (2000). Work stress, burnout, and coping at the turn of the century: An Adlerian perspective. Journal of Individual Psychology, 56(1), 74-87.

Melé, D. (2006). Ethics in management: Exploring the contribution of Mary Parker Follett. Retrieved May 8, 2010, from IESE Business School: http://www.iese.edu/research/pdfs/DI-0618-E.pdf

Mills, C. W. (1959). The sociological imagination. New York: Oxford University Press.

Michigan State University School of Social Work (2007). Developing models of effective child welfare staff recruitment and retention training: A federally-funded child welfare training project at the Michigan State University School of Social Work. Retrieved from Michigan State University, School of Social Work Web site: http://socialwork.msu.edu/outreach/childwelfare.html.

Mitchell, T., \& Lee, R. (2001). The unfolding model of voluntary turnover and job embeddedness: Foundations for a comprehensive theory of attachment. In B. Staw \& R. Sutton (Eds.), Research in organizational behavior. (pp. 189-246). New York: Elsevier Science Ltd.

Mor Barak, M., Nissly, J., \& Levin, A. (2001). Antecedents to retention and turnover among child welfare, social work, and other human service employees: What can we learn from past research? A review and meta-analysis. Social Service Review, 75(4), 625-661. 
Mor Barak, M., Levin, A., Nissly, J., \& Lane, C. (2006). Why do they leave? Modeling child welfare workers' turnover intentions. Children and Youth Services Review, 28(5), 548-577.

National Association of Social Workers (NASW). (2008). Fast Facts. Retrieved March 30, 2008 from http://www.socialworkers.org/advocacy/updates/2003/082003_a.asp.

National Council on Crime and Delinquency. (2006). Job turnover in child welfare and juvenile justice: The voices of former frontline workers. Houston, TX: National Council on Crime and Delinquency. Retrieved March 30, 2008, from http://www.cornerstones4kids.org/images/nccd_voices_306.pdf.

Nissly, J., Mor Barak, M., \& Levin, A. (2005). Stress, support, and workers' intentions to leave their jobs in public child welfare. Administration in Social Work, 29(1), 79-100.

Oregon Department of Human Services (DHS). (2010). 2009 Child welfare data book. Portland, OR: Children, Adults and Families Division, Office of Program, Performance and Reporting. Retrieved from Oregon DHS Web site: http://www.oregon.gov/DHS/abuse/publications/children/2009-cw-databook.pdf.

Ostroff, C., Kinicki, A.J., \& Tamkins, M.M. (2003). Organizational culture and climate. In W.C. Borman, D.R. Ilgen, \& R.J. Klimoski (Eds), Comprehensive 
Handbook of Psychology, Volume 12: I/O Psychology (pp. 565-594). New York: John Wiley \& Sons.

Parkin, W., \& Green, L. (1997). Cultures of abuse within residential child care. Early Child Development and Care, 133(1), 73-86.

Parsons, T., Bales, R., \& Shils, E. (1953). Working papers in the theory of action. Glencoe: The Free Press.

Pasupuleti, S., Allen, R., Lambert, E., \& Cluse-Tolar, T. (2009). The impact of work stressors on the life satisfaction of social service workers: A preliminary study. Administration in Social Work, 33(3), 319-339.

Payne, M. (2002). The politics of system theory within social work. Journal of social Work, 2(3), 269-292.

Pearson, Q. (2008). Role overload, job satisfaction, leisure satisfaction, and psychological health among employed women. Journal of Counseling \& Development, 86(1), 57-63.

Pecora, P., Whittacker, J., Maluccio, A., \& Barth, R. (2000). The child welfare challenge: Policy, practice and research, second edition. Hawthorne: Aldine De Gruyter.

Perkins, D. D., \& Zimmerman, M. A. (1995). Empowerment theory, research and application. American Journal of Community Psychology, 23, 569-579. 
Peterson, N., Lowe, J., Aquilino, M., \& Schneider, J. (2005). Linking social cohesion and gender to intrapersonal and interactional empowerment: support and new implications for theory. Journal of Community Psychology, 33(2): 233-244.

Posner, B., \& Butterfield, D. (1978). Role clarity and organizational level. Journal of Management, 4(2), 81-90.

Potter, C., Comstock, A., Brittain, C., \& Hanna, M. (2009). Intervening in multiple states: Findings from the Western Regional Recruitment Project. Child Welfare, 88(5), 169-185.

Reilly, M. D. (1982). Working wives and convenience consumption. Journal of Consumer Research, 8, 407-418.

Rizzo, J., House, R., \& Lirtzman, S. (1970). Role conflict and ambiguity in complex organizations. Administrative Science Quarterly, 15(2), 150-163.

Rose, S. (1992). Advocacy/empowerment: An approach to clinical practice for social work. Journal of Sociology and Social Welfare, 17(2), 41-51.

Rose, S. (1994). Defining empowerment: A value based approach. In S. P. Robbins (Ed), Melding the personal and the political: Advocacy and empowerment in clinical and community practice (17-24). Proceedings of the Eighth Annual Social Work Futures Conference, May 13-14, 1993. Houston, TX: University of Houston Graduate School of Social Work.

Robbins, S., Chatterjee, P., \& Canda, E. (2006). Contemporary human behavior theory. Boston: Pearson Publishing. 
Rycraft, J. (1994). The party isn't over: The agency role in the retention of public child welfare caseworkers. Social Work, 39(1), 75-80.

Scannapieco, M., \& Connell-Carrick, K. (2007). Child welfare workplace: The state of the workforce and strategies to improve retention. Child Welfare, 86(6), 31-52.

Shafritz J., \& Ott J. Classics of organization theory (4 ${ }^{\text {th }}$ Edition). New York: Harcourt College.

Solomon, B. (1987). Empowerment: Social work in oppressed communities. Journal of Social Work Practice, 2(4), 79-91.

Speer, S. (1999). Feminism and conversation analysis: An oxymoron? Feminism \& Psychology, 9(4): 471-478.

Steel, R., \& Ovalle, N. K. (1984). A review and meta-analysis of research on the relationship between behavioral intentions and employee turnover. Journal of Applied Psychology, 69(4), 673-686.

Strolin-Goltzman, J., Kollar, S., \& Trinkle, J. (2010). Listening to the voices of children in foster care: Youths speak out about child welfare workforce turnover and selection. Social Work, 55(1), 47-53.

Sweeney, J., \& Summers, S. (2002). The effect of the busy season workload on public accountants' job burnout. Behavioral Research in Accounting, 14(1), 223-246.

Tabachnick, B. G., \& Fidell, L. S. (2007). Using Multivariate Statistics (5th ed.). Boston: Allyn and Bacon. 
Thiagarajan, P., Chakrabarty, S., \& Taylor, R. (2006). A confirmatory factor analysis of Reilly's Role Overload Scale. Educational \& Psychological Measurement, 66(4), 657-666.

Thompson, J. (1967). Organizations in action. New York: McGraw-Hill.

Toseland, R., \& Rivas, R. (2005). An Introduction to group work practice. Boston: Allyn \& Bacon.

U.S. Census Bureau. (2009). State \& county Quickfacts: Oregon. Retrieved April 12, 2010, from http://quickfacts.census.gov.

U.S. Department of Health and Human Services. (2005). Office of the Assistant Secretary for Planning and Evaluation. How and why the current funding structure fails to meet the needs of the child welfare field. ASPE Issue Brief. Washington, DC: HHS.

U.S. Department of Health and Human Services. (2007). Assessing promising approaches in child welfare: Strategies for state legislators. Children's Bureau. Retrieved from: http://www.ncsl.org/documents/cyf/promising_approaches_childwelfare.pdf United States Government Accounting Office (USGAO). (2003). Child Welfare: HHS could play a greater role in helping child welfare agencies to recruit and retain staff. (GAO Report No. GAO-03-357).Washington, DC: US General Accounting Office. Retrieved from http://www.gao.gov/new.items/d03357.pdf. 
United States Government Accounting Office. (2006). Improving social service program, training, and technical assistance information would help address long-standing service-level and workforce challenges. (GAO Report No. GAO-07-75).Washington, DC: US General Accounting Office. Retrieved from http://www.gao.gov/new.items/d0775.pdf.

Wanous, P. (1973). Effects of realistic job preview on job acceptance, job attitudes, and job survival. Journal of Applied Psychology, 58(3), 327-332.

Westbrook, T., Ellett, A., \& Deweaver, K. (2009). Development and validation of a measure of organizational culture in public child welfare agencies. Research on Social Work Practice, 19(6), 730-741.

Westbrook, T., Ellis, J., \& Ellett, A. (2006). Improving retention among public child welfare workers: What can we learn from the insights and experiences of committed survivors? Administration in Social Work, 30(4), 37-62.

Yip, B., \& Rowlinson, S. (2009). Job redesign as an intervention strategy of burnout: Organizational perspective. Journal of Construction Engineering \& Management, 135(8), 737-745.

Yoo, J., Brooks, D., \& Patti, R. (2007). Organizational constructs as predictors of effectiveness in child welfare interventions. Child Welfare, 86(1), 53-78.

Zimmerman, M. (1992). Empowerment: Forging new perspectives in mental health. In J. Rappaport and E. Seidman, (Eds.), Handbook of community psychology. New York: Plenum Press. 
Zimmerman, M., Israel, B. A., Schultz, A., \& Checkoway, B. (1992). Further explorations in empowerment theory: An empirical analysis of psychological empowerment. American Journal of Community Psychology, 20(6), 707-727. Zlotnik, DePanfilis, Daining, \& Lane. (2005). Factors influencing retention of child welfare staff: A systematic review of research. Retrieved from the Annie E Casey Web site: http://www.aecf.org/upload/publicationfiles/hs3622h638.pdf.

Zlotnik, J., Strand, V., \& Anderson, G. (2009). Achieving positive outcomes for children and families: Recruiting and retaining a competent child welfare workforce. Child Welfare, 88(5), 7-21. 


\section{APPENDICES}

\section{Appendix A \\ Scale

Advancement
(how strongly do
you agree or disagree,
on a 5 pt Likert from
strongly agree to
strongly disagree)

Scales and Corresponding Survey Questions, 3pp

\section{Burnout: \\ Depersonalization}

(please tell us how often you experience these things...)

\section{Burnout: Emotional Exhaustion}

(please tell us how often you experience these things...)

Scaled "A few times a year or less" to "every day" on a 6pt Likert Scale

Burnout: Personal Accomplishment (please tell us how often you experience these things...)

7d. I feel very energetic.
Questions

13e.This agency emphasizes personal growth and development.

13f. Opportunities for advancement in my position are much higher compared to those in other positions.

$13 \mathrm{~g}$. This agency rewards expertise.

13q. I feel satisfied with my chances for salary increases. 13t. I am satisfied with my chances for promotion.

7i. I feel I treat some recipients as if they were impersonal objects.

$7 \mathrm{j}$. I've become more callous toward people since I took this job.

7k. I think that this job is hardening me emotionally.

71. I don't really care what happens to some clients. 6a. Emotionally drained from my work.

$6 \mathrm{~b}$. Used up at the end of the work day.

6c. Fatigued when I get up in the morning and have to face another day on the job.

6d. Working with people all day is really a strain for me.

6 e. Burned out from my work.

6f. Frustrated by my job.

6g. I'm working too hard on my job.

$6 \mathrm{~h}$. Working with people directly puts too much stress on me.

6 i. I am at the end of my rope.

7a. I can easily understand how my clients feel about things.

7b. I deal very effectively with the problems of my clients.

7c. I feel I'm positively influencing other people's lives through my work.

7 e. I can easily create a relaxed atmosphere with my clients.

7f. I feel exhilarated after working closely with my clients.

$7 \mathrm{~g}$. I have accomplished many worthwhile things in this job.

7h. In my work, I deal with emotional problems very calmly.

( Scaled "A few times a year or less" to "every day" on a 6pt Likert Scale)

\section{Job Readiness}

(how strongly do you agree or disagree with the following statements?) 10a. When I took this job, the expectations I had about my professional responsibilities matched my actual responsibilities.

10b. Interviewers for the agency gave job applicants an accurate picture of the work and the agency.

10c. I was given enough information to make an informed decision about the reality of the job. 


\begin{tabular}{|c|c|}
\hline $\begin{array}{l}\text { SA to SD on a } 5 \mathrm{pt} \\
\text { Likert Scale }\end{array}$ & $\begin{array}{l}\text { 4f. Members of my org are expected to interact positively with each other. } \\
\text { 41. Members of my org are expected to be thoughtful and considerate with } \\
\text { each other. } \\
\text { 13k. Co-workers here generally trust each other. } \\
\text { 131. There is a feeling of cooperation among my co-workers. } \\
13 \mathrm{~m} \text {. When I face a difficult task, the people in my agency help me out. }\end{array}$ \\
\hline Role Clarity & $\begin{array}{l}\text { 5i. My supervisor gives me clear feedback on my job performance. } \\
11 \text {. Whenever we have problems or questions we know who to go to for an } \\
\text { answer. }\end{array}$ \\
\hline $\begin{array}{l}\text { SA to SD on a } 5 \mathrm{pt} \\
\text { Likert Scale }\end{array}$ & $\begin{array}{l}\text { 13h. The objectives and goals of my position are clearly defined. } \\
\text { 13i. I know what the people in my agency expect of me. }\end{array}$ \\
\hline Role Conflict & $\begin{array}{l}\text { 12a. Interests of the client are replaced by bureaucratic concerns (eg } \\
\text { paperwork). }\end{array}$ \\
\hline $\begin{array}{l}\text { SA to SD on a } 5 \mathrm{pt} \\
\text { Likert Scale }\end{array}$ & $\begin{array}{l}\text { 12b. I am unable to satisfy the conflicting demands of my job. } \\
\text { 12c. I am required to do things at work that should be done differently }\end{array}$ \\
\hline Role Overload & $\begin{array}{l}\text { 13a. My job frequently interferes with my family life. } \\
\text { 13b. I am constantly under heavy pressure on my job. }\end{array}$ \\
\hline $\begin{array}{l}\text { SA to SD on a } 5 \mathrm{pt} \\
\text { Likert Scale }\end{array}$ & 13c. I am expected to work more hours than I want to. \\
\hline $\begin{array}{l}\text { Supervisor } \\
\text { Competence } \\
\text { (task roles) }\end{array}$ & $\begin{array}{l}\text { 5a. My supervisor provides the expert help I need to do my job. } \\
\text { 5b. My supervisor knows effective ways to work with children and families. } \\
\text { 5h. My supervisor has expectations for my work that are challenging but } \\
\text { reasonable. }\end{array}$ \\
\hline $\begin{array}{l}\text { SA to SD on a } 5 \mathrm{pt} \\
\text { Likert Scale }\end{array}$ & $\begin{array}{l}\text { 5i. My supervisor gives me clear feedback on my job performance. } \\
5 \mathrm{j} \text {. My supervisor has helped my unit develop into an effective work team. } \\
5 \mathrm{~m} \text {. My supervisor is quite competent in doing his/her job. }\end{array}$ \\
\hline $\begin{array}{l}\text { Supervisor } \\
\text { Satisfaction } \\
\text { (clinical roles) }\end{array}$ & $\begin{array}{l}\text { 5c. My supervisor is willing to help me complete difficult tasks. } \\
\text { 5d. My supervisor encourages creative solutions. } \\
\text { 5e. My supervisor reinforces the training I receive. } \\
\text { 5f. My supervisor helps me learn and improve. } \\
\text { 5g. My supervisor is available when I ask for help. } \\
\text { 5k. My supervisor encourages workers to spend time mentoring new } \\
\text { employees. } \\
\text { 5l. My supervisor encourages workers to help each other with work related } \\
\text { problems. } \\
\text { 5n. My supervisor treats me fairly. } \\
\text { 5o. My supervisor shows interest in the feelings of subordinates. }\end{array}$ \\
\hline $\begin{array}{l}\text { Culture of Caring } \\
\text { Scale }\end{array}$ & $\begin{array}{l}\text { 4a. Members of my org are expected to have up-to-date knowledge. } \\
\text { 4b. Members of my org are expected to improve the well-being of each } \\
\text { client. }\end{array}$ \\
\hline $\begin{array}{l}\text { SA to SD on a } 5 \mathrm{pt} \\
\text { Likert Scale }\end{array}$ & $\begin{array}{l}\text { 4c. Members of my org are expected to place a high priority on the well } \\
\text { being of each client. } \\
4 \mathrm{~d} \text {. Members of my org are expected to become effective in serving clients. } \\
4 \mathrm{~g} \text {. Members of my org are expected to learn new tasks. } \\
4 \mathrm{~h} . \text { Members of my org are expected to pay attention to details. } \\
4 \mathrm{i} . \text { Members of my org are expected to plan for success. } \\
4 \mathrm{j} . \text { Members of my org are expected to be responsive to the needs of each } \\
\text { client. } \\
4 \mathrm{~m} \text {. Members of my org are expected to be available to each client we } \\
\text { serve. }\end{array}$ \\
\hline
\end{tabular}




\begin{tabular}{|c|c|}
\hline & $\begin{array}{l}\text { 4n. Members of my org are expected to really care what happens to each } \\
\text { client. } \\
13 \mathrm{e} \text {. This agency emphasizes professional growth and development. } \\
13 \mathrm{~g} \text {. This agency rewards expertise. }\end{array}$ \\
\hline Intent to leave & $\begin{array}{l}\text { Which of the following is most true? } \\
\text { I am not looking for another job and plan to stay at this agency. ( } 3 \mathrm{pts})\end{array}$ \\
\hline $\begin{array}{l}\text { Total possible score of } \\
0-8 \text { pts. } \\
\text { A low score indicates } \\
\text { highest intent to leave. }\end{array}$ & $\begin{array}{l}\text { I am currently looking for a new job outside of the agency. }(2 \mathrm{pt}) \\
\text { I have applied for a job outside the agency in the last } 12 \text { months. }(1 \mathrm{pt}) \\
\text { I have interviewed for a job outside the agency in the last } 12 \text { months. }(0 \mathrm{pts}) \\
\text { How much longer do you expect to work at Oregon DHS? } \\
\text { Less than } 6 \text { months }(0 \mathrm{pts}) \\
6-12 \text { months }(1 \mathrm{pt}) \\
1-2 \text { years }(2 \mathrm{pts}) \\
3-5 \text { years }(3 \mathrm{pts}) \\
6-10 \text { years }(4 \mathrm{pts}) \\
10 \text { or more years }(5 \mathrm{pts})\end{array}$ \\
\hline Climate & $\begin{array}{l}\text { Supervisor Scales (combined in to one mean score) } \\
\text { Role conflict scale mean } \\
\text { Role overload scale mean } \\
\text { Role clarity scale mean } \\
\text { Depersonalization scale mean } \\
\text { Emotional exhaustion scale mean } \\
\text { Personal accomplishment scale mean } \\
\text { Advancement scale mean } \\
13 p . \text { I like doing the things I do at work. } \\
13 \text { s. I like my co-workers. }\end{array}$ \\
\hline Culture & $\begin{array}{l}\text { Peer support scale mean } \\
\text { Culture of caring scale mean } \\
11 \mathrm{a} \text {. I have to ask a supervisor before I do almost anything. } \\
11 \mathrm{~g} . \text { We are to follow strict operating procedures. } \\
11 \mathrm{~h} \text {. There is only one way to do the job- the boss's way. }\end{array}$ \\
\hline
\end{tabular}




\section{Appendix B}

\section{Data Collection Instrument, 12pp}

\section{Child Welfare Workforce Survey}

This survey is for child welfare case workers employed by the State of Oregon Department of Human Services/Children and Families (CAF). This survey is part of a research study conducted by the Center for Improvement of Child and Family Services at Portland State University. The goal of the study is to collect and provide information to CAF administrators and staff about issues of workforce culture and staff retention in order to better understand the needs of the professional child welfare workforce in our state and develop strategies to meet those needs. Your views, in combination with the views of your coworkers across the state, are extremely important to provide helpful information for meeting the needs of Oregon's public child welfare workforce.

This survey takes approximately 20 minutes to complete and asks questions about your job satisfaction, experiences and your ideas for service and system improvement. Any information that is obtained in connection with this study and that can be linked to you or identify you will be kept confidential: therefore no individual responses will be provided to CAF supervisors or managers. All information from the survey will be reported by geographic region, along with interpretation of the findings. The final report from this study will be made available to all employees of your agency and we will notify you when it is available on our website.

You do not have to fill out this survey all at once. When you select "next" your answers will be saved. You can go back and forward through the pages of the survey to change your responses if you desire. If you leave the survey before you complete it, the next time you go back to this website your answers will be there and you can continue where you left off. Do not select the "submit" button until you are completely finished. You can take this survey at work or at home, but you must use the same computer if you do not complete the survey at one sitting.

We prefer you answer all questions. However, you can feel free to skip any question. Your participation in this survey is voluntary, and you can choose to end your participation at any time.

If you have concerns or problems about your participation in this study or your rights as a research subject, please contact the Human Subjects Research Review Committee, Office of Research and Sponsored Projects, 600 Unitus Bldg., Portland State University, (503) 725 4288 / 1-877-480-4400. If you have questions about the study itself, contact Richard Hunter, Ph.D., Center for Improvement of Child and Family Services, P.O. Box 751, Portland State University (503-725-4161 / hunterr@pdx.edu) 
You can see how close you are to finishing the survey at any time by looking at the progress bar at the bottom of each page.

1) Which of these best describes the type of caseload you carry? Please also tell us if you have a part time or temporary position. (If you work in an office where you have more than one kind of caseload assignment on a regular basis, you can choose more than one answer.)

_Protective Services

_ Ongoing (in home or out of home)

_Foster Care Licensing

_Adoptions

_Intake

_Hotline

_.Specialized (adolescent, pilot project, etc.)

_click here if you only work part time or job share

_click here if you have retired from child welfare and are working here post-retirement _click here if you are classified as a temporary employee

_ Other (please specify)

If you selected other, please specify

2) What do you like the most about your current job?

3) What do you like the least about your current job?

4) How strongly do you agree or disagree with the following statements? Members of my organizational unit are expected to...

\begin{tabular}{|l|l|l|l|l|l|}
\hline & $\begin{array}{c}\text { Strongly } \\
\text { Agree }\end{array}$ & Agree & Neutral & Disagree & $\begin{array}{c}\text { Strongly } \\
\text { Disagree }\end{array}$ \\
\hline have up-to-date knowledge. & & & & & \\
\hline $\begin{array}{l}\text { place a high priority on the well being of } \\
\text { clients. }\end{array}$ & & & & & \\
\hline become more effective in serving clients. & & & & & \\
\hline go along with group decisions. & & & & & \\
\hline interact positively with each other. & & & & & \\
\hline learn new tasks. & & & & & \\
\hline pay attention to details. & & & & & \\
\hline plan for success. & & & & & \\
\hline be responsive to the needs of each client. & & & & & \\
\hline
\end{tabular}




\begin{tabular}{|l|l|l|l|l|l|}
\hline evaluate how much we benefit clients. & & & & & \\
\hline $\begin{array}{l}\text { be thoughtful and considerate with each } \\
\text { other. }\end{array}$ & & & & & \\
\hline be available to each client we serve. & & & & & \\
\hline $\begin{array}{l}\text { really care about what happens to our } \\
\text { clients. }\end{array}$ & & & & & \\
\hline
\end{tabular}

\section{5) How strongly do you agree or disagree with the following statements?}

\section{My supervisor...}

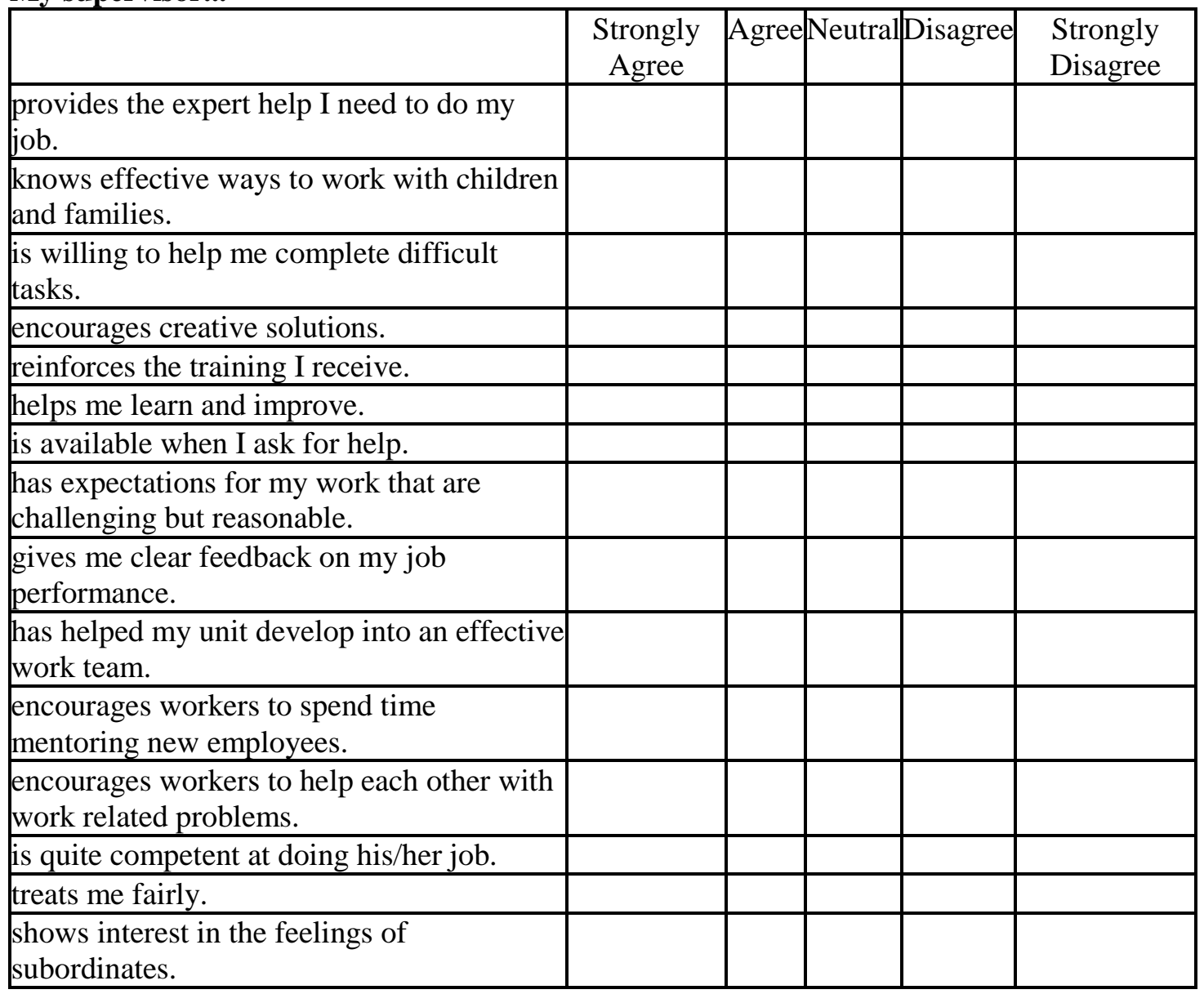


6) Please tell us how often you experience these feelings related to your job.

\begin{tabular}{|c|c|c|c|c|c|c|}
\hline & \multicolumn{6}{|c|}{ Q. How often do you feel this way? } \\
\hline & $\begin{array}{c}\text { A few times } \\
\text { a year or } \\
\text { less }\end{array}$ & Monthly & $\begin{array}{c}\text { A few } \\
\text { times a } \\
\text { month }\end{array}$ & $\begin{array}{l}\text { Every } \\
\text { week }\end{array}$ & $\begin{array}{c}\text { A few } \\
\text { times a } \\
\text { week }\end{array}$ & $\begin{array}{l}\text { Every } \\
\text { day }\end{array}$ \\
\hline $\begin{array}{l}\text { Emotionally drained from my } \\
\text { work. }\end{array}$ & & & & & & \\
\hline $\begin{array}{l}\text { Used up at the end of the work } \\
\text { day. }\end{array}$ & & & & & & \\
\hline $\begin{array}{l}\text { Fatigued when I get up in the } \\
\text { morning and have to face another } \\
\text { day on the job. }\end{array}$ & & & & & & \\
\hline $\begin{array}{l}\text { Working with people all day is } \\
\text { really a strain for me. }\end{array}$ & & & & & & \\
\hline Burned out from my work. & & & & & & \\
\hline Frustrated by my job. & & & & & & \\
\hline I'm working too hard on my job. & & & & & & \\
\hline $\begin{array}{l}\text { Working with people directly puts } \\
\text { too much stress on me. }\end{array}$ & & & & & & \\
\hline I am at the end of my rope. & & & & & & \\
\hline
\end{tabular}

7) These questions are similar to the previous set. Please tell us how often you experience these feelings related to your job.

\begin{tabular}{|c|c|c|c|c|c|c|}
\hline & \multicolumn{6}{|c|}{ How often do you feel this way? } \\
\hline & $\begin{array}{c}\text { A few times } \\
\text { a year or } \\
\text { less } \\
\end{array}$ & Monthly & $\begin{array}{l}\text { A few } \\
\text { times a } \\
\text { month }\end{array}$ & $\begin{array}{l}\text { Every } \\
\text { week }\end{array}$ & $\begin{array}{l}\text { A few } \\
\text { times a } \\
\text { week }\end{array}$ & $\begin{array}{c}\text { Every } \\
\text { day }\end{array}$ \\
\hline $\begin{array}{l}\text { I can easily understand how my } \\
\text { clients feel about things. }\end{array}$ & & & & & & \\
\hline $\begin{array}{l}\text { I deal very effectively with the } \\
\text { problems of my clients. }\end{array}$ & & & & & & \\
\hline $\begin{array}{l}\text { I feel I'm positively influencing } \\
\text { other people's lives through my } \\
\text { work. }\end{array}$ & & & & & & \\
\hline I feel very energetic. & & & & & & \\
\hline $\begin{array}{l}\text { I can easily create a relaxed } \\
\text { atmosphere with my clients. }\end{array}$ & & & & & & \\
\hline $\begin{array}{l}\text { I feel exhilarated after working } \\
\text { closely with my clients. }\end{array}$ & & & & & & \\
\hline $\begin{array}{l}\text { I have accomplished many } \\
\text { worthwhile things in this job. }\end{array}$ & & & & & & \\
\hline
\end{tabular}




\begin{tabular}{|l|l|l|l|l|l|l|}
\hline $\begin{array}{l}\text { In my work, I deal with } \\
\text { emotional problems very calmly. }\end{array}$ & & & & & & \\
\hline $\begin{array}{l}\text { I feel I treat some recipients as if } \\
\text { they were impersonal objects. }\end{array}$ & & & & & & \\
\hline $\begin{array}{l}\text { I've become more callous toward } \\
\text { people since I took this job. }\end{array}$ & & & & & & \\
\hline $\begin{array}{l}\text { I think that this job is hardening } \\
\text { me emotionally. }\end{array}$ & & & & & & \\
\hline $\begin{array}{l}\text { I don't really care what happens } \\
\text { to some clients. }\end{array}$ & & & & & & \\
\hline $\begin{array}{l}\text { I feel clients blame me for some } \\
\text { of their problems. }\end{array}$ & & & & & & \\
\hline
\end{tabular}

\section{8) The following areas have appeared in the child welfare research literature as} suggestions for attention in retaining the best child welfare workers. Which five do you think most need attention in order to best help retain qualified workers in your office? Please rank the most important FIVE of them in order of importance. (List the most important as number one.) If other, please specify.

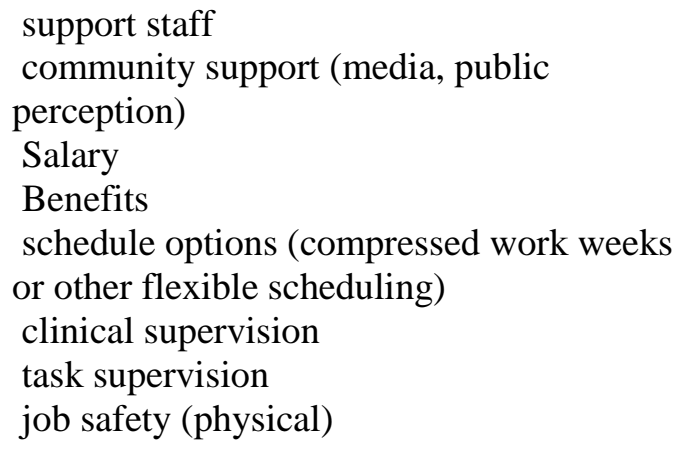

consistency among administration clinical learning opportunities Career ladder/leadership options workplace diversity access to technology caseload size Streamline paperwork peer support opportunities new worker screening/realistic job preview Other

9) If you chose other, please specify.

10) How strongly do you agree or disagree with the following statements?

\begin{tabular}{|l|l|l|l|l|l|}
\hline & $\begin{array}{c}\text { Strongly } \\
\text { Agree }\end{array}$ & Agree & Neutral & Disagree & $\begin{array}{c}\text { Strongly } \\
\text { Disagree }\end{array}$ \\
\hline $\begin{array}{l}\text { When I took this job, the expectations I had } \\
\text { about my professional responsibilities matched } \\
\text { my actual responsibilities. }\end{array}$ & & & & & \\
\hline $\begin{array}{l}\text { Interviewers for the agency gave job applicants } \\
\text { an accurate picture of the work and the agency. }\end{array}$ & & & & & \\
\hline $\begin{array}{l}\text { I was given enough information to make an } \\
\text { informed decision about the reality of the job. }\end{array}$ & & & & & \\
\hline
\end{tabular}


11) How strongly do you agree or disagree with the following statements?

\begin{tabular}{|l|l|l|l|l|l|}
\hline & $\begin{array}{c}\text { Strongly } \\
\text { Agree }\end{array}$ & Agree & Neutral & Disagree & $\begin{array}{c}\text { Strongly } \\
\text { Disagree }\end{array}$ \\
\hline $\begin{array}{l}\text { I have to ask a supervisor before I do almost } \\
\text { anything. }\end{array}$ & & & & & \\
\hline $\begin{array}{l}\text { A person can make his or her own decisions } \\
\text { without checking in with anyone. }\end{array}$ & & & & & \\
\hline $\begin{array}{l}\text { How things are done around here is left pretty } \\
\text { much up to the person doing the work. }\end{array}$ & & & & & \\
\hline $\begin{array}{l}\text { I know which procedures to follow in most } \\
\text { situations. }\end{array}$ & & & & & \\
\hline $\begin{array}{l}\text { I generally know what my work day will be } \\
\text { like day to day. }\end{array}$ & & & & & \\
\hline $\begin{array}{l}\text { Whenever we have problems or questions we } \\
\text { know who to go to for an answer. }\end{array}$ & & & & & \\
\hline $\begin{array}{l}\text { We are to follow strict operating procedures. } \\
\text { There is only one way to do the job --- the } \\
\text { boss's way. }\end{array}$ & & & & & \\
\hline
\end{tabular}

12) How strongly do you agree or disagree with the following statements?

\begin{tabular}{|l|l|l|l|l|l|}
\hline & $\begin{array}{c}\text { Strongly } \\
\text { Agree }\end{array}$ & Agree & Neutral & Disagree & $\begin{array}{c}\text { Strongly } \\
\text { Disagree }\end{array}$ \\
\hline $\begin{array}{l}\text { Interests of the client are replaced by } \\
\text { bureaucratic concerns (e.g. paperwork). }\end{array}$ & & & & & \\
\hline $\begin{array}{l}\text { I am unable to satisfy the conflicting } \\
\text { demands of my job. }\end{array}$ & & & & & \\
\hline $\begin{array}{l}\text { I am required to do things at work that } \\
\text { should be done differently. }\end{array}$ & & & & & \\
\hline
\end{tabular}

\section{3) How strongly do you agree or disagree with the following statements?}

\begin{tabular}{|c|c|c|c|c|}
\hline & $\begin{array}{l}\text { Strongly } \\
\text { Agree }\end{array}$ & Agree Neutral & Disagree & $\begin{array}{l}\text { Strongly } \\
\text { Disagree }\end{array}$ \\
\hline $\begin{array}{l}\text { My job frequently interferes with my family } \\
\text { life. }\end{array}$ & & & & \\
\hline $\begin{array}{l}\text { I am constantly under heavy pressure on my } \\
\text { job. }\end{array}$ & & & & \\
\hline $\begin{array}{l}\text { I am expected to work more hours than I want } \\
\text { to. }\end{array}$ & & & & \\
\hline I am asked to do things that aren't a normal & & & & \\
\hline
\end{tabular}




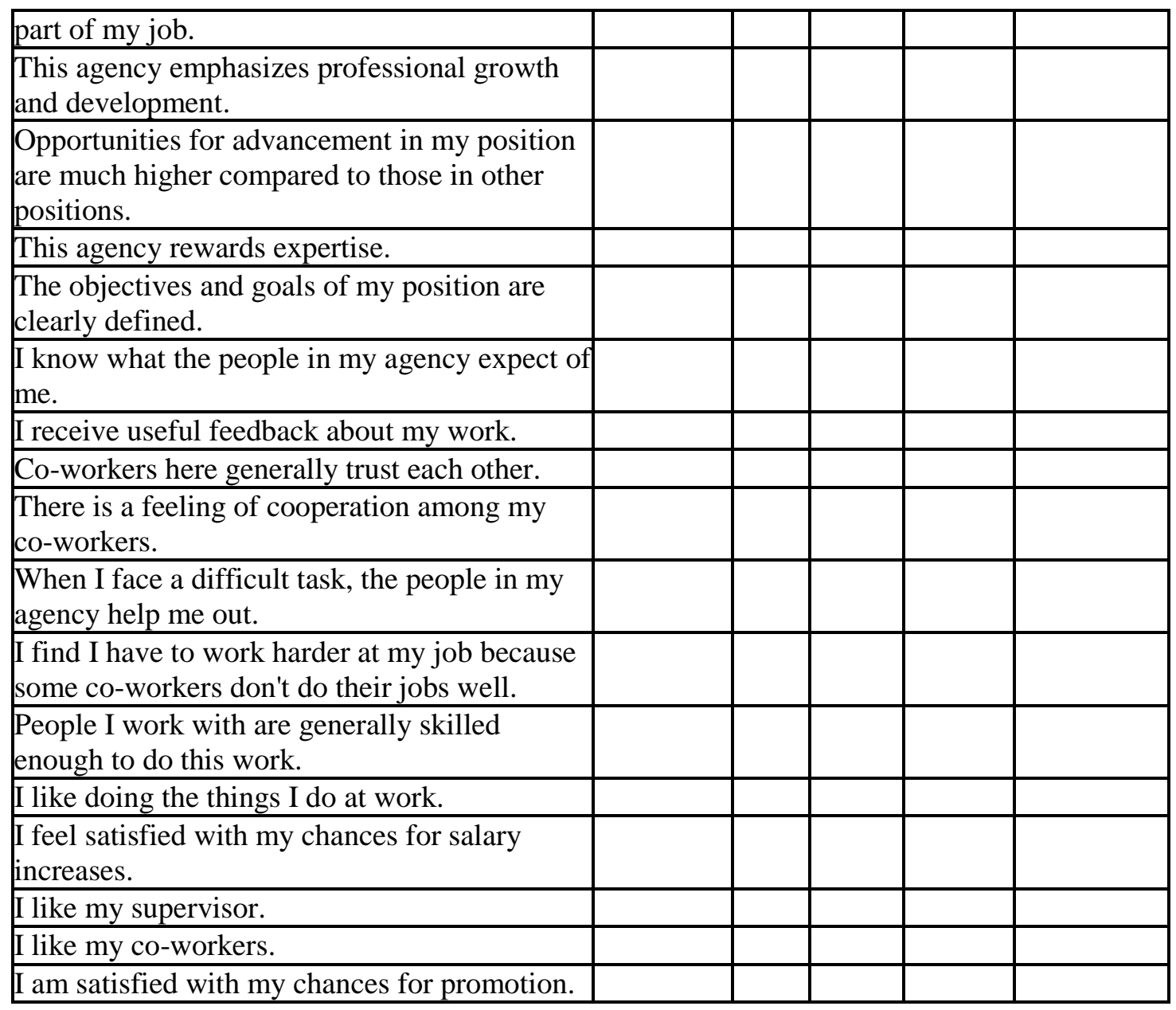

14) Think about the questions that you've answered so far. Is there anything that you would like us to know about why you answered the way you did that would help us understand your experiences?

15) In your own words, please tell us how worker turnover (workers leaving the unit or agency) impacts your work. (You have an unlimited amount of space to respond in the box below.)

16) If you could do anything to improve the climate or culture (how it feels to work here and the shared perceptions of those who work here) of the child welfare office, what would you do? Be as specific as possible in your response. You have an unlimited amount of space to answer in the box below. 
17) Now, please tell us which of the following is most true.

_ I am not looking for another job and plan to stay at this agency.

_ I am currently looking for a new job outside of the agency.

_I have applied for a job outside the agency in the last 12 months.

I have interviewed for a job outside the agency in the last 12 months.

18) How much longer do you expect to work at Oregon DHS?

Less than 6 months

_6-12 months

$1-2$ years

3-5 years

-6-10 years

_10+ years

19) When you stop working for child welfare, which one of the following will most likely influence your decision?

_retirement

_child rearing

return to school

_career change

_relocation

If you selected other, please specify medical or disability

_move to another social services job

_move to a job that is not in social

services

_Other (please specify)

20) How long in (in months) have you worked for child welfare in any casework job role for Oregon DHS? (Not including Social Service Assistant.) months

21) How many months have you been supervised by your CURRENT direct supervisor? (please use whole numbers only, no decimals.) months

22) How many supervisors have you had since you've been working at Oregon DHS, including your current supervisor?

23) On average, how many minutes do you spend per week in supervision with your current supervisor? minutes

24) What is your gender?

_.Male __Female 
25) What year were you born?

26) What is your highest degree?

less than High School Diploma

High School Diploma or GED

_Bachelors in Social Work

Associate

Bachelors (non social work)

_.Masters (non social work)

_.Masters in Social Work

Doctorate

27) Please check ALL the boxes that apply to you.

_ I am not currently in college and I do not have an Masters in Social Work (MSW).

__ I do have a MSW, but did not receive Title IV-E funding.

_ I am currently a Title IV-E funded MSW student.

I I am currently in college working on my MSW, but not a Title IV-E funded MSW student.

_ I graduated from a MSW program after receiving Title IV-E funding.

_I have a BSW or BASW (Bachelor's degree from a CSWE accredited program)

I am working on my LCSW.

__ have obtained my LCSW.

_Other (please specify)

If you selected other, please specify

28) Tell us about yourself. Choose the responses with which you most identify.

_American Indian or Alaska Native

_Asian

_ Native Hawaiian or Other Pacific

Black or African American

Islander

Hispanic

_White

If you selected other, please specify

__ther (please specify)

29) How many children under the age of 18 live with you $50 \%$ or more of the time?
_none
$-3$
$-1$
2
-4 or more

30) What is your current annual income from this job?

31) On average, how many hours of overtime do you work each month?

32) What District (SDA) do you work in? 
33) Please tell us anything that we didn't ask that you would like us to know.

34) After surveys have been collected, we plan to talk to some workers to better understand the answers. We would like to know how many workers might be willing to talk with us. Would you be willing to participate in a follow-up conversation in any of the following ways?

_in a focus group.

in another open-ended survey.

by telephone conference call.

_Not interested

Thank you for completing our survey. Your feedback is important. After the results are tabulated, they will be shared with child welfare staff and administration. Additionally, we hope to visit offices to share the themes found and ways to move forward in improving the child welfare work place. If you have any questions about this survey, please contact either of the following people:

Melanie Sage: melanis@ pdx.edu or 503-725-8006

Richard Hunter: hunterr@pdx.edu or 503-725-4161

Please note: Some items in this survey were adapted and reproduced by special permission of the Publisher, CPP, Inc., Mountain View, CA 94043 from Maslach Burnout InventoryHuman Services Survey by Christina Maslach and Susan E. Jackson. Copyright 1986 by CPP, Inc. All rights reserved. Further reproduction is prohibited without the Publisher's written consent. Additional (MBI-HSS) materials are available at www.cpp.com. 
Appendix C

Variables measured by the Child Welfare Partnership Study, 2pp

\begin{tabular}{|c|c|c|c|}
\hline Scale & Source & $\begin{array}{c}\text { \# of } \\
\text { questions }\end{array}$ & $\begin{array}{c}\text { Corresponding Question } \\
\# \mathrm{~A}\end{array}$ \\
\hline Advancement & CWP & 5 & $13 \mathrm{e}, 13 \mathrm{f}, 13 \mathrm{~g}, 13 \mathrm{q}, 13 \mathrm{t}$ \\
\hline Autonomy & CWP & 4 & $11 \mathrm{~b}, 11 \mathrm{c}, 11 \mathrm{~g}, 11 \mathrm{~h}$ \\
\hline Burnout & Maslach & 22 & Dp, ee, pa \\
\hline $\begin{array}{l}\text { Burnout- } \\
\text { depersonalization }\end{array}$ & Maslach & 5 & $7 \mathrm{i}, 7 \mathrm{j}, 7 \mathrm{k}, 7 \mathrm{l}, 7 \mathrm{~m}$ \\
\hline $\begin{array}{l}\text { Burnout- emotional } \\
\text { exhaustion }\end{array}$ & Maslach & 9 & $\begin{array}{l}\text { 6a, 6b, 6c, 6d, 6e, 6f, 6g, } \\
6 \mathrm{~h}, 6 \mathrm{i}\end{array}$ \\
\hline $\begin{array}{l}\text { Burnout- personal } \\
\text { accomplishment }\end{array}$ & Maslach & 8 & $\begin{array}{l}\text { 7a, 7b, 7c, 7d, 7e, 7f, 7g, } \\
7 \mathrm{~h}\end{array}$ \\
\hline Climate & CWP & 42 & $\begin{array}{l}\text { Supervisor satisfaction } \\
\text { scale (5c, 5d, 5e, 5f, 5g, 5k, } \\
\text { 5l, 5n, 5o, 13r) } \\
\text { Supervisor competence } \\
\text { scale (5a, 5b, 5h,5i, 5j, 5m) } \\
\text { Role Conflict scale (12a, } \\
\text { 12b, 12c) } \\
\text { Role overload scale (13a, } \\
\text { 13b, 13c) } \\
\text { Role clarity scale (5i, 11d, } \\
\text { 11e, 11f, 13d,13h, 13i) } \\
\text { Depersonalization scale } \\
\text { (7i, 7j, 7k, 7l, 7m) } \\
\text { Emotional exhaustion scale } \\
\text { (6a, 6b, 6c, 6d, 6e, 6f, 6g, } \\
\text { 6h, 6i) } \\
\text { Personal accomplishment } \\
\text { scale (7a, 7b, 7c, 7d, 7e, 7f, } \\
\text { 7g, 7h) } \\
\text { Job satisfaction scale (5m, } \\
\text { 5n, 6f, 7f, 7g, 13p, 13q, } \\
\text { 13r, 13s, 13t) } \\
\text { Advancement scale (13e, } \\
\text { 13f, 13g, 13q, 13t) }\end{array}$ \\
\hline
\end{tabular}




\begin{tabular}{|c|c|c|c|}
\hline Culture & CWP & 24 & $\begin{array}{l}\text { Peer support scale (4f, 4l, } \\
13 \mathrm{k}, 13 \mathrm{l}, 13 \mathrm{~m}) \\
\text { Autonomy scale }(11 \mathrm{~b}, 11 \mathrm{c}, \\
11 \mathrm{~g}, 11 \mathrm{~h}) \\
11 \mathrm{a} \\
4 \mathrm{a}, 4 \mathrm{~b}, 4 \mathrm{c}, 4 \mathrm{~d}, 4 \mathrm{e}, 4 \mathrm{~g}, 4 \mathrm{~h}, \\
4 \mathrm{i}, 4 \mathrm{j}, 4 \mathrm{k}, 4 \mathrm{~m}, 4 \mathrm{n} \\
13 \mathrm{e}, 13 \mathrm{~g}, 13 \mathrm{o}\end{array}$ \\
\hline Job Readiness & $\begin{array}{l}\mathrm{NC} \\
\text { Jordan } \\
\text { Institute, } \\
2006\end{array}$ & 3 & $10 \mathrm{a}, 10 \mathrm{~b}, 10 \mathrm{c}$ \\
\hline Job satisfaction & JS & 12 & $\begin{array}{l}5 \mathrm{~m}, 5 \mathrm{n}, 6 \mathrm{f}, 7 \mathrm{f}, 7 \mathrm{~g}, 13 \mathrm{p}, \\
13 \mathrm{q}, 13 \mathrm{r}, 13 \mathrm{~s}, 13 \mathrm{t}\end{array}$ \\
\hline Peer support & CWP & 5 & $4 \mathrm{f}, 41,13 \mathrm{k}, 131,13 \mathrm{~m}$ \\
\hline Role clarity & CWP & 10 & $\begin{array}{l}5 \mathrm{i}, 11 \mathrm{~d}, 11 \mathrm{e}, 11 \mathrm{f}, 13 \mathrm{~d}, 13 \mathrm{~h}, \\
13 \mathrm{i},\end{array}$ \\
\hline Role Conflict & CWP & 3 & $12 \mathrm{a}, 12 \mathrm{~b}, 12 \mathrm{c}$ \\
\hline Role Overload & CWP & 3 & $13 a, 13 b, 13 c$ \\
\hline Supervisor competence & $\begin{array}{l}\mathrm{NC} \\
\text { Jordan } \\
\text { Institute, } \\
2006\end{array}$ & 6 & $5 \mathrm{a}, 5 \mathrm{~b}, 5 \mathrm{~h}, 5 \mathrm{i}, 5 \mathrm{j}, 5 \mathrm{~m}$ \\
\hline Supervisor satisfaction & $\begin{array}{l}\text { NC } \\
\text { Jordan } \\
\text { Institute, } \\
2006\end{array}$ & 10 & $\begin{array}{l}\text { 5c, 5d, 5e, 5f, 5g, 5k, 5l, } \\
5 \mathrm{n}, 5 \mathrm{o}, 13 \mathrm{r}\end{array}$ \\
\hline Intent to leave & $\begin{array}{l}\text { Bluedorn, } \\
\text { S. } \\
\text { Schwartz, } \\
\text { CWP }\end{array}$ & 2 & 17,18 \\
\hline Job role & CWP & 1 & 1 \\
\hline
\end{tabular}




\section{Appendix D \\ Institutional Review Board Statement}

A review is not required for this study, as it meets the conditions outlined by the review board: It is a secondary data analysis, and (1) All identifying information has been removed and data cannot be linked back to individuals; (2) No contact with subjects is/was involved; (3) Data has been previously collected by another investigator, (4) Data already exists. The review waiver request was approved by the Portland State University Human Subjects Research Review Committee on February 22, 2010. 